\title{
ANDRÉ BOZZO ARGENTON
}

\section{Influência do Grau de Etoxilação no Comportamento de Álcoois Secundários Etoxilados}

Dissertação apresentada ao Instituto de Química da Universidade de São Paulo para obtenção do Título de Doutor em Química (Físico-Química) 
André Bozzo Argenton

Influência do Grau de Etoxilação no Comportamento de Álcoois Secundários Etoxilados

Dissertação apresentada ao Instituto de Química da Universidade de São Paulo para obtenção do Título de Doutor em Química (Físico-Química).

Aprovado em:

\section{Banca Examinadora}

Prof. Dr.

Instituição:

Assinatura:

Prof. Dr.

Instituição:

Assinatura:

Prof. Dr.

Instituição:

Assinatura: 
DEDICATÓRIA

À minha esposa, Camila, a meus pais, Liliana e Ayrton e a meus irmãos Renata e Ricardo. 


\section{AGRADECIMENTOS}

Ao Prof. Dr. Frank Herbert Quina pela orientação, pelo incentivo, pela amizade e principalmente por ter acreditado na realização desse estudo mesmo durante minha ausência do país.

A minha esposa, Camila Branquilho, que me apoiou e incentivou durante esse projeto e principalmente pelo suporte na fase final da elaboração da tese quando a dedicação à conclusão desse trabalho fez-me ausente durante um momento difícil de nossas vidas, em um outro país e em uma situação profissional tão adversa quanto a vivida durante a redação desta tese.

Aos meus pais, pelo apoio e incentivo e sem os quais não seria possível a realização desse trabalho e especialmente ao meu pai que é o responsável por ter despertado em mim a paixão pela Ciência, a paixão pela Química, e por ter mostrado que é a dedicação e o trabalho que nos define e nos realiza.

Aos colegas de laboratório do Instituto de Química pelo apoio e discussões.

A Susan Dallessandro por me apoiar, incentivar e flexibilizar minhas obrigações profissionais com a The Dow Chemical Company e a Victor Hugo Monje e Marcelo Fiszner por me apoiar, incentivar e flexibilizar minhas obrigações profissionais com a Dow Brasil SA.

A Keith Harris e Christopher Tucker pelas discussões durante o projeto, a Alvim Jorge, Marcelo Cantu, Renata Lopes e Rui Cruz e pelo apoio e suporte nos laboratórios da Dow Brasil SA e a Bethany Potucek, Becky Wachovicz e Felipe Donate pelo suporte nos laboratórios da The Dow Chemical Company.

Ao Prof. Dr. Claudio Oller do Nascimento e o Group for Chemical Systems Engineering, DEQ-EP-USP, pela colaboração com equipamentos. 


\section{RESUMO}

\section{Argenton, A.B. Influência do Grau de Etoxilação no Comportamento de Álcoois}

Secundários Etoxilados. 2009. 128 p. Tese de Doutorado - Programa de Pós-Graduação em Físico-Química, Instituto de Química, Universidade de São Paulo, São Paulo.

A solubilização de solutos não iônicos através de um processo de partição entre água e a pseudo-fase micelar de tensoativos não iônicos foi estudada para álcoois secundários etoxilados com grau de etoxilação variando entre 7 e 40. Mostrou-se que o coeficiente de incorporação micelar, $K_{s}$, é independente do grau de etoxilação o que corrobora a hipótese de que a partição ocorre entre água e o núcleo hidrocarbônico da micela, que não é alterado pelo aumento do número de grupos de óxido de eteno na cabeça polar do tensoativo.

O uso de relações lineares de energia livre, LSER, para a predição da capacidade de solubilização de álcoois secundários etoxilados forneceu, através de regressão múltipla linear a seguinte LSER como melhor modelo:

$\log K_{s}=-0,42+1,21 E-1,73 S-0,40 A-1,13 B+3,01 V$

com $\mathrm{R}^{2}=0,98$ e valor de teste $\mathrm{F}$ de 1390 . Nesta equação, $V$ é o volume molar do soluto, $A$ e $B$ são a capacidade do soluto de atuar como doador e aceptor de pontes de hidrogênio, $E$ é a refração molar em excesso e $S$ representa a capacidade do soluto de interagir com o meio de solubilização através de interações do tipo dipolo-dipolo e dipolo-dipolo induzido.

Mostrou-se que processos de limpeza aplicados à remoção de sujidades de tecidos e superfícies sólidas não estão correlacionados ao mecanismo de solubilização descrito por um processo de partição. A dependência da redução de tensão interfacial com o grau de etoxilação sugere que a eficiência de limpeza, para superfícies sólidas e para tecidos, está correlacionada de maneira direta, mas não linear, com a capacidade do tensoativo de 
concentrar-se na interface "sujidade-solução aquosa de tensoativo" reduzindo assim a tensão interfacial entre os dois meios.

Palavras-chave: tensoativo, LSER, solubilização. 


\begin{abstract}
Argenton, A.B. The Influence of Ethoxylation Degree in the Behaviour of Secondary Alcohol Ethoxylates. 2009. 128 p. PhD Thesis - Graduate Program in Chemistry. Instituto de Química, Universidade de São Paulo, São Paulo.
\end{abstract}

The solubilization of non-ionic solutes via partitioning between water and the micellar pseudophase of non-ionic surfactants was evaluated for a series of secondary alcohol ethoxylates with hydrophile length varying from 7 to 40 ethylene oxide units. It was demonstrated that the micellar incorporation constant, $K_{s}$, is not dependent on the hydrophile length of the surfactant. The results obtained in this study support the hypothesis that the partitioning between water and the micellar core is not disturbed by the etheylene oxide hydrophilic groups.

Linear solvation free energy relationships, LSER, were used to model the ability of the surfactants to solubilize non-ionic compounds. Multiple linear regression analysis provided the following LSER with $R^{2}$ of 0.98 and $F$ value of 1390:

$$
\log K_{s}=-0,42+1,21 E-1,73 S-0,40 A-1,13 B+3,01 V .
$$

In this LSER, $V$ is a descriptor of solute molar volume, $A$ and $B$ capture the overall ability of the solute to act as a hydrogen bond donor and acceptor, $E$ is the solute excess molar refraction and $S$ is a descriptor of the ability of the solute to interact via dipole-dipole and dipole-induced dipole interactions with its surroundings.

It was demonstrated that hard and soft surface cleaning efficiencies are not correlated with the solubilization process. It was shown, however, that the change in interfacial tension caused by the change in the hydrophile portion of the surfactants has a direct, but non-linear impact on the cleaing properties of aqueous solutions containing these surfactants.

Keywords: surfactant, LSER, solubilization. 


\section{ÍNDICE DE FIGURAS}

Figura 1: Representação das variações em propriedades físico-químicas de soluções aquosas em função da concentração de tensoativo.

Figura 2: Representação na variação de propriedades termodinâmicas em função da temperatura no processo de micelização. 24

Figura 3: Componentes que agem na formação de micelas.

Figura 4: Redução de cmc em função do número de carbonos no hidrófobo para: ( $\square$ )

brometos de alquiltrimetil amônio, ( $)$ alquil sulfatos de sódio e ( $\Delta$ ) alquil sulfonatos de sódio

Figura 5: Estrutura de álcoois secundários etoxilados TERGITOL 15-S onde $\mathrm{m}+\mathrm{n}=9 \sim 11$ e $\mathrm{x}$ varia entre 7 e 40

Figura 6: Esquema ilustrativo do processo de transferência de um soluto entre duas fases condensadas (interações entre soluto e solventes não são representadas neste esquema) ......39 Figura 7: Esquema ilustrativo do processo de transferência de um soluto de uma fase gasosa a uma fase condensada.

Figura 8: Gráfico da tensão superficial em função do logaritmo da concentração de tensoativo.

Figura 9: Gráfico de $\mathrm{A}_{\mathrm{o}} / \mathrm{A}_{\mathrm{i}}$ em função da concentração de TERGITOL 15-S-7 micelizado para cetonas. (O) 2-octanona; ( $\square$ ) 2-heptanona.

Figura 10: Gráfico de $\mathrm{A}_{\mathrm{o}} / \mathrm{A}_{\mathrm{i}}$ em função da concentração de TERGITOL 15-S-9 micelizado para cetonas. (O) 2-octanona; ( $\square$ ) 2-heptanona.

Figura 11: Gráfico de $A_{o} / A_{i}$ em função da concentração de TERGITOL 15-S-12 micelizado para cetonas. (O) 2-octanona; ( $\square$ ) 2-heptanona. 68

Figura 12: Gráfico de $\mathrm{A}_{\mathrm{o}} / \mathrm{A}_{\mathrm{i}}$ em função da concentração de TERGITOL 15-S-15 micelizado

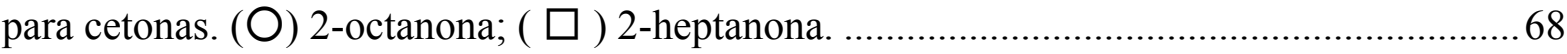
Figura 13: Gráfico de $\mathrm{A}_{\mathrm{o}} / \mathrm{A}_{\mathrm{i}}$ em função da concentração de TERGITOL 15-S-20 ................6 69 Figura 14: Gráfico de $\mathrm{A}_{\mathrm{o}} / \mathrm{A}_{\mathrm{i}}$ em função da concentração de TERGITOL 15-S-30 .................69

Figura 15: Gráfico de $\mathrm{A}_{\mathrm{o}} / \mathrm{A}_{\mathrm{i}}$ em função da concentração de TERGITOL 15-S-40 ................. 70

Figura 16: Gráfico de $\mathrm{A}_{\mathrm{o}} / \mathrm{A}_{\mathrm{i}}$ em função da concentração de TERGITOL 15-S-7 .................. 71

Figura 17: Gráfico de $A_{o} / A_{i}$ em função da concentração de TERGITOL 15-S-9 ................... 71

Figura 18: Gráfico de $\mathrm{A}_{\mathrm{o}} / \mathrm{A}_{\mathrm{i}}$ em função da concentração de TERGITOL 15-S-12 ................. 72

Figura 19: Gráfico de $\mathrm{A}_{\mathrm{o}} / \mathrm{A}_{\mathrm{i}}$ em função da concentração de TERGITOL 15-S-15 ................. 72

Figura 20: Gráfico de $\mathrm{A}_{\mathrm{o}} / \mathrm{A}_{\mathrm{i}}$ em função da concentração de TERGITOL 15-S-20 ................ 73 
Figura 21: Gráfico de $\mathrm{A}_{\mathrm{o}} / \mathrm{A}_{\mathrm{i}}$ em função da concentração de TERGITOL 15-S-30 ..................73

Figura 22: Gráfico de $\mathrm{A}_{\mathrm{o}} / \mathrm{A}_{\mathrm{i}}$ em função da concentração de TERGITOL 15-S-7 ...................74

Figura 23: Gráfico de $\mathrm{A}_{\mathrm{o}} / \mathrm{A}_{\mathrm{i}}$ em função da concentração de TERGITOL 15-S-9 ....................74

Figura 24: Gráfico de $\mathrm{A}_{\mathrm{o}} / \mathrm{A}_{\mathrm{i}}$ em função da concentração de TERGITOL 15-S-12 ................. 75

Figura 25: Gráfico de $\mathrm{A}_{\mathrm{o}} / \mathrm{A}_{\mathrm{i}}$ em função da concentração de TERGITOL 15-S-15 .................75

Figura 26: Gráfico de $\mathrm{A}_{\mathrm{o}} / \mathrm{A}_{\mathrm{i}}$ em função da concentração de TERGITOL 15-S-20 .................76

Figura 27: Gráfico de $\mathrm{A}_{\mathrm{o}} / \mathrm{A}_{\mathrm{i}}$ em função da concentração de TERGITOL 15-S-30 .................76

Figura 28: Gráfico de $\mathrm{A}_{\mathrm{o}} / \mathrm{A}_{\mathrm{i}}$ em função da concentração de TERGITOL 15-S-40 ................ 77

Figura 29: Gráfico de $\mathrm{A}_{\mathrm{o}} / \mathrm{A}_{\mathrm{i}}$ em função da concentração de TERGITOL 15-S-7 ...................77

Figura 30: Gráfico de $A_{0} / A_{i}$ em função da concentração de TERGITOL 15-S-9 ................... 78

Figura 31: Gráfico de $A_{o} / A_{i}$ em função da concentração de TERGITOL 15-S-12 .................78

Figura 32: Gráfico de $\mathrm{A}_{\mathrm{o}} / \mathrm{A}_{\mathrm{i}}$ em função da concentração de TERGITOL 15-S-15 ................ 79

Figura 33: Gráfico de $A_{o} / A_{i}$ em função da concentração de TERGITOL 15-S-20 .................79

Figura 34: Gráfico de $\mathrm{A}_{\mathrm{o}} / \mathrm{A}_{\mathrm{i}}$ em função da concentração de TERGITOL 15-S-7 micelizado para álcoois: (O) 1-heptanol; ( $\square$ ) 1-hexanol, ( $\diamond)$ 1-pentanol.

Figura 35: Gráfico de $\mathrm{A}_{\mathrm{o}} / \mathrm{A}_{\mathrm{i}}$ em função da concentração de TERGITOL 15-S-9 micelizado

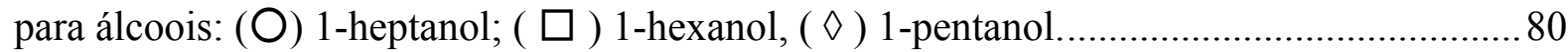
Figura 36: Gráfico de $\mathrm{A}_{\mathrm{o}} / \mathrm{A}_{\mathrm{i}}$ em função da concentração de TERGITOL 15-S-12 micelizado para álcoois: $(\bigcirc)$ 1-heptanol; $(\square)$ 1-hexanol, ( $\diamond)$ 1-pentanol.

Figura 37: Gráfico de $\mathrm{A}_{\mathrm{o}} / \mathrm{A}_{\mathrm{i}}$ em função da concentração de TERGITOL 15-S-15 micelizado para álcoois: $(\bigcirc)$ 1-heptanol; $(\square)$ 1-hexanol, $(\diamond)$ 1-pentanol.

Figura 38: Gráfico de $\mathrm{A}_{\mathrm{o}} / \mathrm{A}_{\mathrm{i}}$ em função da concentração de TERGITOL 15-S-20 micelizado

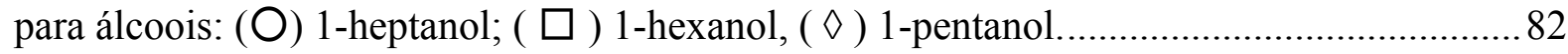
Figura 39: Gráfico de $\mathrm{A}_{\mathrm{o}} / \mathrm{A}_{\mathrm{i}}$ em função da concentração de TERGITOL 15-S-30 micelizado para álcoois: $(O)$ 1-heptanol; $(\square)$ 1-hexanol, $(\diamond)$ 1-pentanol............................................ 82 Figura 40: Gráfico de $\mathrm{A}_{\mathrm{o}} / \mathrm{A}_{\mathrm{i}}$ em função da concentração de TERGITOL 15-S-40 micelizado para álcoois: $(O)$ 1-heptanol; $(\square)$ 1-hexanol, $(\diamond)$ 1-pentanol.

Figura 41: Gráfico de $\mathrm{A}_{\mathrm{o}} / \mathrm{A}_{\mathrm{i}}$ em função da concentração de TERGITOL 15-S-7 micelizado para álcoois: $(\bigcirc)$ n-dodecano; ( $\square$ ) n-undecano.

Figura 42: Gráfico de $\mathrm{A}_{\mathrm{o}} / \mathrm{A}_{\mathrm{i}}$ em função da concentração de TERGITOL 15-S-20 micelizado para álcoois: $(\mathrm{O})$ n-dodecano; $(\square)$ n-undecano. 
Figura 43: Gráfico de $\mathrm{S}_{\mathrm{t}} / \mathrm{S}_{\mathrm{o}}$ em função da concentração de TERGITOL 15-S-7 micelizado para: (O) pireno; $(\square)$ antraceno.

Figura 44: Gráfico de $\mathrm{S}_{\mathrm{t}} / \mathrm{S}_{\mathrm{o}}$ em função da concentração de TERGITOL 15-S-9 micelizado para: (O) pireno; ( $\square$ ) antraceno. 86

Figura 45: Gráfico de $\mathrm{S}_{\mathrm{t}} / \mathrm{S}_{\mathrm{o}}$ em função da concentração de TERGITOL 15-S-12 micelizado para: $(\bigcirc)$ pireno; $(\square)$ antraceno.

Figura 46: Gráfico de $\mathrm{S}_{\mathrm{t}} / \mathrm{S}_{\mathrm{o}}$ em função da concentração de TERGITOL 15-S-15 micelizado para: (O) pireno; $(\square)$ antraceno.

Figura 47: Gráfico de $\mathrm{S}_{\mathrm{t}} / \mathrm{S}_{\mathrm{o}}$ em função da concentração de TERGITOL 15-S-20 micelizado para: (O) pireno; ( $\square$ ) antraceno.

Figura 48: Gráfico de $\mathrm{S}_{\mathrm{t}} / \mathrm{S}_{\mathrm{o}}$ em função da concentração de TERGITOL 15-S-30 micelizado para: (O) pireno; $(\square)$ antraceno. .88

Figura 49: Gráfico de $\mathrm{S}_{\mathrm{t}} / \mathrm{S}_{\mathrm{o}}$ em função da concentração de TERGITOL 15-S-40 micelizado para: (O) pireno; $(\square)$ antraceno.

Figura 50: Gráfico de $\mathrm{S}_{\mathrm{t}} / \mathrm{S}_{\mathrm{o}}$ em função da concentração de TERGITOL 15-S-9 micelizado para: ( $\bigcirc)$ bifenila; $(\square$ ) benzofenona. .89

Figura 51: Gráfico de $\mathrm{S}_{\mathrm{t}} / \mathrm{S}_{\mathrm{o}}$ em função da concentração de TERGITOL 15-S-12 micelizado para: (O) bifenila; ( $\square$ ) benzofenona. 90

Figura 52: Gráfico de $\mathrm{S}_{\mathrm{t}} / \mathrm{S}_{\mathrm{o}}$ em função da concentração de TERGITOL 15-S-15 micelizado para: (O) bifenila; ( $\square$ ) benzofenona.

Figura 53: Gráfico de $\mathrm{S}_{\mathrm{t}} / \mathrm{S}_{\mathrm{o}}$ em função da concentração de TERGITOL 15-S-20 micelizado para: ( $\bigcirc)$ bifenila; $(\square$ ) benzofenona.

Figura 54: Gráfico de $\mathrm{S}_{\mathrm{t}} / \mathrm{S}_{\mathrm{o}}$ em função da concentração de TERGITOL 15-S-30 micelizado para: $(\mathrm{O})$ bifenila; $(\square$ ) benzofenona.

Figura 55: Gráfico de $\mathrm{S}_{\mathrm{t}} / \mathrm{S}_{\mathrm{o}}$ em função da concentração de TERGITOL 15-S-40 micelizado para: $(\mathrm{O})$ bifenila. 92

Figura 56: Gráfico de $\mathrm{S}_{\mathrm{t}} / \mathrm{S}_{\mathrm{o}}$ em função da concentração de TERGITOL 15-S-7 micelizado para ácido 2-hidroxibenzóico.

Figura 57: Gráfico de $\mathrm{S}_{\mathrm{t}} / \mathrm{S}_{\mathrm{o}}$ em função da concentração de TERGITOL 15-S-20 micelizado para ácido 2-hidroxibenzóico.

Figura 58: Curva de calibração típica de trioleina em tetrahidrofurano utilizando-se hexadecanoato de etila como padrão interno $\left(\mathrm{R}^{2}=0,998\right)$. 
Figura 59: Gráfico comparando a fração de trioleina removida do tecido para os tensoativos com grau de etoxilação entre 7 e 40 e água.

Figura 60: Gráfico comparando a fração de trioleina removida do tecido para os tensoativos com grau etoxilação 7 e 40 em função da concentração de tensoativo: ( $\Delta$ ) TERGITOL 15-S-7, (О) TERGITOL 15-S-40 e (×) água

Figura 61: Gráfico comparando a eficiência de limpeza para sujeira padrão para os tensoativos com grau de etoxilação entre 7 e 40 .

Figura 62: Gráfico comparando a eficiência de limpeza para sujeira padrão para os tensoativos com grau etoxilação 7 e 40 em função da concentração de tensoativo: $(\Delta)$ TERGITOL 15-S-7, (○) TERGITOL 15-S-40 e (×) água. 100

Figura 63: Gráfico de $\ln (\mathrm{cmc})$ em função do grau de etoxilação 101

Figura 64: Gráfico de $\log K_{s}$ em função do grau de etoxilação dos tensoativos para álcoois, antraceno e benzofenona 104

Figura 65: Gráfico de $\log K_{s}$ em função do grau de etoxilação dos tensoativos para alcinos, aromáticos e pireno

Figura 66: Gráfico de $\log K_{s}$ em função do grau de etoxilação dos tensoativos para alquil aminas, cetonas e bifenilo 105

Figura 67: Gráfico de $\log K_{s}$ experimental versus $\log K_{s}$ predito para TERGITOL 15-S..... 109 Figura 68: Distribuição dos parâmetros de solubilidade de Abraham utilizados neste estudo.

Figura 69: Gráfico da matriz de correlação dos parâmetros E, S, A, B e V dos solutos estudados

Figura 70: Gráfico de $\log K_{s}$ experimental versus $\log K_{s}$ predito para TERGITOL 15-S com exclusão de aromáticos específicos. do conjunto de solutos.

Figura 71: Detergência de superfície sólida em função da tensão interfacial entre as soluções de TERGITOL 15-S e a sujidade padrão 117

Figura 72: Detergência de tecido em função da tensão interfacial entre as soluções de TERGITOL $15-\mathrm{S}$ e a trioleina. 


\section{ÍNDICE DE TABELAS}

Tabela 1: Exemplos de Tensoativos e aplicações industriais .............................................. 18

Tabela 2: Relação entre parâmetro crítico de empacotamento e geometria micelar. ..............21

Tabela 3: Comparação do efeito da adição de um grupo $\mathrm{CH}_{2}$ em parâmetros termodinâmicos no processo de micelização e no processo de transferência de n-alcanos entre água e o próprio

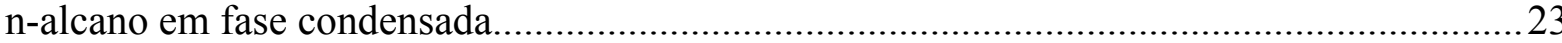

Tabela 4: Valores de cmc para tensoativos iônicos e não iônicos com mesmo hidrófobo......27

Tabela 5: Redução da cmc de alquil sulfatos de sódio em função do aumento da concentração

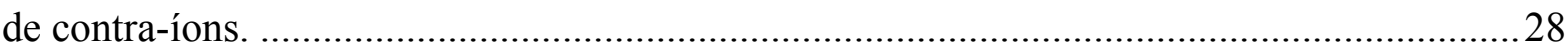

Tabela 6: Propriedades físico-químicas típicas de TERGITOL 15-S-x. ................................. 34

Tabela 7: Propriedades dos tensoativos TERGITOL 15-S- em soluções aquosas ................... 35

Tabela 8: Notações, atual e original, dos parâmetros de Abraham .......................................... 42

Tabela 9: Parâmetros usados na análise de fase vapor por cromatografia gasosa..................56

Tabela 10: Parâmetros usados na determinação por solubilização em saturação com análise espectrofotométrica

Tabela 11: Condições cromatográficas para análise de trioleina extraída em tetrahidrofurano

Tabela 12: Valores de concentração micelar crítica.

Tabela 13: Constante de incorporação micelar, $\log \mathrm{K}_{\mathrm{s}}$ para os solutos e tensoativos estudados.

Tabela 14: Coeficientes de correlação para as regressões lineares na determinação da constante de incorporação micelar, $\log \mathrm{K}_{\mathrm{s}}$ para os solutos e tensoativos estudados.

Tabela 15: Valores de concentração micelar crítica, concentração em excesso superficial e área por molécula 103

Tabela 16: Coeficientes de correlação para regressão linear de $\log K_{s}$ em função do grau de etoxilação dos tensoativos TERGTOL 15-S. 106

Tabela 17: Parâmetros de solubilidade de Abraham para solutos estudados. 108

Tabela 18: Valores de F parciais e erros para os coeficientes da equação de correlação determinada para TERGITOL $15-\mathrm{S}$

Tabela 19: Limite inferior e limite superior dos parâmetros descritivos dos solutos utilizados. (os valores do limite inferior de E, S, A e B desse estudo mostrados na tabela excluem os alcanos que apresentam valor zero para esses parâmetros) 
Tabela 20: Matriz de correlação dos parâmetros E, S, A, B e V dos solutos estudados.

Tabela 21: Valores de F parciais e erros para os coeficientes da equação de correlação determinada para TERGITOL 15-S com exclusão de policíclicos aromáticos. do conjunto de solutos.

Tabela 22: Matriz de correlação dos parâmetros E, S, A, B e V com exclusão de policíclicos aromáticos. do conjunto de solutos estudados 114

Tabela 23: Comparação entre os coeficientes das LSERs obtidas para o conjunto total de solutos e o subconjunto de solutos (com exclusão de policíclicos aromáticos). 


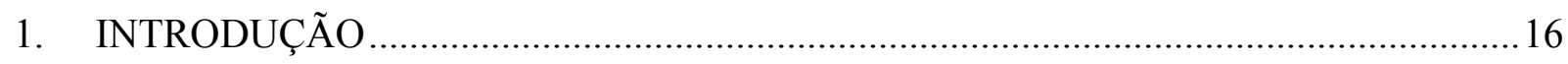

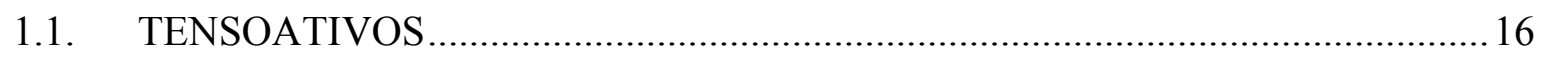

1.2. ÁLCOOIS SECUNDÁRIOS ETOXILADOS........................................................29

1.3. INCORPORAÇÃO DE SOLUTOS NÃO IÔNICOS EM MICELAS DE

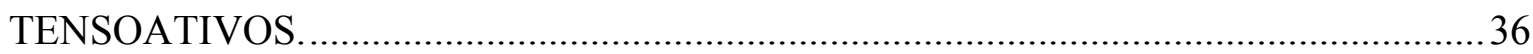

1.4. RELAÇÕES LINEARES DE ENERGIA LIVRE COMO MODELO PREDITIVO

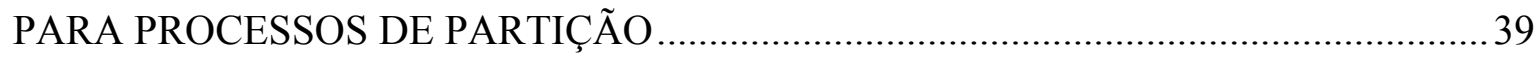

1.4.1. O uso de Relações Lineares de Energia Livre na predição da partição de solutos entre água e a pseudo-fase micelar..................................................................... 48

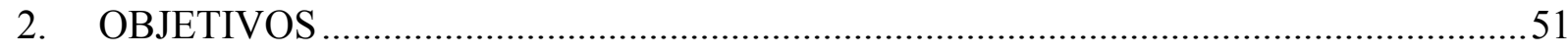

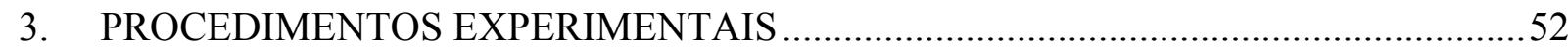

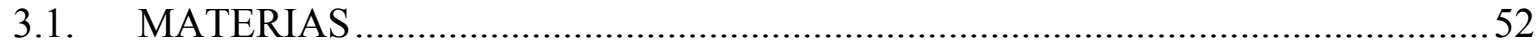

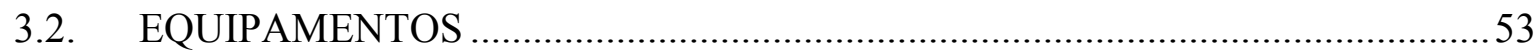

3.2.1. Determinação de constante de incorporação micelar …………………………...53

3.2.2. Determinação de tensão interfacial e superficial...............................................53

3.2.3. Determinação de eficiência de limpeza para superfícies sólidas........................54

3.2.4. Determinação de eficiência de limpeza em tecidos.............................................54

3.2.5. Regressões, cálculos estatísticos e gráficos ......................................................54

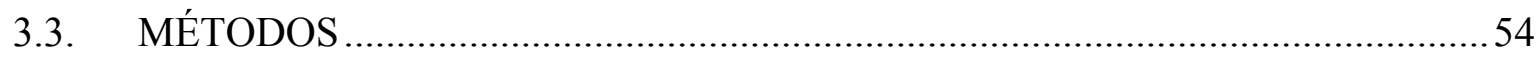

3.3.1. Determinação de constante de incorporação micelar com análise de fase vapor

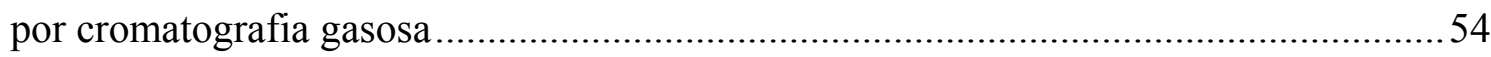

3.3.2. Determinação de constante de incorporação micelar por solubilização em

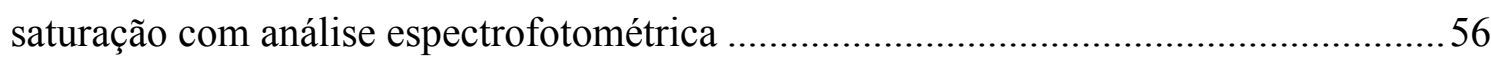

3.3.3. Determinação da tensão interfacial e superficial...............................................57

3.3.4. Determinação da eficiência de limpeza em tecidos...........................................58

3.3.5. Determinação da eficiência de limpeza em superfícies sólidas.........................59

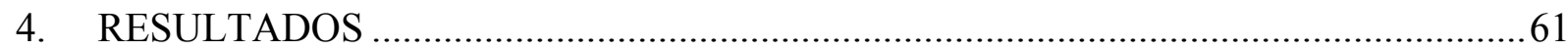

4.1. DETERMINAÇÃO DA CONCENTRAÇÃO MICELAR CRÍTICA........................61

4.2. DETERMINAÇÃO DA TENSÃO INTERFACIAL ENTRE TERGITOL 15-S E

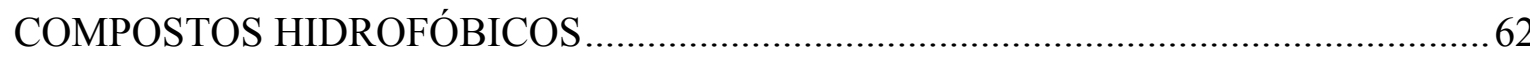


4.3. DETERMINAÇÃO DA CONSTANTE DE INCORPORAÇÃO MICELAR POR ANÁLISE DE VASE VAPOR POR CROMATOGRAFIA GASOSA

4.4. DETERMINAÇÃO DA CONSTANTE DE INCORPORAÇÃO MICELAR POR SOLUBILIZAÇÃO EM SATURAÇÃO COM ANÁLISE ESPECTROFOTOMÉTRICA85 4.5. EFICIÊNCIA DE LIMPEZA …………………….........................................96

4.5.1. Eficiência de limpeza no processo de lavagem de tecidos ...............................96

4.5.2. Eficiência de limpeza para superfícies sólidas ................................................98

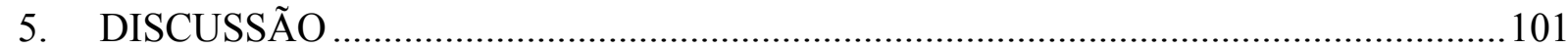

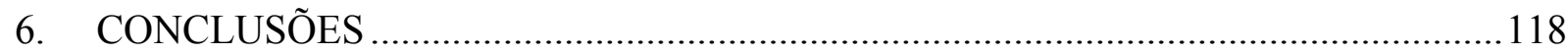

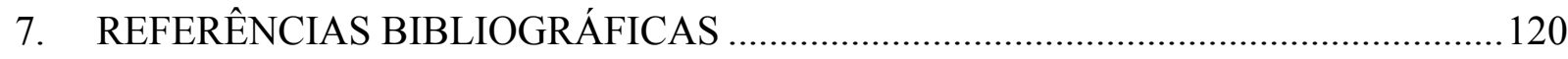




\section{INTRODUÇÃO}

\subsection{TENSOATIVOS}

Substâncias capazes de reduzir a tensão superficial do meio na qual estão dissolvidas, e/ou capazes de reduzir a tensão interfacial entre o meio na qual estão dissolvidas e um outro meio em fase líquida, e que nesses processos adsorvam respectivamente na interface líquidovapor ou líquido-líquido são definidas como tensoativos (EVERETT, 1972). Tensoativos são também comumente chamados de detergentes ou surfactantes (do termo em inglês surfactant que é uma contração das palavras surface active agent, agente ativo em superfície). O termo detergente, entretanto, é mais corretamente utilizado quando se refere a um tensoativo ou mistura de tensoativos que, quando diluídos em água, conferem propriedades de limpeza a essa solução.

A característica estrutural comum aos vários compostos classificados como tensoativos, e que confere a esses um caráter anfifílico, é a presença de uma fração hidrofóbica na molécula, também chamada de cauda hidrofóbica, unida a uma fração da molécula com característica hidrofílica, também chamada de cabeça hidrofílica. A descrição das frações da molécula como hidrofílica e hidrofóbica é válida quando o meio no qual o tensoativo está presente é aquoso. Quando o tensoativo está presente em um sistema não aquoso, como óleo e ar, moléculas contendo frações organofílicas e organofóbicas também podem apresentar caráter anfifílico.

A cauda hidrofóbica, para maioria dos tensoativos, é constituída por uma cadeia alquílica, linear ou ramificada, com número de carbonos variando tipicamente de 6 a 20 ou por uma cadeia alquil aromática. A cabeça hidrofílica dos tensoativos pode ser de natureza iônica ou não iônica. Essa propriedade é comummente utilizada para classificar os 
tensoativos em uma das quatro categorias: i) aniônicos, ii) catiônicos, iii) não-iônicos e iv) anfotéricos ou zwitteriônicos. A Tabela 1 mostra alguns exemplos dos diferentes grupos de tensoativos e ilustra algumas das aplicações industriais destes. 
Tabela 1: Exemplos de Tensoativos e aplicações industriais

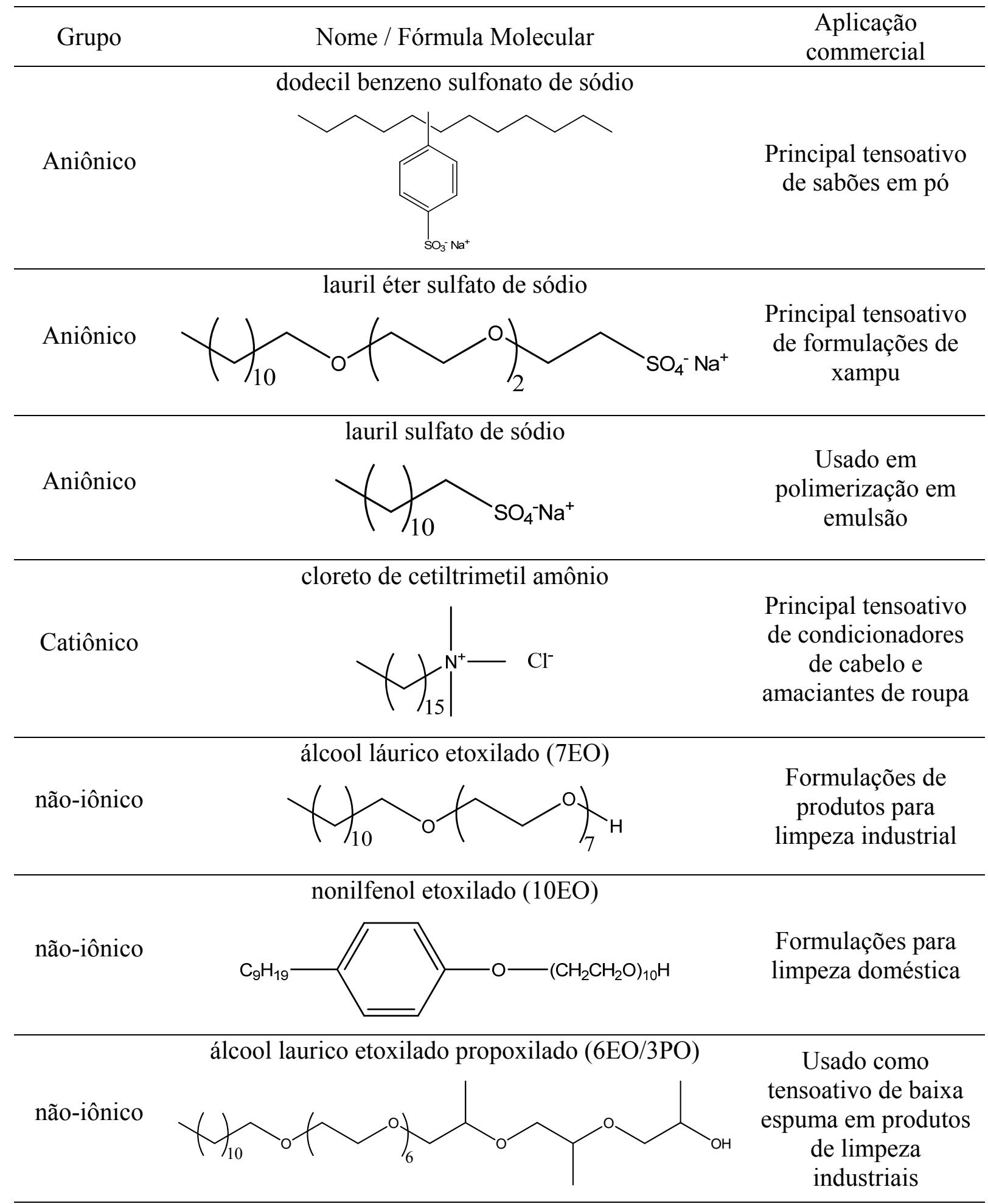

Alquilamido propil betaina<smiles>[R]C(=O)NCCC[N+](C)(C)CC(=O)O[Na]</smiles>

Usado como aditivo em xampus. 
Em baixas concentrações em soluções aquosas, os tensoativos adsorvem na superfície água-ar ou nas interfaces líquido-líquido, resultando na redução de tensão superficial ou interfacial. O aumento da concentração de tensoativos na solução resulta na auto-agregação dos monômeros, formando estruturas chamadas de micelas (TANFORD, 1974).

A auto agregação de monômeros de tensoativos formando micelas resulta em uma série de mudanças nas propriedades físico-químicas das soluções contendo tensoativos. Essas mudanças são evidenciadas através da descontinuidade em propriedades físico-químicas em função da concentração de tensoativo em solução. A descontinuidade nas propriedades físicoquímicas da solução ocorre em uma faixa de concentração suficientemente estreita definida como concentração micelar crítica $(\mathrm{cmc})$. A Figura 1 representa a variação em algumas dessas propriedades em função da concentração de tensoativos na região pré-micelização e na região pós-micelização.

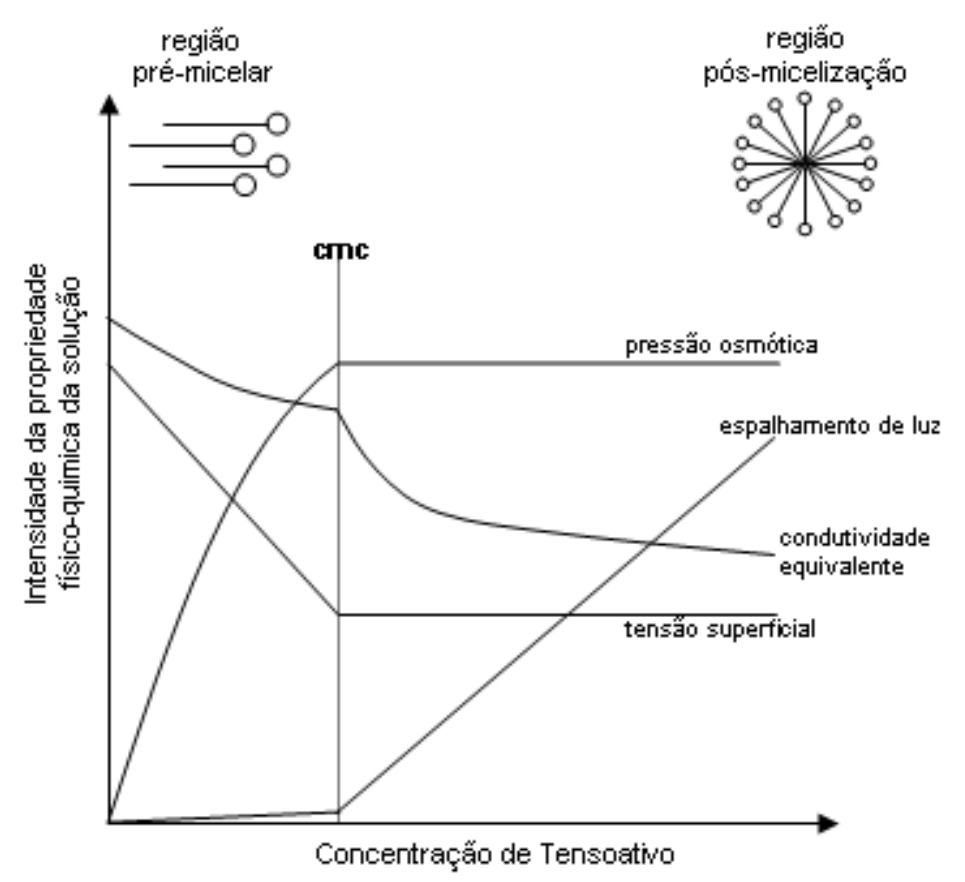

Figura 1: Representação das variações em propriedades físico-químicas de soluções aquosas em função da concentração de tensoativo. 
Hartley (1936) descreve a micela como um agregado de geometria esférica de monômeros de tensoativos onde o grupo alquil do hidrófobo do tensoativo constitui o centro da micela. Esse modelo descreve o centro da micela como um meio líquido e anidro. Consequentemente, o modelo assume o raio máximo da micela sendo o comprimento do tensoativo, resultando em um número de agregação (número de monômeros presentes na micela) máximo entre 50 e 100 moléculas. A geometria esférica desse modelo é valida em determinadas condições definidas pelos seguintes parâmetros geométricos: área do hidrófilo, $a_{0}$, volume do hidrófobo, $v$, e comprimento máximo do hidrófobo, $l_{c}$. A Equação 1 descreve como esses parâmetros definem o parâmetro crítico de empacotamento (PCE) (ISRAELACHVILI 1991):

$$
P C E=\frac{v}{a_{0} l_{c}}
$$

A Tabela 2 descreve as restrições no parâmetro crítico de empacotamento que definem a geometria micelar: 
Tabela 2: Relação entre parâmetro crítico de empacotamento e geometria micelar.

\begin{tabular}{|c|c|c|}
\hline PCE & $\begin{array}{c}\text { Geometria do } \\
\text { empacotamento }\end{array}$ & Estrutura micelar \\
\hline$<1 / 3$ & & Esférica \\
\hline $1 / 3-1 / 2$ & & Cilíndrica \\
\hline $1 / 2-1$ & & Vesícula \\
\hline$\approx 1$ & & Lamela plana \\
\hline$>1$ & & Micela invertida \\
\hline
\end{tabular}

No caso de tensoativos não iônicos com hidrófilos constituídos de polióxidos de eteno, a temperatura apresenta um efeito pronunciado no parâmetro crítico de empacotamento pois reduz a área do hidrófilo, $a_{0}$, devido a desidratação parcial dos hidrófilos (NILSSON e LINDMAN 1983 e PUVVADA e BLANCKSTEIN 1990). Consequentemente, com o aumento da temperatura, micelas esféricas de tensoativos não iônicos crescem em volume e migram para uma geometria cilíndrica (KATO e SEIMIYA 1986).

A micelização pode ser descrita, como uma separação de fases que ocorre a partir da concentração micelar crítica. Acima da $\mathrm{cmc}$, as micelas passam a existir como uma fase 
distinta da fase na qual estão dispersas. Os potenciais químicos dos tensoativos podem ser descritos pelas seguintes equações:

$$
\begin{aligned}
& \mu_{s}=\mu_{s}^{0}+R T \ln X_{S} \\
& \mu_{m}=\mu_{m}^{0}
\end{aligned}
$$

Nessas equações, $\mu_{s}$ e $\mu_{m}$ representam, respectivamente, os potenciais químicos dos monômeros de tensoativo em solução e na pseudo-fase micelar e o sobrescrito 0 indica o potencial químico em seu estado padrão. $O$ termo $R$ é a constante universal dos gases, o termo $T$ é a temperatura absoluta e o termo $X_{S}$ refere-se a fração molar do monômero em fase aquosa. Quando o sistema encontra-se em equilíbrio termodinâmico, os potenciais químicos dos monômeros nos dois meios condensados, fase-aquosa e pseudo-fase micelar, são iguais. Com isso pode-se estabelecer a igualdade entre as Equações 2 e 3:

$$
\begin{aligned}
& \mu_{s}=\mu_{m}=\mu_{m}^{0}=\mu_{s}^{0}+R T \ln X_{S} \\
& \ln X_{S}=\frac{\left(\mu_{m}^{0}-\mu_{s}^{0}\right)}{R T}
\end{aligned}
$$

Finalmente, na concentração micelar crítica, a fração molar do monômero em fase aquosa, $X_{S}$, é definida como a cmc, expressa em fração molar, $X_{c m c}$. Assim sendo, a energia livre padrão do processo de micelização, $\Delta G_{m}^{0}=\mu_{m}^{0}-\mu_{s}^{0}$, é representada pela equação 6 :

$$
\Delta G_{m}^{0}=R T \ln X_{c m c}
$$


A Tabela 3 compara valores de energia livre de micelização e entalpia de micelização com os valores de energia livre e entálpicos referentes a transferência de n-alcanos entre dois meios condensados: água para n-alcano puro.

Tabela 3: Comparação do efeito da adição de um grupo $\mathrm{CH}_{2}$ em parâmetros termodinâmicos no processo de micelização e no processo de transferência de n-alcanos entre água e o próprio n-alcano em fase condensada.

\begin{tabular}{|c|c|c|}
\hline Tensoativo / Processo & $\begin{array}{c}\text { Incremento em } \Delta G_{m}^{0} \\
\text { por grupo } \mathrm{CH}_{2} \text { no } \\
\text { hidrófobo }\left(\mathrm{kJ} \mathrm{mol}^{-1}\right)\end{array}$ & $\begin{array}{l}\text { Incremento em } \Delta H_{m} \text { por grupo } \\
\mathrm{CH}_{2} \text { no hidrófobo }\left(\mathrm{kJ} \mathrm{mol}^{-1}\right)\end{array}$ \\
\hline $\mathrm{R}-\mathrm{SO} \cdot \mathrm{CH}_{3}$ & $-3,30$ & $-1,4^{1}$ \\
\hline $\mathrm{R}-\mathrm{PO} \cdot\left(\mathrm{CH}_{3}\right)_{2}$ & $-3,11$ & $-1,1^{1}$ \\
\hline $\mathrm{R}-\mathrm{E}_{6}^{*}$ & $-2,92$ & $-2,0^{2}$ \\
\hline $\mathrm{R}-\mathrm{E}_{8}{ }^{*}$ & $-2,85$ & $-1,4^{3}$ \\
\hline n-alcano (aq. $\rightarrow$ líq.) & $-3,14$ & $-0,9^{4}$ \\
\hline n-alcano (aq. $\rightarrow$ líq.) & $-3,56$ & $-2,1^{5}$ \\
\hline \multicolumn{3}{|c|}{${ }^{1}$ Clint e Walker (1975), ${ }^{2}$ Corkill et al. (1964), ${ }^{3}$ Merguro et al. (1981), ${ }^{4}$ Nemethy an } \\
\hline \multicolumn{3}{|c|}{ Scheraga (1962), ${ }^{5}$ Nelson e Deligny (1968) apud Clint (1992), ${ }^{*} \mathrm{R}-\mathrm{E}_{X}$ representa um } \\
\hline
\end{tabular}

Os dados apresentados na Tabela 3 reforçam a hipótese de que o centro da micela comporta-se de maneira similar a um alcano líquido.

Finalmente, uma análise sobre o efeito da variação entrópica do processo de micelização é necessária. Clint e Walker (1975) reportaram valores positivos para entropia do processo de micelização o que contradiz a expectativa simplista de que um processo de agregação deveria gerar uma variação negativa na entropia do sistema. Uma das hipóteses (FRANK e EVANS, 1945) é de que a presença do hidrófobo em solução induz estruturação entre as moléculas de água e no processo de micelização as moléculas de água estruturadas revertem à água livre, o que resulta em um aumento entrópico no sistema. Geiger (1990) apud Clint (1992), em trabalho simulando a variação da estrutura da água em função da 
densidade, mostrou que o número de pontes de hidrogênio por molécula de água varia entre quatro e cinco. Em função do aumento da densidade, o número médio de pontes de hidrogênio aproxima-se de cinco e a mobilidade de moléculas de água é mais alta do que em baixas densidades onde o número de pontes de hidrogênio aproxima-se de quatro. A introdução de um hidrófobo em água poderia limitar a formação de pontes de hidrogênio e consequentemente moléculas de água próximas a moléculas hidrofóbicas apresentam menor mobilidade o que corrobora com a hipótese de Frank e Evans. Essa hipótese encontra, entretanto, limitações descritas por Evans (1988). Nesse trabalho (ver representação dos resultados na Figura 2) a variação entrópica e entálpica do processo de micelização de brometo de tetradeciltrimetil amônio foram determinadas em função da temperatura.

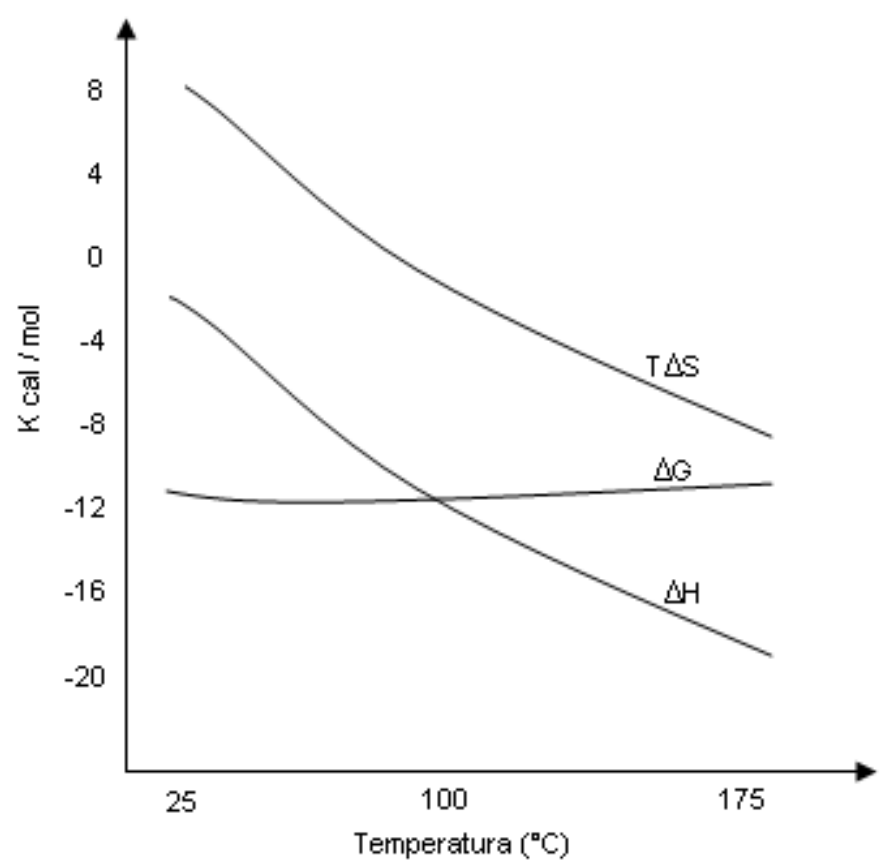

Figura 2: Representação na variação de propriedades termodinâmicas em função da temperatura no processo de micelização. 
Fica claro que o aumento entrópico do processo de micelização somente ocorre a baixas temperaturas, decrescendo praticamente linearmente com o aumento de temperatura. A altas temperaturas o processo de micelização continua ocorrendo, como esperado uma vez que a energia livre de micelização permanece constante; entretanto, o processo ocorre com variação entrópica negativa refletindo o aumento da ordenação no sistema com a agregação micelar. Consequentemente, o processo de micelização a altas temperaturas passa a ser governado pela variação entálpica negativa.

Em sistemas aquosos, o balanço de três fatores determina a concentração micelar crítica de tensoativos (Figura 3).

\section{Interação entre "cabeça" hidrofílica}

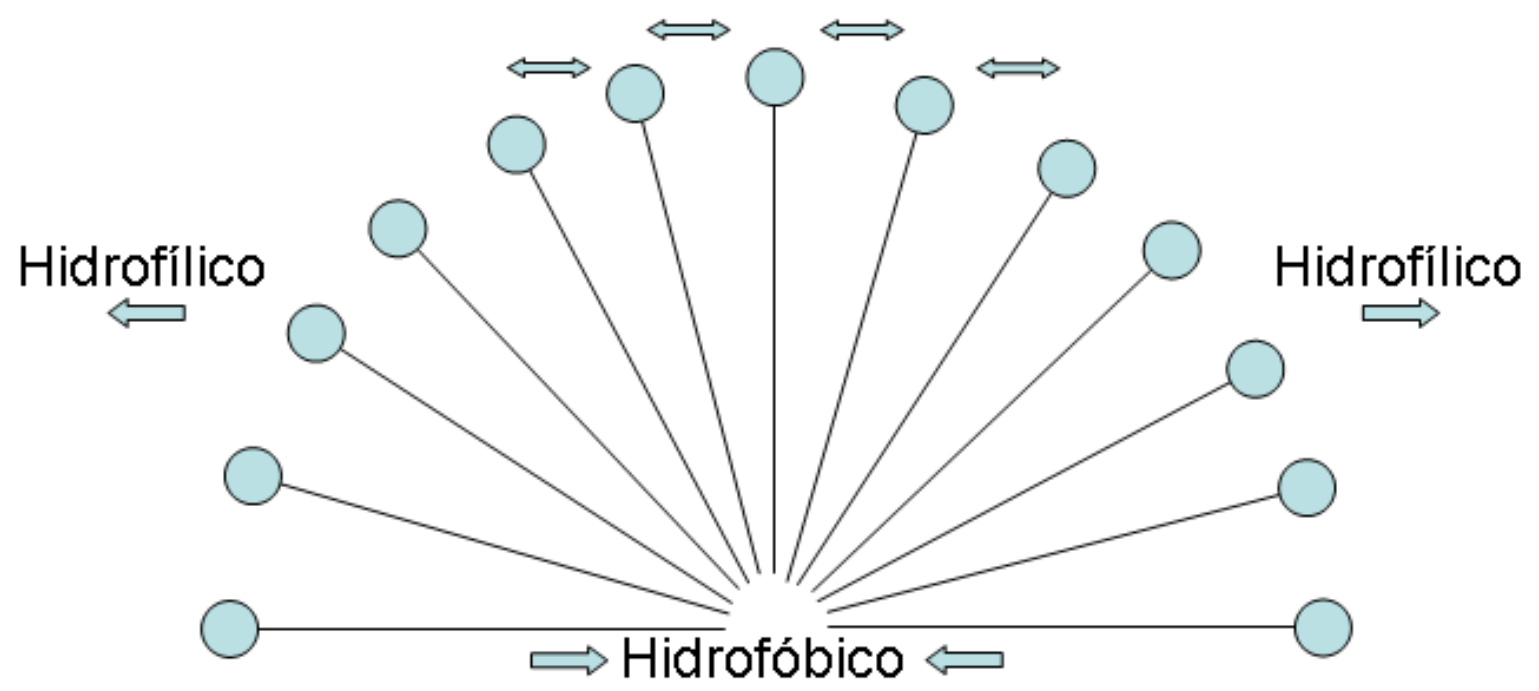

Figura 3: Componentes que agem na formação de micelas. 
A insolubilidade do hidrófobo é um dos parâmetros que contribui diretamente no valor de concentração micelar crítica. A Figura 4 ilustra claramente este fenômeno para brometos de alquiltrimetil amônio (BARRY e RUSSEL, 1972), alquil sulfonatos de sódio (KLEVENS, 1948 e BUJAKE e GODDARD, 1965) e alquil sulfatos de sódio (EVANS, 1956).

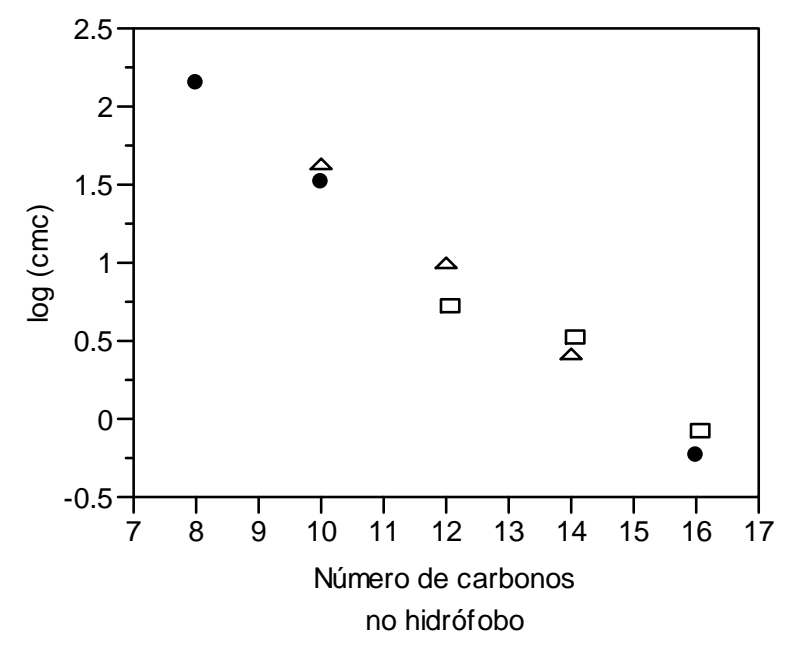

Figura 4: Redução de cmc em função do número de carbonos no hidrófobo para: ( $\square$ )

brometos de alquiltrimetil amônio, ( • ) alquil sulfatos de sódio e ( $\Delta$ ) alquil sulfonatos de sódio.

Como regra geral, a adição de um grupo $\mathrm{CH}_{3}$ a um hidrófobo de cadeia linear resulta na redução da cmc à metade de seu valor inicial para tensoativos iônicos (BOURREL e SCHECHTER 1988). Para tensoativos não iônicos, o aumento de duas unidades $\mathrm{CH}_{3}$ no hidrófobo reduz, de maneira geral, a cmc à $1 / 10$ do valor prévio (ROSEN 1978). Outros parâmetros na estrutura do hidrófobo como ramificação na cadeia carbônica, presença de insaturações ou tensoativos apresentando mais de um hidrófobo apresentam menor influência nos valores de cmc (CLINT 1992)

Outro parâmetro que contribui significativamente com o valor da $\mathrm{cmc}$ de tensoativos é a natureza iônica do hidrófilo. Para tensoativos aniônicos e catiônicos, a interação, de 
natureza eletrostática repulsiva, entre hidrófilos contribui para um aumento da $\mathrm{cmc}$ em relação aos análogos não iônicos. Como exemplo, a Tabela 4 compara o valor da $\mathrm{cmc}$ para tensoativos não iônicos, aniônicos e catiônicos com a mesma cadeia hidrofóbica.

Tabela 4: Valores de cmc para tensoativos iônicos e não iônicos com mesmo hidrófobo.

$$
\begin{aligned}
& \begin{array}{cc}
\hline \text { Composto } & \mathrm{Cmc}(\mathrm{mM}) \\
\hline \mathrm{C}_{12} \mathrm{H}_{25} \mathrm{SO}_{4}{ }^{-} \mathrm{Na}^{+} & 8,2^{*}
\end{array} \\
& \mathrm{C}_{12} \mathrm{H}_{25} \mathrm{SO}_{4}{ }^{-} \mathrm{Li}^{+} \quad 8,9^{* *} \\
& \mathrm{C}_{12} \mathrm{H}_{25} \mathrm{SO}_{3}{ }^{-} \mathrm{Na}^{+} \quad 10^{* *} \\
& \mathrm{C}_{12} \mathrm{H}_{25} \mathrm{~N}\left(\mathrm{CH}_{3}\right)_{3}{ }^{+} \mathrm{Br}^{-} \quad 16^{* * *} \\
& \mathrm{C}_{12} \mathrm{H}_{25} \mathrm{~N}\left(\mathrm{CH}_{3}\right)_{3}{ }^{+} \mathrm{Cl}^{-} \quad 17^{* *} \\
& \mathrm{C}_{12} \mathrm{H}_{25}\left(\mathrm{OC}_{2} \mathrm{H}_{4}\right)_{4} \mathrm{OH} \quad 0,046^{* *} \\
& \text { *Elworthy e Mysels (1966), }{ }^{* *} \mathrm{Clint}(1992){ }^{* * *} \mathrm{~K} \text { Klevens }(1948),{ }^{* * * *} \text { Schick e Gilbert (1965) }
\end{aligned}
$$

Fica claro que para tensoativos não iônicos, onde não há repulsão de natureza eletrostática entre as cabeças hidrofílicas, o valor da cmc é significativamente mais baixo que os valores de cmc de tensoativos iônicos para um tensoativo de mesma cauda hidrofóbica.

Outra consequência da existência de interações repulsivas entre cabeças iônicas de tensoativos é o fato de que a adição de contra-íons na solução resulta na redução da repulsão entre hidrófilos (Corrin e Hawkins, 1947) o que resulta na redução da cmc como exemplificado na Tabela 5. 
Tabela 5: Redução da cmc de alquil sulfatos de sódio em função do aumento da concentração de contra-íons.

\begin{tabular}{ccc}
\hline Concentração $\mathrm{NaCl}(\mathrm{M})$ & $\begin{array}{c}\mathrm{C}_{12} \\
\mathrm{cmc}(\mathrm{mM})\end{array}$ & $\begin{array}{c}\mathrm{C}_{10} \\
\mathrm{cmc}(\mathrm{mM})\end{array}$ \\
\hline 0 & 8,1 & \\
0,02 & 3,8 & \\
0,03 & 3,1 & \\
0,10 & 1,4 & \\
0,20 & 0,8 & \\
0,30 & & 7,3 \\
0,40 & 0,5 & 6,5 \\
1,0 & & 2,8 \\
\hline${ }^{*}$ Phillips, (1955), ${ }^{* *}$ Mysels e Mysels (1965)
\end{tabular}

Ainda em relação à contribuição da natureza do hidrófilo para a cmc, tensoativos não iônicos, cuja cabeça hidrofílica é normalmente constituída por grupos $\left(-\mathrm{CH}_{2}-\mathrm{CH}_{2}-\mathrm{O}-\right)$, apresentam um aumento da cmc com aumento de unidades $\left(-\mathrm{CH}_{2}-\mathrm{CH}_{2}-\mathrm{O}-\right)$ presentes no hidrófilo do tensoativo (CROOK et al. 1963 e 1964 ). 


\section{2.ÁLCOOIS SECUNDÁRIOS ETOXILADOS}

Entre os tensoativos não iônicos produzidos em larga escala, podem-se destacar, de acordo com a fonte de hidrofilicidade do tensoativo, duas classes de compostos. A primeira classe é composta de tensoativos onde a contribuição hidrofílica dos tensoativos dá-se através da presença de grupos (- $\left.\mathrm{CH}_{2}-\mathrm{CH}_{2}-\mathrm{O}-\right)$ na cabeça dos tensoativos enquanto na segunda classe a contribuição hidrofílica dá-se através do uso de compostos contendo múltiplas hidroxilas na cabeça dos tensoativos. Os principais exemplos da primeira classe de compostos são:

- Álcoois etoxilados

- Monoalcanolamidas etoxiladas

- Aminas graxas etoxiladas

- Ácidos graxos etoxilados

- Copolímeros de bloco com monômeros derivados de óxido de eteno, óxido de propeno e óxido de buteno

- Alquilfenol etoxilados

Os principais exemplos da segunda classe de compostos são:

- Ésteres de glicerol e poligliceróis

- Ésteres de Sorbitan

- Alquil poliglicosídeos

Os álcoois etoxilados apresentam grande importância por serem estes os tensoativos não iônicos de maior aplicação industrial e de maior volume de produção global. Dentre as várias aplicações nas quais álcoois etoxilados são utilizados, destacam-se (PORTER 1991): 
- Produtos de limpeza: utilizados em formulações como limpadores de superfície bem como em formulações de lava-roupas.

- Detergentes indústrias: utilizados em formulações de detergentes indústrias que necessitam de baixo nível de espumação (os álcoois etoxilados são normalmente pós-reagidos com óxido de propeno para conferir propriedades de baixa espumação a esses tensoativos).

- Indústria têxtil: utilizados como agentes promotores de molhamento de fibras e assistentes no processo de tingimento de lã.

- Emulsionantes: tensoativos com número médio de unidades $\left(-\mathrm{CH}_{2} \mathrm{CH}_{2} \mathrm{O}-\right)$ próximo a 3 e hidrófobo entre $C_{12}$ e $C_{15}$ são utilizados como emulsionantes em sistemas água em óleo para óleos, parafinas e solventes clorados; para ceras e triglicérides, emulsões são produzidas com hidrófobo entre $\mathrm{C}_{12}$ e $\mathrm{C}_{15} \mathrm{e}$ número médio de unidades $\left(-\mathrm{CH}_{2} \mathrm{CH}_{2} \mathrm{O}-\right)$ próximo a 7.

- Agricultura: álcoois etoxilados são utilizados em conjunto com tensoativos aniônicos para emulsão de pesticidas.

- Polimerização em emulsão: emulsionantes no processo de polimerização em emulsão, amplamente utilizados devido sua tolerância a eletrólitos e tolerância a variações no $\mathrm{pH}$.

Os álcoois etoxilados são produzidos através da reação entre álcoois e óxido de eteno.

O Esquema 1 representa de maneira simplificada a produção de álcoois etoxilados.

$\mathrm{R}-\mathrm{OH}+\mathrm{n}$

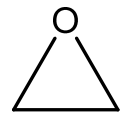

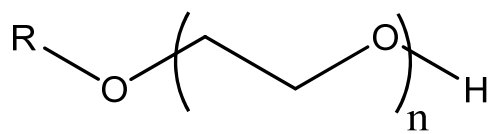

Esquema 1: Síntese simplificada de álcoois etoxilados. 
A reação dá-se em meio básico e envolve um ataque nucleofílico do iniciador ao carbono do óxido de eteno, gerando um alcóxido que passa a ser o agente nucleófilo que reage com outro óxido de eteno, propagando o crescimento da cadeia do poliéter. A etapa limitante desta reação é a abertura do óxido de eteno, que ocorre através de um mecanismo $\mathrm{S}_{\mathrm{N}} 2$ como demonstrado para nonilfenóis (SANTACESARIO et al. 1990) e outros álcoois (GEE et al. 1959a e 1959b).

O Esquema 2 mostra em detalhes as etapas envolvidas na síntese de álcoois primários etoxilados onde $\mathrm{B}^{-}$é o catalisador básico, normalmente $\mathrm{NaOH}$ ou $\mathrm{KOH}$ (NACE 1996), BH é seu ácido conjugado, $\mathrm{ROH}$ é o álcool utilizado e também chamado de iniciador, $\mathrm{RO}^{-}$é seu ânion correspondente e $\mathrm{R}\left(\mathrm{OCH}_{2} \mathrm{CH}_{2}\right)_{\mathrm{n}} \mathrm{O}^{-}$é o ânion polietoxilado.

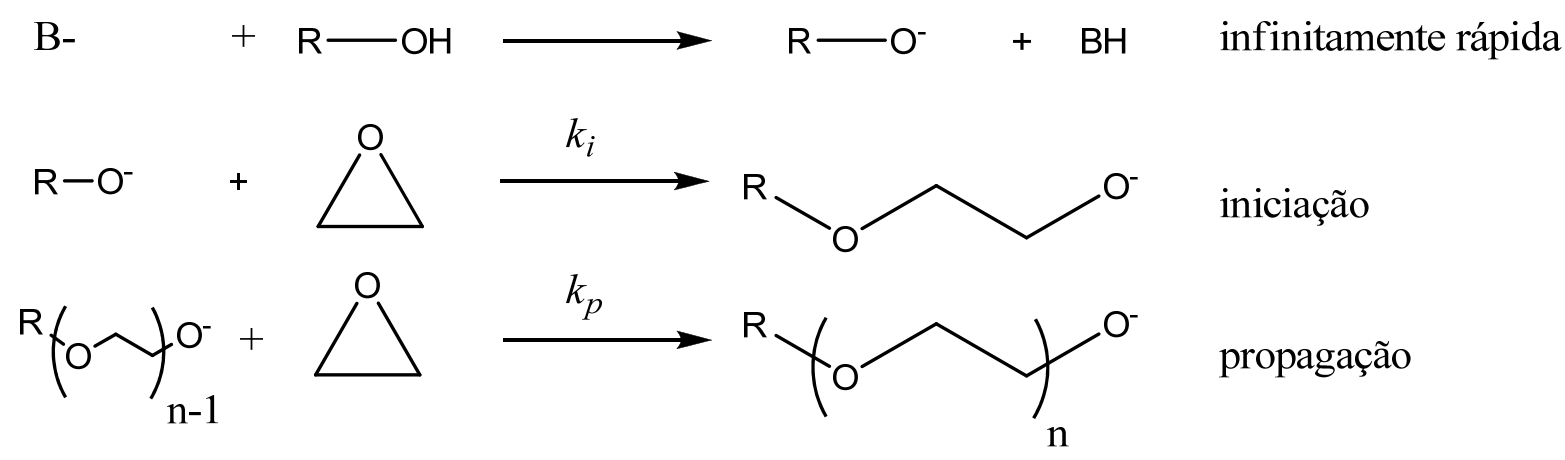

Esquema 2: Síntese detalhada de álcoois etoxilados.

Ao final do processo é necessário neutralizar a base, o que industrialmente é realizado através da adição de ácido fosfórico ou ácido acético. Para aplicações industriais pode ser necessário remover o sal formado no processo de neutralização em função da aplicação especifica na qual o tensoativo será utilizado uma vez que a presença de sal pode interferir em propriedades físico-químicas das soluções de tensoativos (SCHOTT et al. 1984).

Os álcoois secundários etoxilados utilizados neste estudo são produzidos pela The Dow Chemical Company nos Estados Unidos da América e comercializados no Brasil 
através da Dow Brasil SA. A Figura 5 mostra a estrutura desses tensoativos cujo nome comercial é TERGITOL 15-S-x, onde x representa o valor médio de etoxilação desses tensoativos.

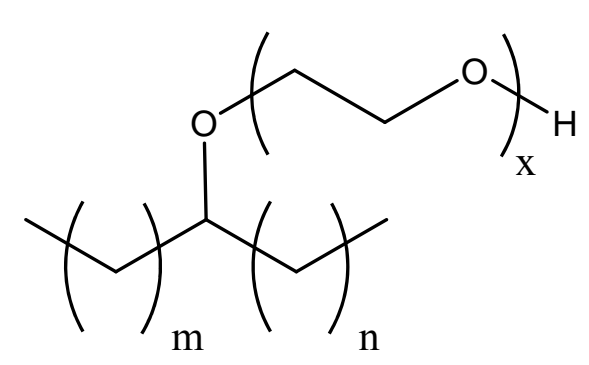

Figura 5: Estrutura de álcoois secundários etoxilados TERGITOL 15-S onde $\mathrm{m}+\mathrm{n}=9 \sim 11 \mathrm{e}$ $\mathrm{x}$ varia entre 7 e 40 .

A produção de álcoois secundários etoxilados normalmente dá-se em duas etapas (RAKUTANI et at. 1999): a primeira etapa é a etoxilação do álcool na presença de catalisador ácido até o grau de etoxilação 3 seguida da destilação do álcool não reagido. A segunda etapa dá-se através do processo supra descrito onde o álcool etoxilado com 3 unidades de óxido de eteno reage na presença de catalisador básico para formação de tensoativos com mais alto grau de etoxilação. A necessidade da produção em duas etapas dáse pelo fato de que a produção em uma única etapa geraria concentrações altas de álcool não reagido, uma vez que, após iniciada a reação, existiria uma competição no sistema entre alcóxidos de álcoois primários e secundários e, sendo o primeiro um melhor nucleófilo, a etoxilação sobre um álcool já etoxilado prevaleceria sobre a etoxilação sobre o álcool secundário original.

Algumas propriedades descritas em literatura dos álcoois secundários etoxilados são (RAKUTANI et at. 1999 e The Dow Chemical Company 1996): baixo odor (resultado da baixa concentração de álcool não reagido), baixa irritação aos olhos e pele (também consequência da baixa concentração de álcool não reagido), fácil manuseio em aplicações 
industriais e formulações, pois apresenta baixa viscosidade em faixa ampla de concentração em soluções aquosas (em comparação a álcoois primários etoxilados e nonilfenois etoxilados que apresentam alta viscosidade em faixas amplas de concentração em soluções aquosas), excelente detergência e biodegradabilidade de acordo com teste OECD 301. 
A Tabela 6 apresenta propriedades típicas do tensoativos TERGITOL 15-S.

Tabela 6: Propriedades físico-químicas típicas de TERGITOL 15-S-X.

\begin{tabular}{|c|c|c|c|c|c|c|}
\hline \multirow[t]{2}{*}{$\mathrm{X}$} & \multirow[t]{2}{*}{ Aparência } & \multirow[t]{2}{*}{ HLB } & Viscosidade & Densidade & $\begin{array}{c}\text { Ponto } \\
\text { de } \\
\text { Ignição }\end{array}$ & $\begin{array}{l}\text { Ponto de } \\
\text { escoamento }\end{array}$ \\
\hline & & & $\mathrm{cP}\left(25^{\circ} \mathrm{C}\right)$ & $\begin{array}{l}\mathrm{g} / \mathrm{mL} \\
\left(20^{\circ} \mathrm{C}\right)\end{array}$ & ${ }^{\circ} \mathrm{C}$ & ${ }^{\circ} \mathrm{C}$ \\
\hline 7 & $\begin{array}{l}\text { líquido } \\
\text { incolor }\end{array}$ & 12,1 & 51 & 0,991 & 186 & 2 \\
\hline 9 & $\begin{array}{l}\text { líquido } \\
\text { incolor }\end{array}$ & 13,3 & 60 & 1,006 & 193 & 9 \\
\hline 12 & $\begin{array}{l}\text { semi- } \\
\text { sólido } \\
\text { branco }\end{array}$ & 14,5 & 85 & 1,026 & 227 & 20 \\
\hline 15 & $\begin{array}{l}\text { sólido } \\
\text { branco }\end{array}$ & 15,4 & $43^{+}$ & $1,007^{++}$ & 232 & 28 \\
\hline 20 & $\begin{array}{l}\text { sólido } \\
\text { branco }\end{array}$ & 16,3 & $49^{+}$ & $1,038^{+++}$ & 232 & 32 \\
\hline 30 & $\begin{array}{l}\text { sólido } \\
\text { branco }\end{array}$ & 17,4 & $92^{+}$ & $1,053^{++}$ & 249 & 39 \\
\hline 40 & $\begin{array}{l}\text { sólido } \\
\text { branco }\end{array}$ & 18,0 & $166^{+}$ & $1,059^{++}$ & 252 & 44 \\
\hline
\end{tabular}

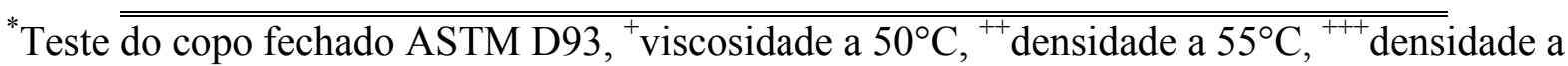
$40^{\circ} \mathrm{C}$ 
A Tabela 7 apresenta propriedades típicas dos tensoativos TERGITOL 15-S em soluções aquosas.

Tabela 7: Propriedades dos tensoativos TERGITOL 15-S- em soluções aquosas

\begin{tabular}{|c|c|c|c|}
\hline$X$ & $\begin{array}{l}\text { Ponto de } \\
\text { Turvação }\end{array}$ & $\begin{array}{c}\begin{array}{c}\text { Concentração Teste } \\
\text { de molhamento de } \\
\text { "Draves"+ }\end{array} \\
\text { (D) }\end{array}$ & $\begin{array}{l}\text { Nível de espuma pelo } \\
\text { teste Ross-Miles }\end{array}$ \\
\hline & $\begin{array}{l}{ }^{\circ} \mathrm{C}(1 \% \\
\text { em água) }\end{array}$ & $\begin{array}{l}\% \text { em massa } \\
\left(25^{\circ} \mathrm{C} / 50^{\circ} \mathrm{C}\right)\end{array}$ & $\frac{\mathrm{mm}}{\text { (inicial / após } 5 \mathrm{~min} \text { ) }}$ \\
\hline 7 & 37 & $0,05 / 0,05$ & $\begin{array}{l}(92 / 45)^{1} \\
(90 / 15)^{2} \\
(77 / 18)^{3}\end{array}$ \\
\hline 9 & 60 & $0,06 / 0,05$ & $\begin{array}{l}(95 / 20)^{1} \\
(100 / 8)^{2} \\
(95 / 10)^{3}\end{array}$ \\
\hline 12 & 89 & $0,11 / 0,06$ & $\begin{array}{c}(120 / 84)^{1} \\
(105 / 8)^{2} \\
(98 / 7)^{3}\end{array}$ \\
\hline 15 & $>100$ & $0,70 / 0,21$ & $\begin{array}{l}(127 / 8)^{1} \\
(131 / 7)^{2} \\
(123 / 5)^{3}\end{array}$ \\
\hline 20 & $>100$ & & $\begin{array}{l}(120 / 55)^{1} \\
(125 / 55)^{2} \\
(120 / 12)^{3}\end{array}$ \\
\hline 30 & $>100$ & & $\begin{array}{l}(118 / 28)^{1} \\
(112 / 22)^{2} \\
(122 / 22)^{3}\end{array}$ \\
\hline 40 & $>100$ & & $\begin{array}{l}(57 / 10)^{1} \\
(100 / 35)^{2} \\
(105 / 35)^{3}\end{array}$ \\
\hline
\end{tabular}

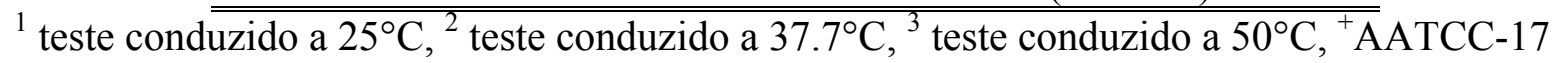
$2005{ }^{++}$ASTM D1173 2007. 


\subsection{INCORPORAÇÃO DE SOLUTOS NÃO IÔNICOS EM MICELAS DE TENSOATIVOS.}

Uma das propriedades mais importantes de tensoativos é sua capacidade de solubilizar em meio aquoso uma grande variedade de compostos de baixa solubilidade e de diferentes polaridades e hidrofobicidades.

O modelo de ação de massas para incorporação de solutos em micelas (SEPULVEDA et al., 1986) descreve a incorporação de solutos em etapas sucessivas de equilíbrio entre soluto na fase aquosa e agregados micelares:

$$
\begin{array}{cccc}
\mathrm{M}_{0}+ & \mathrm{S}_{\mathrm{w}} \stackrel{\mathrm{k}_{1}}{\rightleftharpoons} \mathrm{MS}_{1} & \\
\mathrm{MS}_{1}+ & \mathrm{S}_{\mathrm{w}} & \stackrel{\mathrm{k}_{2}}{\rightleftharpoons} & \mathrm{MS}_{2} \\
& & \mathrm{k}_{\mathrm{n}} & \\
\mathrm{MS}_{\mathrm{n}-1}+ & \mathrm{S}_{\mathrm{w}} & \mathrm{MS}_{\mathrm{n}} &
\end{array}
$$

onde $\mathrm{S}_{\mathrm{w}}$ é o soluto na fase aquosa, $\mathrm{M}_{0}$ é o agregado micelar livre do soluto e $\mathrm{MS}_{\mathrm{n}}$ é o agregado micelar com $\mathrm{n}$ solutos incorporados.

Assim, para a enésima incorporação, podemos descrever a constante de equilíbrio $\mathrm{K}_{\mathrm{n}}$ como:

$$
K_{n}=\frac{k_{n}}{k_{-n}}=\frac{\left[M S_{n}\right]}{\left[M S_{n-1}\right]\left[S_{w}\right]}
$$

São necessárias as seguintes suposições para que possamos simplificar o modelo (SEPULVEDA et al., 1986):

i) número de agregação micelar independente da presença de soluto; 
ii) $\mathrm{k}_{+\mathrm{n}}=\mathrm{k}_{+}$, velocidade de entrada do soluto na micela independente do número de moléculas de soluto presentes na micela;

iii) $\mathrm{k}_{-\mathrm{n}}=\mathrm{n} . \mathrm{k}_{-1}$, velocidade de saída proporcional ao número de solutos na micela;

iv) capacidade de incorporação infinita $(n \rightarrow \infty)$.

Assim, obtem-se a seguinte constante de equilíbrio:

$$
K_{M}=\frac{\left[S_{M}\right]}{\left[S_{w}\right][M]}
$$

onde $\left[S_{M}\right]$ é a concentração analítica de soluto incorporado na fase micelar, $\left[S_{W}\right]$ é a concentração de soluto na fase aquosa e $[M]$ é a concentração total de micelas no sistema.

Baseado na Equação 8, fica claro que, para expressarmos a incorporação micelar em termos de $K_{M}$, passamos a depender do conhecimento da concentração de micelas no sistema, $[M]$, que é dada pela razão entre a concentração de tensoativo micelizado $C_{D}$ e o número médio de agregação:

$$
[M]=\frac{\left[C_{D}\right]}{N}
$$

na qual,

$$
\left[C_{D}\right]=\left[C_{T}\right]-c m c
$$

na qual $\left[C_{T}\right]$ é a concentração total de detergente no sistema e $c m c$ é a concentração micelar crítica. 
Como a determinação do número médio de agregação, $N$, é imprecisa e os valores reportados em literatura são limitados, é mais conveniente expressar a partição do soluto em termos da concentração de tensoativo micelizado:

$$
K_{s}=\frac{K_{M}}{N}=\frac{\left[S_{M}\right]}{\left[S_{W}\right]\left[C_{D}\right]}
$$

A interpretação da Equação 11 é um modelo onde o soluto particiona entre a fase aquosa e uma pseudo-fase micelar e é utilizada no decorrer deste trabalho. 


\subsection{RELAÇÕES LINEARES DE ENERGIA LIVRE COMO MODELO PREDITIVO PARA PROCESSOS DE PARTIÇÃO}

A partição de um soluto entre dois solventes, definida em termos de um coeficiente de partição, $P$, pode ser definida em função da resultante de duas partições entre uma fase gasosa e as fases condensadas como representado esquematicamente na Figura 6

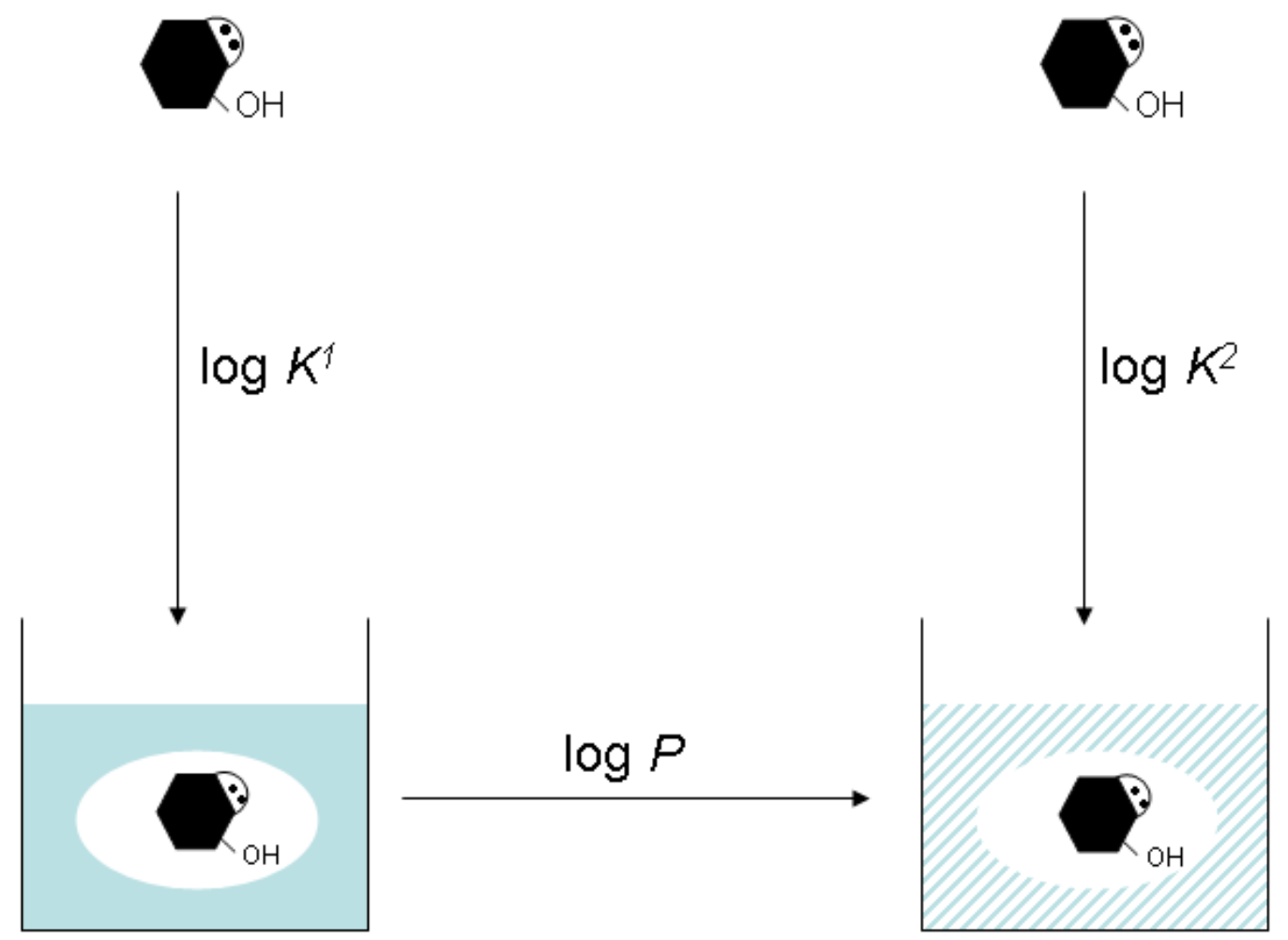

Figura 6: Esquema ilustrativo do processo de transferência de um soluto entre duas fases condensadas (interações entre soluto e solventes não são representadas neste esquema) . 
onde a constante de equilíbrio $K^{X}$ é definida de acordo com a Equação 12.

$$
K^{x}=\frac{\text { concentração do soluto no solvente } \mathrm{x}}{\text { concentração do soluto na fase gasosa }}
$$

Assim, a partição de um soluto entre os solvente 1 e 2 pode ser obtida através das diferenças entre as partições deste soluto de uma fase gasosa e os respectivos meios condensados:

$$
\log P=\log K^{1}-\log K^{2}
$$

Baseado em relações lineares de energia livre (LSER), Abraham (1993a) e Abraham et al. (1988 e 1994) propuseram que a partição de um soluto entre a fase gasosa e a fase condensada, solvente, pode ser tratada como um processo envolvendo três etapas sucessivas:

(a) a criação de uma cavidade no solvente envolvendo a quebra de interações intermoleculares do solvente. Esta cavidade deve ter o volume necessário para acomodar o soluto a ser transferido.

(b) reestruturação das moléculas do solvente ao redor da cavidade aberta. Nesse processo a energia livre de reorganização é negligenciável (ABRAHAM et al. 2004).

(c) introdução do soluto na cavidade e consequentemente a ocorrência de interações intermoleculares entre o soluto e o solvente. A natureza das interações intermoleculares entre soluto e solvente pode ainda ser dividida em interações específicas e não específicas. 
A Figura 7 mostra de maneira ilustrativa as etapas envolvidas neste processo.
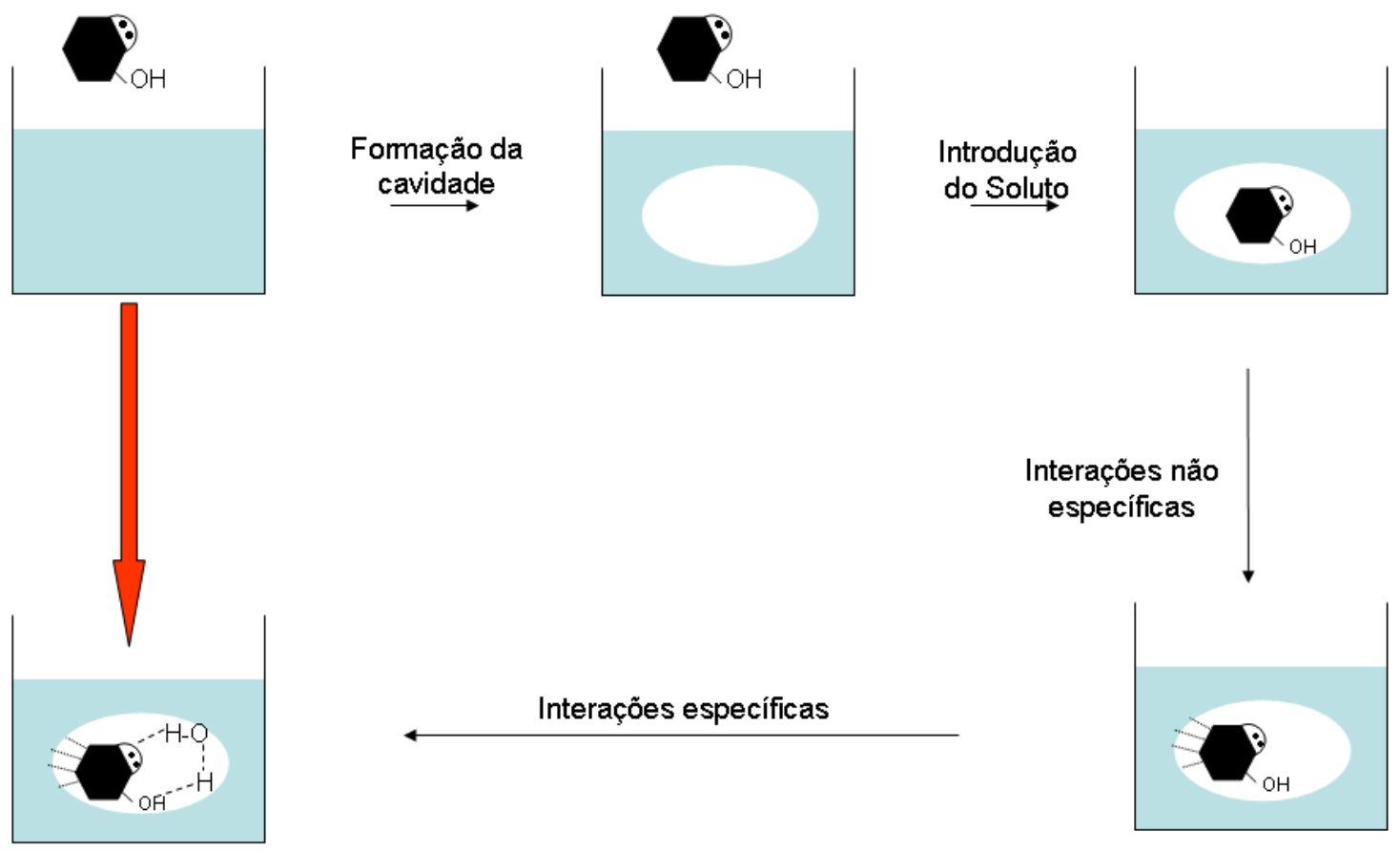

Interações específicas

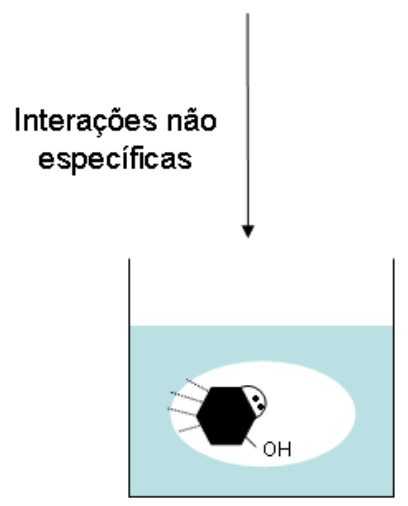

Figura 7: Esquema ilustrativo do processo de transferência de um soluto de uma fase gasosa a uma fase condensada.

Para descrever o processo de transferência entre duas fases condensadas, o modelo de relações lineares de energia livre propõe utilizar uma série de parâmetros descritores do soluto a ser transferido entre as duas fases. Esses parâmetros representam os processos envolvidos na abertura da cavidade conforme descrito na etapa (a) e as interações específicas e não específicas mencionadas na etapa (c). A Equação 14 correlaciona o coeficiente de partição com os parâmetros descritivos das propriedades do soluto: 


$$
\log P=c+e E+s S+a A+b B+v V
$$

Os parâmetros utilizados na Equação 14 são denominados parâmetros de Abraham. A Tabela 8 descreve a notação atual dos parâmetros de Abraham bem como a notação original desses parâmetros (a notação original é descrita uma vez que muitos artigos existentes ainda utilizam esta notação).

Tabela 8: Notações, atual e original, dos parâmetros de Abraham

\begin{tabular}{lcc}
\hline Parâmetro & Notação atual & Notação original \\
\hline Refração molar em excesso & $E$ & $R_{2}$ \\
Dipolaridade / Polarizabilidade & $S$ & $\pi_{2}$ \\
Acidez para pontes de hidrogênio & $A$ & $\Sigma \alpha_{2}$ \\
Basicidade para pontes de hidrogênio & $B$ & $\Sigma \beta_{2}$ \\
Volume de McGowan & $V$ & $V_{x}$ \\
\hline
\end{tabular}

A definição de E é bastante direta e objetiva (ABRAHAM et al. 1990). É a diferença entra a refração molar do composto, $\mathrm{MR}_{X}$, calculada utilizando o volume de McGowan e a refração molar de um alcano de mesmo volume de McGowan. A refração molar é definida como:

$$
\operatorname{MR}_{X}=10\left[\frac{\left(\eta^{2}-1\right)}{\left(\eta^{2}+2\right)}\right] V
$$

onde $\eta$ é o índice de refração do soluto como líquido puro a $20^{\circ} \mathrm{C}$ e $V$ está em unidades de $\left(\mathrm{cm}^{3} \mathrm{~mol}^{-1}\right) / 100$. 
Como a refração molar em excesso, E, é derivada do índice de refração, esse parâmetro fornece uma medida sobre as interações que surgem entre soluto e solvente devido a presença de elétrons polarizáveis no soluto.

O volume de McGowan, $V$, é calculado a partir da estrutura molecular do soluto, Abraham e McGowan (1987). O valor de $V$ é obtido em função dos átomos presentes e o número de ligações covalentes (independente de serem ligações simples, duplas ou triplas). Para moléculas de estrutura complexa, a determinação do número total de ligações covalentes, $B_{n}$, pode facilmente levar a erros. O algoritmo proposto por Abraham (1993a), descrito na Equação 16 pode ser utilizado.

$$
B_{n}=N_{a}-1-R
$$

onde $N_{a}$ é o número total de átomos e $R$ é o número total de anéis.

O volume de McGowan não diferencia alcanos acíclicos lineares e ramificados. Palatinus et al. (2006) propuseram um parâmetro modificado, $V_{Y}$, que consegue diferenciar alcanos lineares de modificados e, consequentemente, resulta em uma melhoria na qualidade de correlações entre volume e propriedades físico químicas para alcanos acíclicos. O uso do parâmetro modificado, $V_{Y}$, ainda não foi incorporado em trabalhos atuais, que utilizam o volume de McGowan como um descritor do soluto, salvo aqueles dos autores que o propuseram.

Para elucidar o significado, bem como o processo de determinação, dos parâmetros $A$, $B$ e $S$, é necessário recorrer ao uso de relações lineares de energia livre na predição do tempo de retenção de solutos em cromatografia gás-líquido. Abraham et al. (1991), Abraham e Whiting (1992) e Abraham (1993b) mostraram que o tempo de retenção de solutos em uma 
fase estacionária não polar, normalmente a $100^{\circ} \mathrm{C}$, pode ser correlacionado através da seguinte Equação:

$$
\log \left(t_{r}\right)=c+e E+l L
$$

onde $t_{r}$ é o tempo de retenção soluto, $E$ é a refração molar em excesso supra descrita e $L$ é o logaritmo da constante de equilíbrio de partição gás-hexadecano.

A tentativa de utilização da Equação 17 com fases estacionárias polares leva a desvios entre os valores preditos e experimentais. Entretanto, a Equação 17 é capaz de predizer o tempo de retenção em fases estacionárias polares para o caso específico de solutos não polares como alcanos, o que evidencia a necessidade da introdução de outros parâmetros capazes de incorporar a contribuição de interações do tipo ponte de hidrogênio, $A$ e $B$, bem como interações oriundas da polarizabilidade do soluto, $S$.

Para compostos polares que não apresentam capacidade de atuarem como doadores ou receptores em interações do tipo ponte de hidrogênio, é necessário incorporar um parâmetro que contenha informação sobre a polarizabilidade do soluto, S. Como exemplo, Abraham e Whiting (1992) determinaram que o tempo de retenção de solutos em tetracloroftalato de bin-propila a $90^{\circ} \mathrm{C}$ pode ser obtido através da seguinte Equação:

$$
\log \left(t_{r}\right)=-3,433+1,640 S+0,618 L
$$

Assim, várias equações similares ou adicionalmente contendo o parâmetro $E$ foram utilizadas para obter os valores de $S$ para uma grande variedade de solutos (ABRAHAM et al. 1991, ABRAHAM e WHITING 1992 e ABRAHAM 1993b).

A obtenção dos valores de $A$ e $\mathrm{B}$ começa na obtenção de parâmetros de acidez e basicidade, $\alpha_{2}^{H}$ e $\beta_{2}^{H}$, descrita em detalhes por Abraham et al. (1989) para $\alpha_{2}^{H}$ e Abraham et 
al. (1990b) para $\beta_{2}^{H}$. Como os processos de obtenção desses parâmetros seguem uma lógica comum, a descrição da criação da escala $\alpha_{2}^{H}$ é utilizada como exemplo. O processo baseia-se em interações 1:1 de pontes de hidrogênio conforme descrito no Esquema 3.

$$
\mathrm{A}-\mathrm{H}+\mathrm{B} \rightleftharpoons \mathrm{K} \rightleftharpoons \mathrm{A}-\mathrm{H}^{\prime \prime \prime \prime \prime \prime \prime \prime ~ B ~}
$$

Esquema 3: Interações do tipo ponte de hidrogênio entre um doador AH e um aceptor B

Para um conjunto especifico de bases, e uma série de ácidos, cujo valor de log $K$ é conhecido, uma série de Equações foram construídas conforme descrito na Equação 19:

$\log K($ para uma série de ácidos com a base 1$)=L_{1} \log K_{\mathrm{A}}^{\mathrm{H}}+D_{1}$ $\log K($ para uma série de ácidos com a base 2$)=L_{2} \log K_{\mathrm{A}}^{\mathrm{H}}+D_{2}$ $\log K($ para uma série de ácidos com a base $\mathrm{n})=L_{n} \log K_{\mathrm{A}}^{\mathrm{H}}+D_{n}$ (19): Equações utilizadas na construção da escala de acidez.

onde as constantes $L_{\mathrm{n}}$ e $\mathrm{D}_{\mathrm{n}}$ caracterizam a base e o valor de $\log K_{\mathrm{A}}^{\mathrm{H}}$ define a acidez do soluto. Através de um processo de regressões lineares múltiplas os valores de $\log K_{\mathrm{A}}^{\mathrm{H}}$ foram definidos como uma escala de acidez para os solutos estudados. Um processo similar foi realizado para obtenção de $\log K_{\mathrm{B}}^{\mathrm{H}}$, parâmetro que define a basicidade do soluto.

Os valores de $\alpha_{2}^{H}$ e $\beta_{2}^{H}$ são baseados em interações do tipo ponte de hidrogênio 1:1 e evidentemente sua utilização na tentativa de incorporar esses parâmetros em LSERs para predição de tempos de retenção em cromatografia gasosa falhou para compostos que apresentam mais de um sítio doador ou aceptor de pontes de hidrogênio. Abraham introduziu as escalas de $\sum \alpha_{2}^{H}$ e $\sum \beta_{2}^{H}$ onde $\sum$ implica que o valor total da capacidade como doador ou 
aceptor de pontes de hidrogênio do soluto é considerado nesta escala. A obtenção dessas escalas ocorreu no início da década de 90 e é descrita em detalhes por Abraham (1993a) para $\sum \alpha_{2}^{H}$ e Abraham (1993c) para $\sum \beta_{2}^{H}$

A escala de $\sum \alpha_{2}^{H}$ foi obtida utilizando-se os valores de acidez do soluto $\alpha_{2}^{H}$ como parâmetros iniciais na predição de tempos de retenção de cromatografia gasosa. Neste processo a correlação é estabelecida e determinam-se os coeficientes das LSERs utilizando-se inicialmente solutos com apenas um sítio doador de pontes de hidrogênio (etapa 1). Com os coeficientes da LSER obtidos, solutos com múltiplos sites doadores de pontes de hidrogênio são introduzidos no conjunto de dados e os valores de $\sum \alpha_{2}^{H}$ são obtidos fazendo-se a regressão inversa onde os coeficientes obtidos na etapa 1 são fixados e a regressão é realizada visando obter os valores de $\sum \alpha_{2}^{H}$. Esse processo segue até que o sistema seja robusto e estável para os coeficientes das LSERs e os parâmetros $\sum \alpha_{2}^{H}$. A notação moderna, utilizada nesse trabalho, para $\sum \alpha_{2}^{H}$ é $A$.

De maneira similar, valores de $\sum \beta_{2}^{H}$ foram obtidos baseando-se, não na predição de tempos de retenção e sim na predição de partição de solutos entre água e solventes, $\log P$. O motivo para utilização de $\log P$ ao invés de $\log t_{r}$ é a quantidade limitada de fases estacionárias que sejam significativamente ácidas para doação de pontes de hidrogênio e que portanto pudessem ser utilizadas na determinação de $\sum \beta_{2}^{H}$. A notação moderna, utilizada nesse trabalho, para $\sum \beta_{2}^{H}$ é $B$.

Atualmente, a determinação de S, A e B é facilitada pela existência de inúmeras LSERs do tipo descrito na Equação 20. Abraham et al. (2004) apresenta 29 LSERs para partição gás-líquido que permite a obtenção das LSERs de partições líquido-líquido).

$$
\log P=c+e E+s S+a A+b B+v V
$$


Tendo disponíveis os coeficientes das LSERs e facilmente calculando $V$ (através da estrutura molecular) e calculando $E$ (através de valores de índice de refração de fácil determinação experimental), podemos reescrever a Equação 30 conforme descrito na Equação 22:

$$
\begin{gathered}
X=s S+a A+b B \\
\text { onde, } \\
X=\log P-c-e E-v V
\end{gathered}
$$

Uma vez que a LSER, Equação 20, é conhecida, o valor de $X$ na Equação 22 é conhecido bem como os valores dos coeficientes $s, a$ e $b$. Dessa maneira, basta, em princípio, medir experimentalmente a partição do soluto em questão entre três sistemas de LSERs conhecidas que os valores de $A, B$ e $S$ podem ser obtidos através da resolução de um sistema com três variáveis e três equações. É recomendado (VITHA e CARR 2006) que a determinação de $A, B$ e $S$ utilize mais de três LSERs e idealmente utilize sistemas que apresentem grande variação em suas composições químicas e que possam, consequentemente, apresentarem diferentes sensibilidades aos parâmetros $A, B$ e $S$.

É importante citar o trabalho de Mutelet et al. 2003 que permite a determinação de parâmetros $B$ e $S$ para compostos de alto ponto de ebulição através do uso de cromatografia líquida micelar. Esse método é particularmente interessante pois a determinação de parâmetros de solubilidade de compostos de alto ponto de ebulição como hidrocarbonetos aromáticos não pode ser realizada por cromatografia gasosa. O método é baseado na utilização sistemas micelares cuja LSER seja conhecida e de maneira similar à descrita 
anteriormente, os coeficientes referentes ao sistema micelar são fixados e a regressão linear é realizada para obter os parâmetros do soluto.

\subsubsection{O uso de Relações Lineares de Energia Livre na predição da partição de solutos entre água e a pseudo-fase micelar}

Conforme descrito na seção 1.3, o processo de solubilização de um soluto por tensoativos pode ser tratado como a partição deste soluto entra a fase aquosa e a pseudo-fase micelar representado pela constante de incorporação micelar, $K_{s}$, conforme descrito na Equação 11.

Quina et al. (1995) utilizaram esta abordagem para encontrar LSERs que correlacionem a constante de incorporação micelar, $\mathrm{K}_{\mathrm{s}}$, com os cinco parâmetros de soluto descritos acima para dodecil sulfato de sódio (SDS), brometo de hexadeciltrimetil amônio (CTAB), brometo de dodeciltrimetil amônio (DTAB) e o detergente não iônico Brij-35:

Para SDS:

$$
\log K_{s}=-0.62-0,08 A-1,84 B-0,57 S+0,32 E+3,25 V
$$

Para DTAB:

$$
\log K_{s}=-0,87+0,28 A-1,82 B-0,40 S+0,57 E+2,98 V
$$

Para CTAB:

$$
\log K_{s}=-0,76+1,02 A-3,78 B-0,32 S+0,76 E+3,57 V
$$

Para Brij-35

$$
\log K_{s}=-1,39+1,62 A-3,83 B-0,37 S+1,63 E+3,65 V
$$

A análise dos coeficientes de ajuste das equações acima permite concluir que as maiores contribuições à constante de incorporação micelar provém dos parâmetros volume, $V$, 
e basicidade, B. Um aumento do volume do soluto favorece a partição desse para a pseudofase micelar. Esse comportamento deve ser interpretado como uma maior facilidade de formação de cavidade na pseudo-fase micelar em relação a água, o que indica maior coesão na fase aquosa do que a coesão existente da pseudo-fase micelar. É também claro que um aumento da basicidade do soluto favorece a partição para a fase aquosa, o que sugere maior acidez da fase aquosa em relação a pseudo-fase micelar (QUINA et al., 1995).

Vitha et al. (1997) comparou os resultados de LSER para SDS de quatro estudos diferentes. Dois desses estudos eram baseados em dados de literaturas obtidos por diferentes técnicas e condições experimentais. Um dos estudos era baseado em dados de coeficientes de partição obtidos por cromatografia capilar eletrocinética e o quarto estudo era baseado em dados obtidos a partir de análise de fase vapor por cromatografia gasosa (HSGC). As interpretações químicas obtidas a partir dos quatro estudos comparados são similares mostrando a robustez do modelo de LSER.

Vitha e Carr (1998) fizeram uso da análise comparativa entre DTAB e solventes puros para os parâmetros de Abraham para mostrar que o ambiente micelar desse detergente é fortemente dipolar e doador de pontes de hidrogênio e moderadamente aceptor de pontes de hidrogênio. Assim, o modelo de LSER mostrou-se eficaz na elucidação do mecanismo de solubilização por sistemas micelares.

Abraham et al. (1997) estudou o coeficiente de partição entre água e micelas de cloreto de hexadecilpiridina e encontrou, para esse detergente, os seguintes termos correlacionando $\log \mathrm{K}_{\mathrm{s}}$ com os parâmetros do soluto: $+0,769 A,-2,840 B,-0,736 S,+0,973 E \mathrm{e}$ $+3,386 \mathrm{~V}$.

Para esse detergente como para os descritos pelas equações 8-11, os valores grandes e negativos dos coeficientes de $\Sigma \beta_{2}$ evidenciam que o ambiente de solubilização micelar é um mal doador de pontes de hidrogênio quando comparado ao meio aquoso. 
O modelo de LSER mostrou-se também útil na descrição do comportamento de solubilização por micelas mistas. Rodrigues et al. (1999) utilizou a técnica de LSER para descrever o comportamento de solubilização de micelas mistas de CTAB/Brij-35. Neste estudo, interações específicas envolvendo pontes de hidrogênio foram caracterizadas como predominante no desvio da idealidade de solubilização em micelas mistas. Bailey e Dorsey (2001), usando LSER, mostraram a alteração no mecanismo de solubilização em micelas de SDS pela adição de decanol como co-surfactante. 


\section{OBJETIVOS}

O objetivo principal deste trabalho é elucidar o efeito do grau de etoxilação no processo de solubilização de compostos por tensoativos não iônicos da família dos álcoois secundários etoxilados.

A elucidação do papel da cabeça hidrofílica no processo de solubilização é de fundamental importância uma vez permite a utilização otimizada desses tensoativos naqueles processos onde a o mecanismo de atuação dos tensoativos é governado por um processo de solubilização.

É também objetivo deste trabalho estabelecer a capacidade preditiva de solubilização para os álcoois secundários etoxilados através de relações lineares de energia livre.

Como as aplicações de maior consumo industrial para tensoativos não iônicos é seu emprego em formulações de produtos de limpeza, esse estudo também busca elucidar se o processo de solubilização descreve ou está correlacionado com os critérios definidos industrialmente como eficiência de limpeza. A tentativa de elucidar a correlação entre solubilização, definida como um processo de partição, com os critérios de eficiência de limpeza dá-se para concentrações e sujidades típicas na limpeza de tecidos e na limpeza de superfícies sólidas. 


\section{PROCEDIMENTOS EXPERIMENTAIS}

\subsection{MATERIAS}

Os seguintes reagentes foram utilizados sem purificação adicional: 1-pentanol 98\% (Merck), 1-hexanol 99\% (Merck), 1-heptanol 99.5\% (Merck), benzeno 99.5\% (Merck), tolueno 99.5\% (Merck), etilbenzeno 99\% (Merck), propilbenzeno 99\% (Merck), antraceno 99\% (Aldrich), pireno 99\% (Aldrich), 1-hexino 97\% (Aldrich), 1-octino 97\% (Aldrich), 2heptanona 97\% (Aldrich), 2-octanona 99\% (Aldrich), n-hexilamina 98\% (Aldrich), noctilamina 98\% (Aldrich), benzofenona 99\% (Aldrich), bifenila 99\% (Aldrich)., ácido salicilico 99\% (Aldrich), trioleina 95\% (XYZ), hexadecanoato de etila 99\% (The Dow Chemical Company), n-undecano 98\% (Aldrich) e n-dodecano 99\% (Aldrich), Edenor (mistura de triglicerídeos, $\mathrm{C}_{8}-\mathrm{C}_{10}$ COGNIS), Óleo de Soja comercial (Mazola).

Dedecano foi purificado através da eluição do solvente em uma coluna de óxido de alumínio ativado de caráter básico, Brockmann I, mesh 150, $58 \AA$, área superficial de 155 $\mathrm{m}^{2} / \mathrm{g}$ (Sigma Aldrich) por 4 vezes de acordo com procedimento descrito por Goebel e Lukenheimer (1997).

A sujidade padrão para os testes de eficiência de limpeza em superfície sólida foi preparada através da mistura de 58\% Nafta 60/110, 26\% Edenor, 13\% de óleo de soja e 3\% de negro de fumo para coloração da sujidade. A superfície a ser limpa foi definida como Paviflex produzido pela FADEMAC pois trata-se do material padrão utilizado pela indústria.

Os surfactantes utilizados foram cedidos pela DOW BRASIL SA e utilizados sem purificação prévia: TERGITOL 15-S-7 álcool secundário etoxilado com valor médio de etoxilação 7 (peso molecular médio de 508 g/mol), TERGITOL 15-S-9 álcool secundário etoxilado com valor médio de etoxilação 9 (peso molecular médio de 596 g/mol), TERGITOL 15-S-12 álcool secundário etoxilado com valor médio de etoxilação 12 (peso 
molecular médio de 728 g/mol), TERGITOL 15-S-15 álcool secundário etoxilado com valor médio de etoxilação 15 (peso molecular médio de 860 g/mol), TERGITOL 15-S-20 álcool secundário etoxilado com valor médio de etoxilação 20 (peso molecular médio de 1080 g/mol), TERGITOL 15-S-30 álcool secundário etoxilado com valor médio de etoxilação 30 (peso molecular médio de $1320 \mathrm{~g} / \mathrm{mol}$ ), TERGITOL 15-S-40 álcool secundário etoxilado com valor médio de etoxilação 40 (peso molecular médio de $1760 \mathrm{~g} / \mathrm{mol}$ ).

\subsection{EQUIPAMENTOS}

\subsubsection{Determinação de constante de incorporação micelar}

As medidas de cromatografia em fase gasosa, com sistema de análise da fase vapor foram feitas com um equipamento SHIMADZU composto por cromatógrafo GC-17A com detector de ionização de chamas, sistema de injeção automática HSS4A, módulo de comunicação CBM-102 e coluna capilar DB-5 da J\&W Scientific (5\% fenil-95\% metilpolisiloxano, $30 \mathrm{~m}$ de comprimento, $0,25 \mathrm{~mm}$ de diâmetro e $0,25 \mu \mathrm{m}$ de espessura da fase estacionária).

Para as medidas espectrofotométricas pelo método de solubilização em saturação utilizou-se um espectrofotômetro Diode Array 8452 da Hewlett Packard.

\subsubsection{Determinação de tensão interfacial e superficial}

As medidas de tensão interfacial entre soluções aquosas de tensoativos e dodecano, trioleina e sujidade padrão foram realizadas com um equipamento OCA 100 da DataPhysics com sistema de captura de imagem de 60 quadros por segundo. As medidas de tensão superficial foram realizadas com um equipamento Kibron Delta-8. 


\subsubsection{Determinação de eficiência de limpeza para superfícies sólidas}

Para as medidas de eficiência de limpeza utilizou-se um equipamento para avaliação de abrasão modelo Wear Tester D10 (Paul N. Gardner Company Inc) e um scanner Epson Scanner Perfection 4990 Photo. Os valores de cinza da escala RGB utilizados para determinação de eficiência de limpeza foram determinados utilizando-se o software de uso livre, imageJ versão $1.42 \mathrm{~d}$.

\subsubsection{Determinação de eficiência de limpeza em tecidos}

Para as medidas de eficiência de limpeza em tecido utilizou-se um cromatógrafo HP6890 II com amostrador automático GC Autosampler 7673A com detector de ionização de chamas da Hewlett Packard e coluna capilar HP-5 (5\% fenil-95\% metilpolisiloxano, $1 \mathrm{~m}$ de comprimento, $0,25 \mathrm{~mm}$ de diâmetro e $0,25 \mu \mathrm{m}$ de espessura da fase estacionária).

\subsubsection{Regressões, cálculos estatísticos e gráficos}

As regressões lineares múltiplas, análises estatísticas e gráficos utilizados na determinação das constantes de partição entre água e pseudo-fase micelar foram realizados com o software JMP Statistical Discovery Software 7.0.2 (SAS) sob licença da The Dow Chemical Company.

\subsection{MÉTODOS}

\subsubsection{Determinação de constante de incorporação micelar com análise de fase vapor por cromatografia gasosa}

Preparou-se soluções estoque dos seguintes sistemas: álcoois: 1,0 mM 1-pentanol, 1,0 $\mathrm{mM}$ 1-hexanol, 1,0 mM heptanol; alquil aminas: $0,9 \mathrm{mM}$-hexilamina, $0,8 \mathrm{mM}$ octilamina (pH foi mantido acima de 12,2 com a adição de hidróxido de sódio). aromáticos: 0,06 mM benzeno, 0,05 $\mathrm{mM}$ tolueno, 0,04 $\mathrm{mM}$ etilbenzeno, $0,04 \mathrm{mM}$ propilbenzeno; cetonas: $0,2 \mathrm{mM}$ 
2-heptanona, 0,2 mM 2-octanona; alcinos: 0,3 $\mathrm{mM}$ de 1-hexino, 0,2 $\mathrm{mM}$ de 1-octino, alcanos: $0.02 \mathrm{mM}$-undecano, $0.02 \mathrm{mM}$ de $\mathrm{n}$-dodecano. As soluções estoque contendo os solutos permaneceram em repouso por no mínimo 12 horas antes do uso. Foi observado se essas soluções apresentam separação de fases e em cão positivo, um funil de separação foi utilizado para garantir que excesso de soluto não seja carregado para as análises.

Utilizando-se as soluções estoques, preparou-se para cada tensoativo soluções em concentrações variando entre 0 e $50 \mathrm{mM}$. Adicionou-se $20 \mathrm{~mL}$ das soluções dos tensoativos em frascos de $27 \mathrm{~mL}$ de volume total. Esses frascos foram lacrados com septos de borracha, com superfície de teflon, próprios para análise de fase vapor por cromatografia gasosa. Cada frasco foi termostatizado por 50 minutos a $30 \pm 0.2^{\circ} \mathrm{C}$ antes da injeção. Uma alíquota de 0.4 $\mathrm{ml}$ da fase vapor foi injetada no cromatógrafo.

As condições cromatográficas utilizadas estão descritas na Tabela 9. 
Tabela 9: Parâmetros usados na análise de fase vapor por cromatografia gasosa.

\begin{tabular}{|c|c|c|c|c|}
\hline \multirow{2}{*}{ Parâmetro } & \multicolumn{4}{|c|}{ Valor } \\
\hline & $\begin{array}{l}\text { cetonas } \\
\text { alcinos } \\
\end{array}$ & Alquil aminas & Aromáticos & Alcanos \\
\hline $\begin{array}{l}\text { Temperatura de Injetor } \\
\left({ }^{\circ} \mathrm{C}\right)\end{array}$ & 150 & 200 & 150 & 250 \\
\hline $\begin{array}{l}\text { Temperatura do Detetor } \\
\left({ }^{\circ} \mathrm{C}\right)\end{array}$ & 150 & 200 & 150 & 250 \\
\hline $\begin{array}{l}\text { Temperatura da coluna } \\
\left({ }^{\circ} \mathrm{C}\right)\end{array}$ & 90 & 100 & 85 & 75 \\
\hline $\begin{array}{l}\text { Fluxo da Coluna } \\
(\mathrm{mL} / \mathrm{min})\end{array}$ & 0.78 & 0.75 & 0.8 & 0.8 \\
\hline Pressão da coluna $(\mathrm{kPa})$ & 80 & 80 & 80 & 80 \\
\hline Razão do divisor (1:X) & 10 & 10 & 10 & 10 \\
\hline $\begin{array}{l}\text { Temperatura do frasco } \\
\left({ }^{\circ} \mathrm{C}\right)\end{array}$ & 30 & 30 & 30 & 30 \\
\hline $\begin{array}{l}\text { Temperatura da seringa } \\
\left({ }^{\circ} \mathrm{C}\right)\end{array}$ & 40 & 40 & 40 & 40 \\
\hline $\begin{array}{l}\text { Condicionamento do } \\
\text { frasco (min) }\end{array}$ & 50 & 50 & 50 & 50 \\
\hline Gás de arraste & Hélio & Hélio & Hélio & Hélio \\
\hline
\end{tabular}

\subsubsection{Determinação de constante de incorporação micelar por solubilização em saturação com análise espectrofotométrica}

Preparou-se $10 \mathrm{~mL}$ de soluções aquosas de tensoativos com concentrações variando entre 0 e $90 \mathrm{mM}$ em frascos de $20 \mathrm{~mL}$. Em cada um desses frascos foi adicionado, individualmente para cada composto, excesso dos solutos estudados (em relação ao limite de solubilidade desses solutos). Os frascos foram mantidos em agitação constante a $30^{\circ} \pm 1^{\circ} \mathrm{C}$ durante 3 dias. Após esse período os frascos foram mantidos em repouso a $30 \pm 1^{\circ} \mathrm{C}$ por 24 
horas. Diluiu-se uma alíquota do sobrenadante em acetonitrila para determinação da intensidade de absorbância.

A Tabela 10 descreve o comprimento de onda, $\lambda$, no qual foi determinada a intensidade de absorção do analito bem como a concentração do composto em água na ausência de tensoativos para os solutos estudados por essa técnica.

Tabela 10: Parâmetros usados na determinação por solubilização em saturação com análise espectrofotométrica.

\begin{tabular}{ccc}
\hline Soluto & $\lambda(\mathrm{nm})$ & {$\left[\mathrm{S}_{\mathrm{o}}\right]$} \\
\hline pireno & 336 & $6,0 \times 10^{-7 *}$ \\
antraceno & 358 & $2,2 \times 10^{-9 *}$ \\
Bifenilo & 256 & $6,12 \times 10^{-5 *}$ \\
benzofenona & 252 & $5,3 \times 10^{-5 * *}$ \\
Ácido 2-hidroxibenzóico & 304 & $8.2 \times 10^{-3 * * *}$ \\
\hline
\end{tabular}

*Almgren et al. (1979), ${ }^{* *}$ Freitas (2001), ${ }^{* * *}$ Mota et al. 2008

\subsubsection{Determinação da tensão interfacial e superficial}

Purificou-se o solvente, dodecano, eluindo-o em uma coluna de alumina básica 4 vezes consecutivas até que a tensão interfacial entre o solvente e água apresente uma variação inferior a $0,5 \mathrm{mN} / \mathrm{m}$ em um período de 10 minutos.

Para a determinação da tensão interfacial, o método da gota pendente foi utilizado. Uma gota de solvente foi produzida dentro de uma solução aquosa de tensoativo na concentração descrita na seção dos resultados. Devido ao fato do solvente apresentar uma densidade inferior à densidade da solução aquosa, a agulha utilizada tem seu orifício em direção ao topo da solução aquosa. As medidas de tensão interfacial foram feitas com uma 
gota apresentando o volume de no mínimo $80 \%$ de seu volume máximo para evitar erros devido a gotas esféricas (HOORFAR e NEUMANN, 2006).

As medidas de tensão superficial foram realizadas através do método descrito por Padday et al. (1975) baseado no fato de que a força máxima em um cilindro vertical que mantém um menisco em suspensão é função da tensão superficial do líquido, do raio do cilindro, da densidade do líquido e da aceleração gravitacional. As soluções aquosas de tensoativos foram preparadas através de diluições a partir de uma solução estoque de 4\% para os tensoativos com valor médio de etoxilação de 20, 30 e 40 e a partir de uma solução estoque de $1 \%$ dos tensoativos com valor médio de etoxilação de 7, 9, 12 e 15 .

\subsubsection{Determinação da eficiência de limpeza em tecidos}

Para determinação da eficiência de limpeza em tecidos, $0,0066 \mathrm{~g}$ de trioleina foi adicionado a um pedaço de tecido de poliéster $(1 \mathrm{~cm} \times 2 \mathrm{~cm}, 0,0865 \mathrm{~g})$. Após 12 horas, foi adicionado $5 \mathrm{~mL}$ da solução aquosa de tensoativo a um frasco cilíndrico de $20 \mathrm{~mL}$ contendo o tecido contaminado e três esferas de vidro de $4 \mathrm{~mm}$ de diâmetro. Os frascos foram agitados em uma mesa agitadora horizontal por 20 minutos seguido de enxágue para remoção de tensoativo residual. O processo de enxágue foi repetido 3 vezes para cada frasco e consistiu de adição de $10 \mathrm{~mL}$ de água destilada seguido de inversão do frasco por 5 vezes para homogeneização e descarte da água de enxágue. Após o enxágue, os pedaços de tecido foram transferidos para um fraco cilíndrico de capacidade máxima de $5 \mathrm{~mL}$. Foi adicionado aos frascos de $5 \mathrm{~mL}, 2,5 \mathrm{~g}$ de tetrahidrofurano contendo o $0,38 \%$ de padrão interno, hexadecanoato de etila, para extração da trioleina residual. Após 5 minutos de agitação, uma alíquota da solução de tetrahidrofurano foi removida para análise cromatográfica.

A Tabela 11 descreve as condições cromatográficas utilizadas na determinação de trioleina em tetrahidrofurano. 
Tabela 11: Condições cromatográficas para análise de trioleina extraída em tetrahidrofurano

\begin{tabular}{cc}
\hline Parâmetro & Valor \\
\hline Temperatura de Injetor $\left({ }^{\circ} \mathrm{C}\right)$ & 370 \\
Temperatura do Detetor $\left({ }^{\circ} \mathrm{C}\right)$ & 380 \\
Temperatura da coluna $\left({ }^{\circ} \mathrm{C}\right)$ & $80(2 \mathrm{~min})$ \\
Fluxo da Coluna $(\mathrm{mL} / \mathrm{min})$ & $370\left(45^{\circ} \mathrm{C} / \mathrm{min}\right)$ \\
Pressão da coluna $(\mathrm{kPa})$ & 1,5 \\
Razão do divisor $(1: \mathrm{X})$ & 6,5 \\
Gás de arraste & 1 \\
\hline
\end{tabular}

Para quantificação da concentração de trioleina foi construída uma curva de calibração com concentrações conhecidas de trioleina nas mesmas condições cromatográficas da análise, descritas na Tabela 11.

\subsubsection{Determinação da eficiência de limpeza em superfícies sólidas}

O processo de determinação da eficiência de limpeza em superfícies sólidas foi adaptado do método ASTM D5343-06 e consiste das seguintes etapas:

1) Aplica-se com uma esponja de poliuretano $1 \mathrm{~mL}$ da sujidade padrão sobre a superfície (substrato) a ser limpa (dimensão da superfície: $11 \times 7 \mathrm{~cm}$ ). 
2) Após a evaporação total do solvente utilizado na preparação da sujidade, esta é limpa através da aplicação de $5 \mathrm{~mL}$ da solução aquosa de tensoativo sobre a sujidade seguido de 10 ciclos de movimentos horizontais esfregando-se a esponja de poliuretano sobre a superfície (para que a pressão seja constante, utiliza-se equipamento específico para avaliação de abrasão modelo Wear Tester D10).

3) a superfície limpa é colocada por 20s sobre água corrente para remoção de sujidade residual.

4) Após secagem do substrato, a imagem da superfície é capturada com um scanner

5) O software de uso livre, imageJ, é utilizado na determinação do valor de cinza na escala de cor RGB. Esse valor varia entra 0 (preto) e 255 (branco) (STONE, 2003).

A eficiência de limpeza é determinada através da Equação 27.

$$
\text { Eficiência de Limpeza }(\%)=\frac{G_{l}-G_{s}}{G_{M}-G_{s}} \times 100
$$

onde $G_{l}$ é o valor de cinza após o processo de limpeza, $G_{s}$ é o valor de cinza do substrato sujo antes de ser limpo e $G_{M}$ é o valor máximo na escala de cinza que é obtido antes da aplicação da sujidade na placa. 


\section{RESULTADOS}

\subsection{DETERMINAÇÃO DA CONCENTRAÇÃO MICELAR CRÍTICA}

Com os dados de tensão superficial obtidos, foram construídos os gráficos de tensão superficial em função do logaritmo da concentração de tensoativo, Figura 8. Os valores de concentração micelar crítica foram obtidos através da intersecção das retas de regressão do pontos pré e pós micelização. Nessa análise, os pontos próximos ao valor de cmc foram excluídos da regressão.

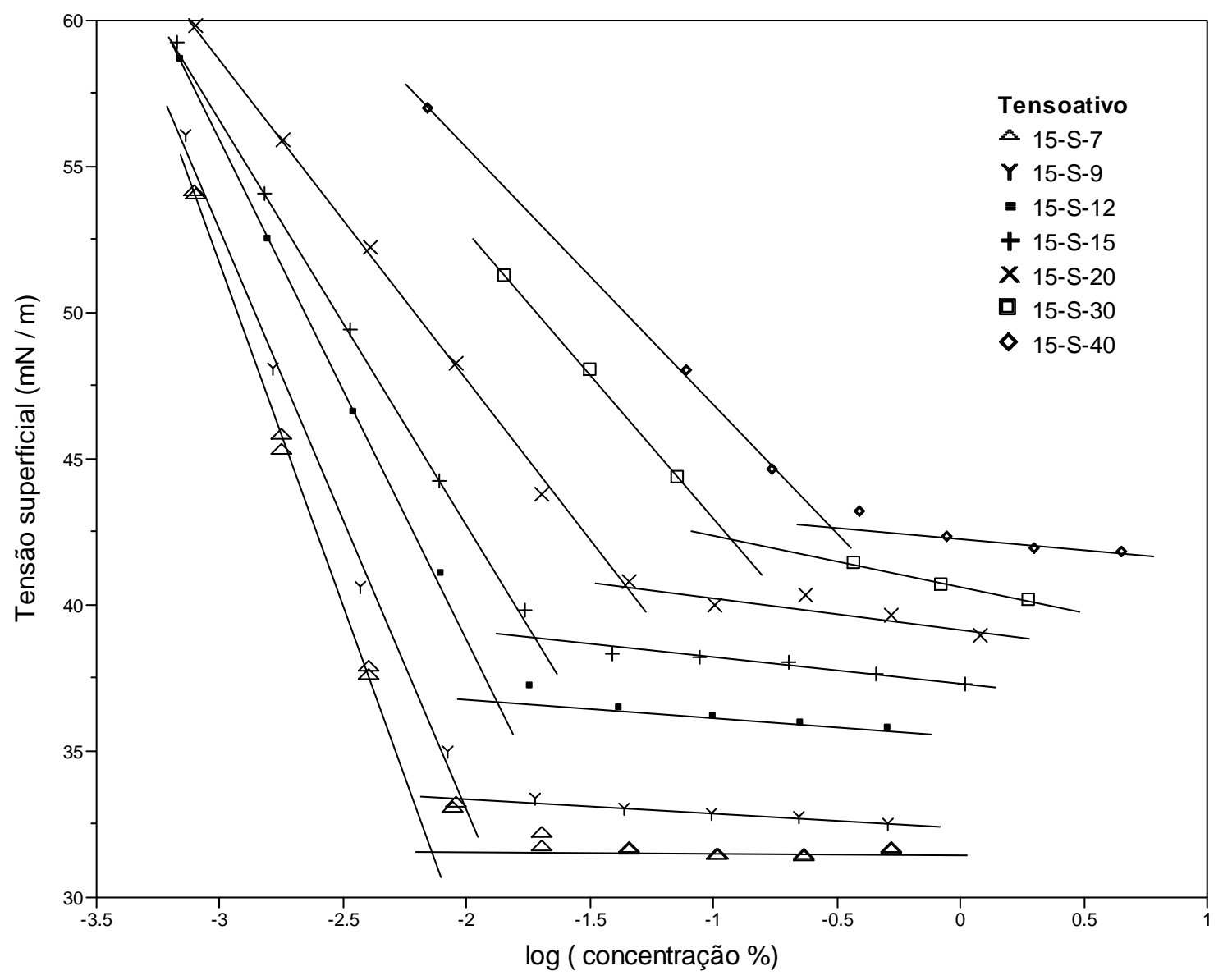

Figura 8: Gráfico da tensão superficial em função do logaritmo da concentração de tensoativo. 
Os resultados obtidos para concentração micelar crítica estão descritos na Tabela 12.

Tabela 12: Valores de concentração micelar crítica.

\begin{tabular}{cc}
\hline Tensoativo & $\mathrm{cmc}(\mathrm{mM})$ \\
\hline TERGITOL 15-S-7 & 0,15 \\
TERGITOL 15-S-9 & 0,16 \\
TERGITOL 15-S-12 & 0,18 \\
TERGITOL 15-S-15 & 0,21 \\
TERGITOL 15-S-20 & 0,41 \\
TERGITOL 15-S-30 & 0,66 \\
TERGITOL 15-S-40 & 1,5 \\
\hline
\end{tabular}

\subsection{DETERMINAÇÃO DA TENSÃO INTERFACIAL ENTRE TERGITOL 15-S E COMPOSTOS HIDROFÓBICOS}

A determinação da tensão interfacial entre soluções aquosas e compostos hidrofóbicos foi realizada através do método da gota pendente. Andreas et al. (1932) foram os primeiros a gerar dados acurados para uma série de solventes através do método da gota pendente. A descrição matemática detalhada da obtenção interfacial através desse método é explorada por Rusanov e Prokhorow (1996). O método é baseado no fato de que a condição de equilíbrio entre dois líquidos não miscíveis separados por uma interface é descrita pela Equação de Laplace. Esta Equação correlaciona a diferença de pressão ao longo de uma interface com a tensão interfacial e o raio de curvatura desta interface.

$$
\gamma\left(\frac{1}{R_{1}}+\frac{1}{R_{2}}\right)=\Delta P
$$


onde $\gamma$ é a tensão interfacial entre os dois meios, $\Delta P$ é a diferença de pressão ao longo da interface e $R_{1}$ e $R_{2}$ são os raios de curvatura principais que descrevem a interface. Desta maneira, a partir de uma determinada tensão interfacial, os raios de curvatura de uma interface podem ser calculados. Hoorfar e Neumann (2006) descrevem as limitações do método e possíveis fontes de erro, sendo a mais importante, a obtenção de tensões superficiais ou interfaciais a partir de gotas pendentes para gotas esféricas (pouco elongadas). Outro erro comum descrito por esses autores é o efeito de propriedades dinâmicas como o movimento do líquido durante a formação das gotas que pode deformar a gota, o que resulta em valores de tensão interfacial não acurados.

Com o objetivo de minimizar erros causados por gotas esféricas, os dados obtidos foram gerados com o volume da gota definidos como $80 \%$ do volume máximo da gota para a tensão interfacial específica do sistema. Esse procedimento é realizado produzindo-se gotas continuamente com a baixa vazão, $1 \mu 1 / \mathrm{s}$, até que ocorra o desprendimento da gota. $\mathrm{O}$ volume de desprendimento é determinado através desse processo e o volume definido para as medidas de tensão interfacial é $80 \%$ do volume de desprendimento. Para evitar efeitos dinâmicos na deformação da gota, as medidas foram realizadas 1 minuto após a formação da gota.

As medidas de tensão interfacial entre TERGITOL 15-S e dodecano e a mistura de óleos foram realizadas a uma concentração de 1\% de tensoativo (a concentração foi definida pela concentração típica em que esses tensoativos são utilizados em processos de detergência de superfícies sólidas). 


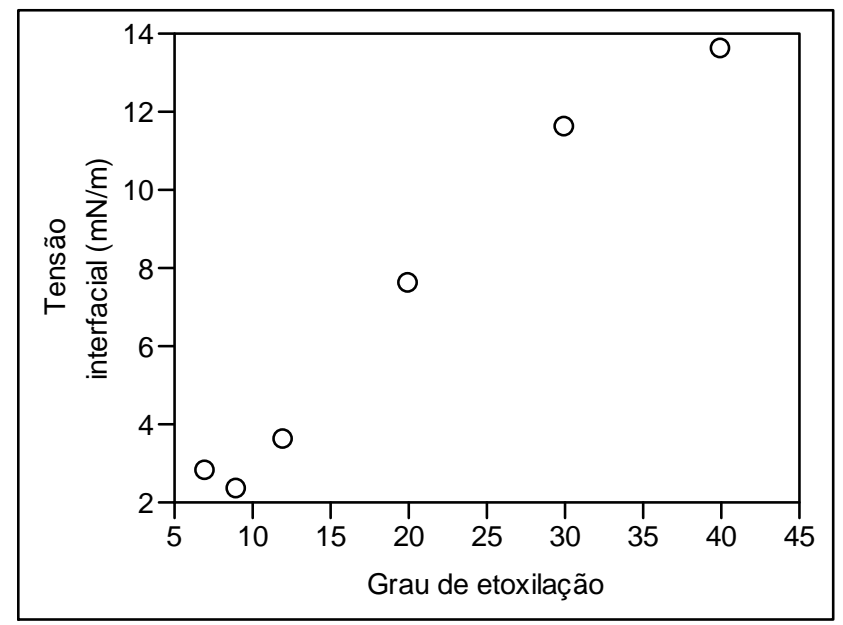

Equação 1: Tensão interfacial entre dodecano e TERGITOL 15-S com grau de etoxilação entre 7 e 40.

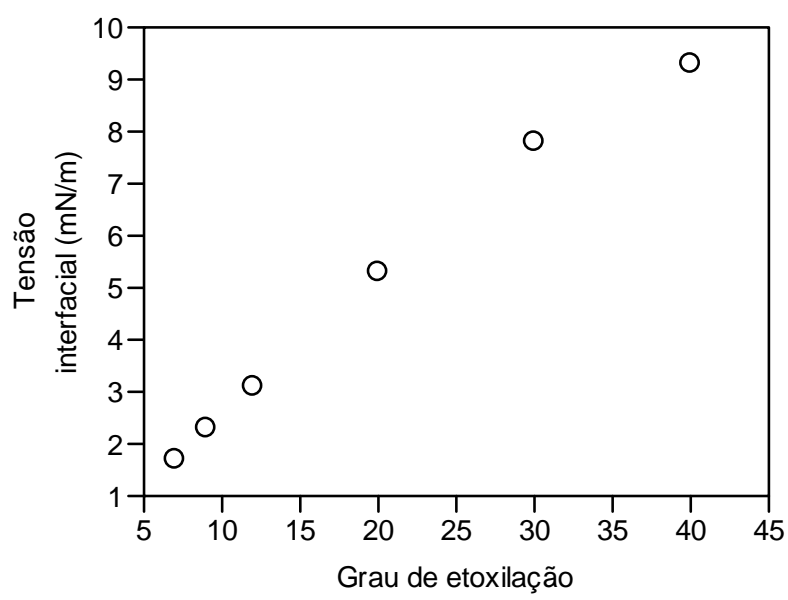

Equação 2: Tensão interfacial entre mistura de óleos e TERGITOL 15-S com grau de etoxilação entre 7 e 40.

As medidas de tensão interfacial entre TERGITOL 15-S e trioleina foram realizadas a uma concentração de 2000 ppm de tensoativo (a concentração foi definida pela concentração 
típica em que esses tensoativos são utilizados em processos de detergência a ser discutido nessa tese).

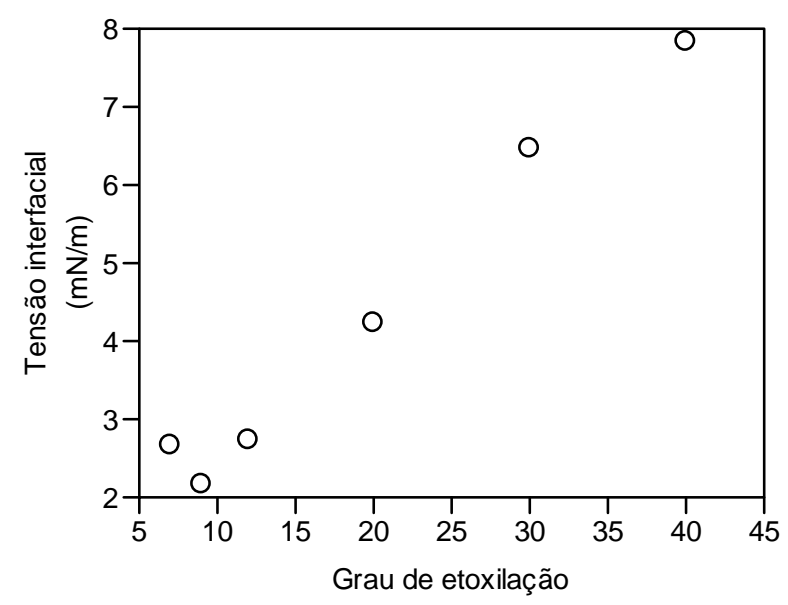

Equação 3: Tensão interfacial entre trioleina e TERGITOL 15-S com grau de etoxilação entre 7 e 40.

A existência de um ponto mínimo da tensão superficial está de acordo com os rebotados descritos por Becher (1963) e Hansen e Fagerheim (1998).

\subsection{DETERMINAÇÃO DA CONSTANTE DE INCORPORAÇÃO MICELAR POR ANÁLISE DE VASE VAPOR POR CROMATOGRAFIA GASOSA}

O princípio da determinação da constante de incorporação micelar por análise da fase vapor por cromatografia gasosa baseia-se no fato de que a concentração de soluto na fase vapor em equilíbrio com uma fase condensada é proporcional à quantidade de soluto não incorporado pelas micelas na fase aquosa, onde a constante de proporcionalidade é dada pela constante de Henry. 
A área cromatográfica, A, obtida na injeção da fase vapor é proporcional a concentração de soluto na fase vapor:

$$
A=\alpha[S]_{g}
$$

na qual $\alpha$ é o fator de resposta cromatográfico e $[\mathrm{S}]_{\mathrm{g}}$ é a concentração de soluto na fase gasosa. A adição de tensoativo à fase condensada contendo uma concentração fixa de soluto resulta na incorporação deste nas micelas, diminuindo assim a quantidade de soluto livre na fase aquosa e, consequentemente, reduzindo a quantidade de soluto na fase vapor. Assim, pode-se determinar a constante de incorporação, $\mathrm{K}_{\mathrm{s}}$, por meio da inclinação da reta em um gráfico $\mathrm{A}_{0} / \mathrm{A}_{\mathrm{i}}$ em função de $\left[C_{D}\right]$, onde $\mathrm{A}_{0}$ e $\mathrm{A}_{\mathrm{i}}$ são, respectivamente, as áreas cromatográficas na ausência e na presença de tensoativo e $\left[C_{D}\right]$ é a concentração de tensoativo micelizado:

$$
\frac{A_{0}}{A_{i}}=1+K_{s}\left[C_{D}\right]
$$

As figuras 9 a 15 mostram os gráficos de $A_{0} / A_{i}$ em função da concentração de tensoativo micelizado utilizados na determinação da constante de incorporação micelar para 2-octanona e 2-heptanona. 


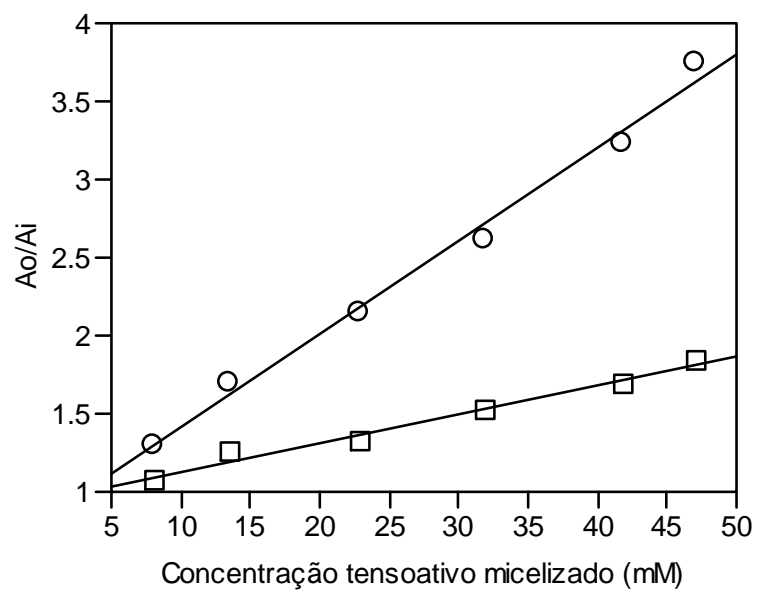

Figura 9: Gráfico de $\mathrm{A}_{\mathrm{o}} / \mathrm{A}_{\mathrm{i}}$ em função da concentração de TERGITOL 15-S-7 micelizado para cetonas. (

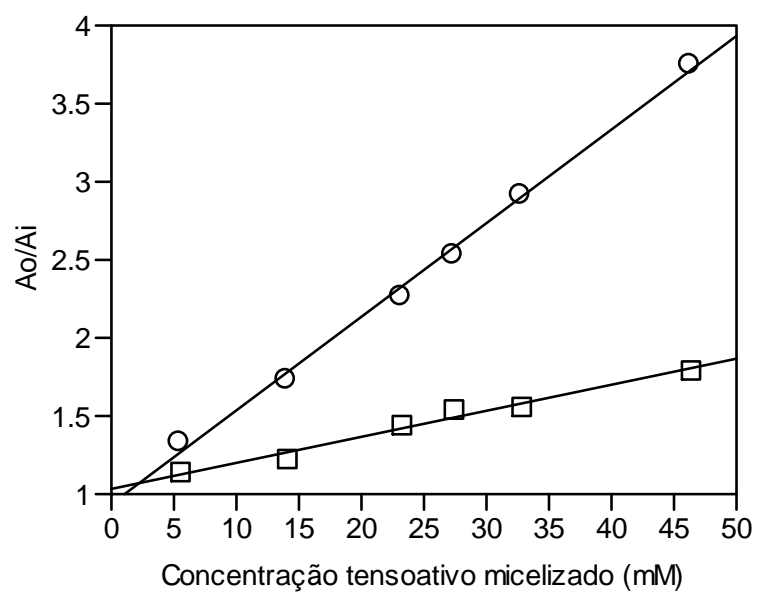

Figura 10: Gráfico de $A_{o} / A_{i}$ em função da concentração de TERGITOL 15-S-9 micelizado para cetonas. ( $)$ ) 2-octanona; ( $\square$ ) 2-heptanona. 


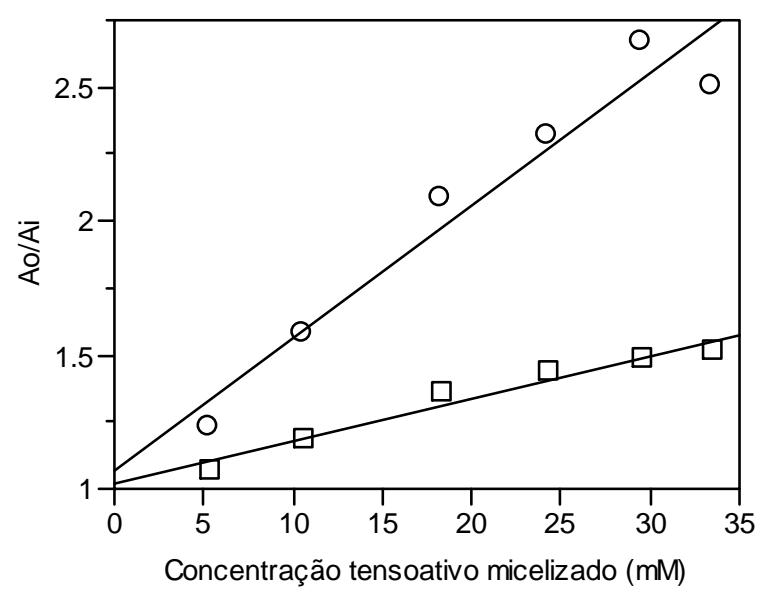

Figura 11: Gráfico de $A_{o} / A_{i}$ em função da concentração de TERGITOL 15-S-12 micelizado para cetonas. ( ○) 2-octanona; ( $\square$ ) 2-heptanona.

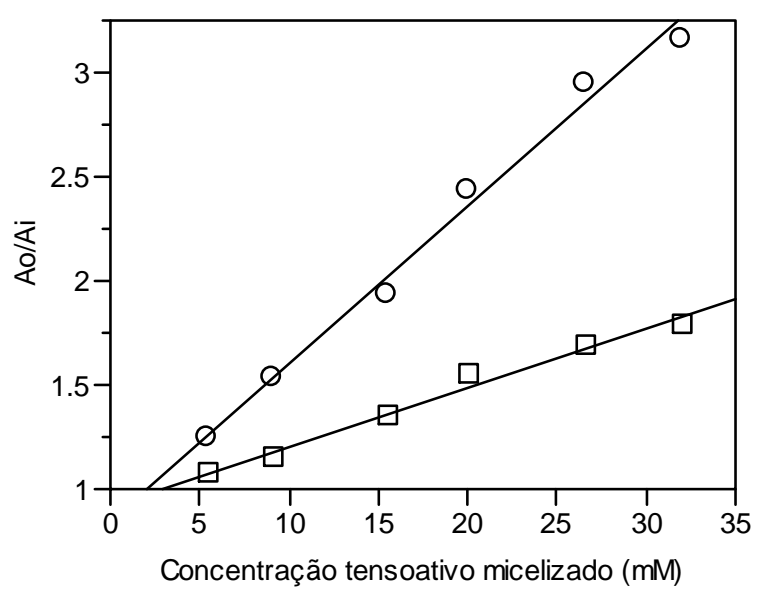

Figura 12: Gráfico de $A_{o} / A_{i}$ em função da concentração de TERGITOL 15-S-15 micelizado para cetonas. ( $($ ) 2-octanona; ( $\square$ ) 2-heptanona. 


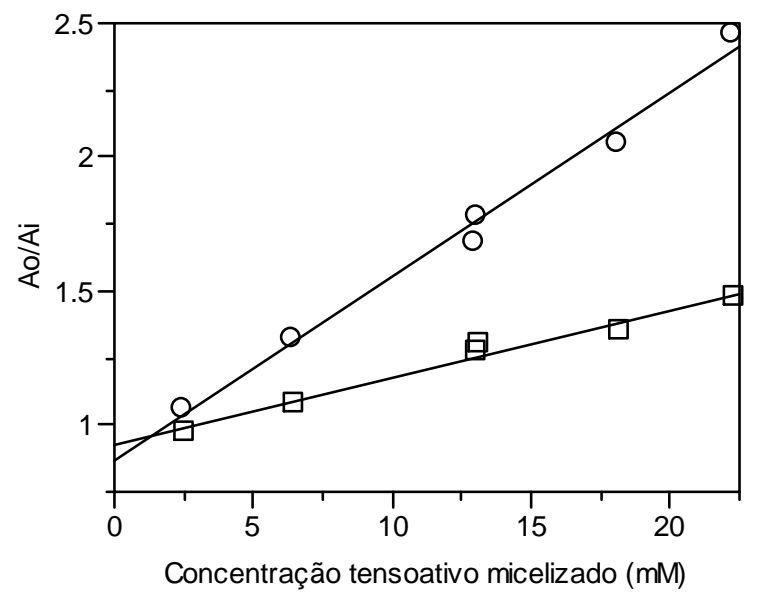

Figura 13: Gráfico de $A_{o} / A_{i}$ em função da concentração de TERGITOL 15-S-20 micelizado para cetonas. ( $($ ) 2-octanona; ( $\square$ ) 2-heptanona.

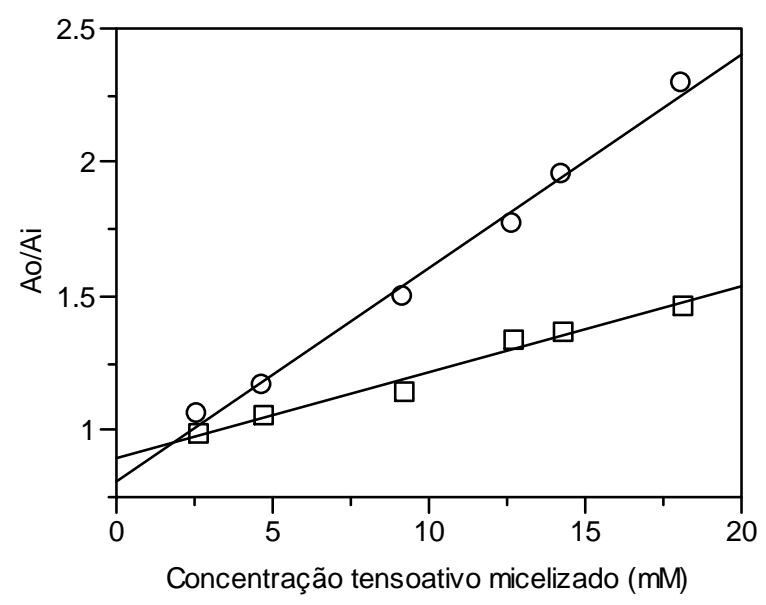

Figura 14: Gráfico de $\mathrm{A}_{\mathrm{o}} / \mathrm{A}_{\mathrm{i}}$ em função da concentração de TERGITOL 15-S-30 micelizado para cetonas. ( ( ) 2-octanona; ( $\square$ ) 2-heptanona. 


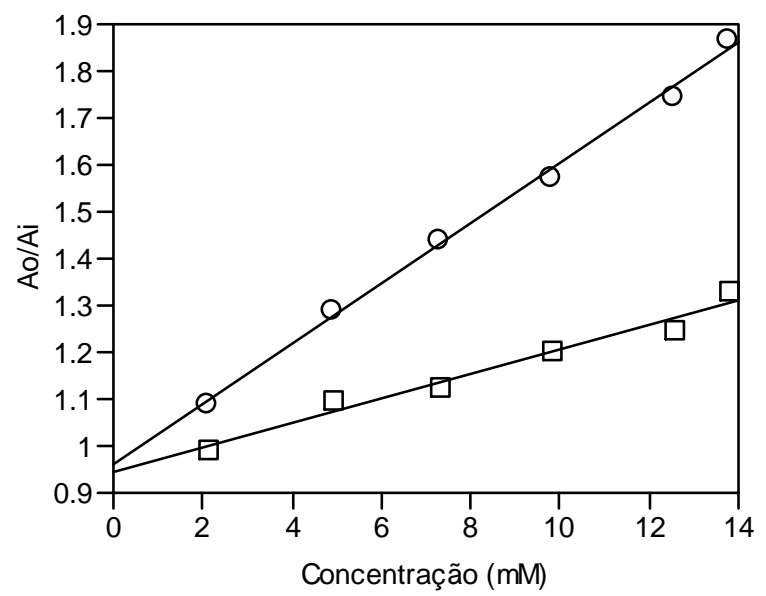

Figura 15: Gráfico de $\mathrm{A}_{\mathrm{o}} / \mathrm{A}_{\mathrm{i}}$ em função da concentração de TERGITOL 15-S-40 micelizado para cetonas. ( $($ ) 2-octanona; ( $\square$ ) 2-heptanona. 
As figuras 16 a 21 mostram os gráficos de $A_{0} / A_{i}$ em função da concentração de tensoativo micelizado utilizados na determinação da constante de incorporação micelar para benzeno, metil benzeno, etil benzeno e propil benzeno.

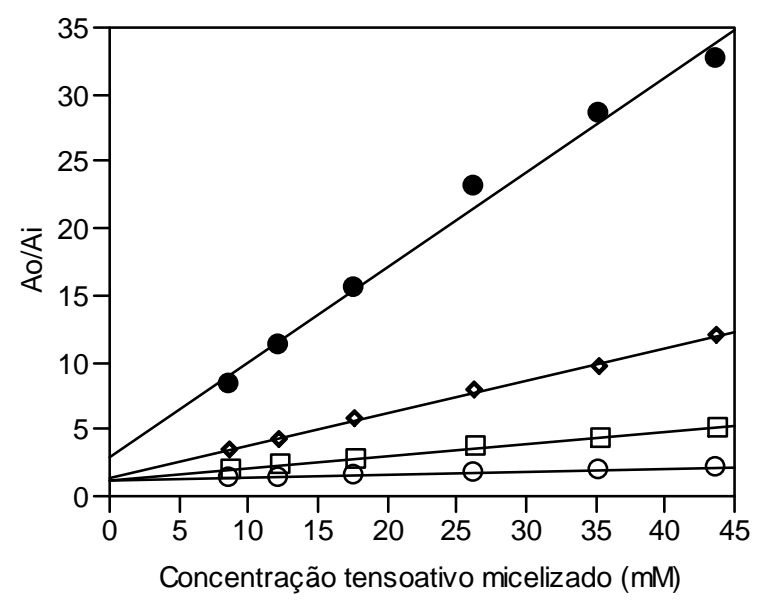

Figura 16: Gráfico de $A_{o} / A_{i}$ em função da concentração de TERGITOL 15-S-7 micelizado para aromáticos: $(\circ)$ benzeno; $(\square)$ metil benzeno; $(\diamond)$ etil benzeno; $(\bullet)$ propil benzeno.

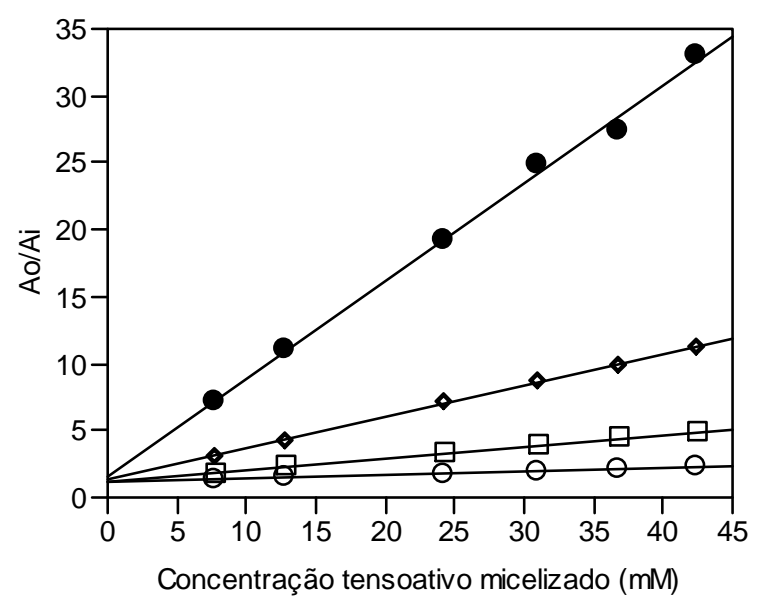

Figura 17: Gráfico de $A_{o} / A_{i}$ em função da concentração de TERGITOL 15-S-9 micelizado para aromáticos: $(\circ)$ benzeno; $(\square)$ metil benzeno; $(\diamond)$ etil benzeno; $(\bullet)$ propil benzeno. 


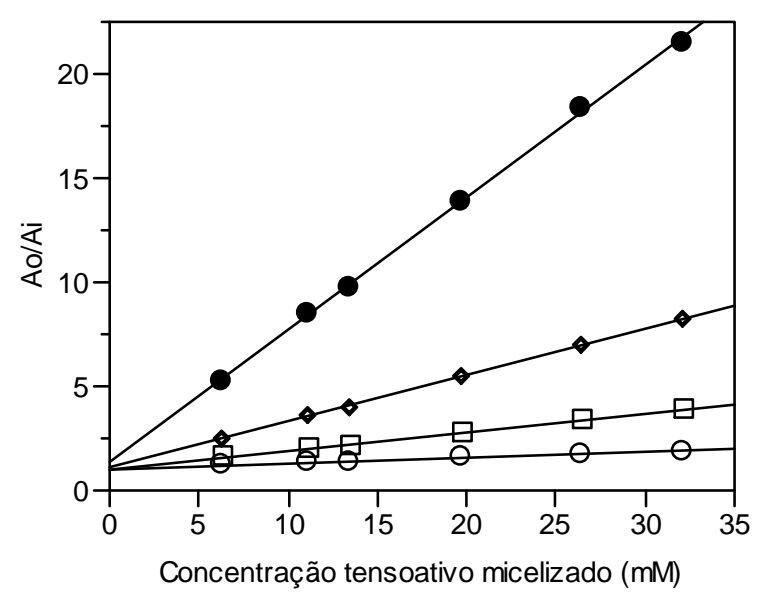

Figura 18: Gráfico de $\mathrm{A}_{\mathrm{o}} / \mathrm{A}_{\mathrm{i}}$ em função da concentração de TERGITOL 15-S-12 micelizado para aromáticos: $(\circ)$ benzeno; $(\square)$ metil benzeno; $(\diamond)$ etil benzeno; $(\bullet)$ propil benzeno.

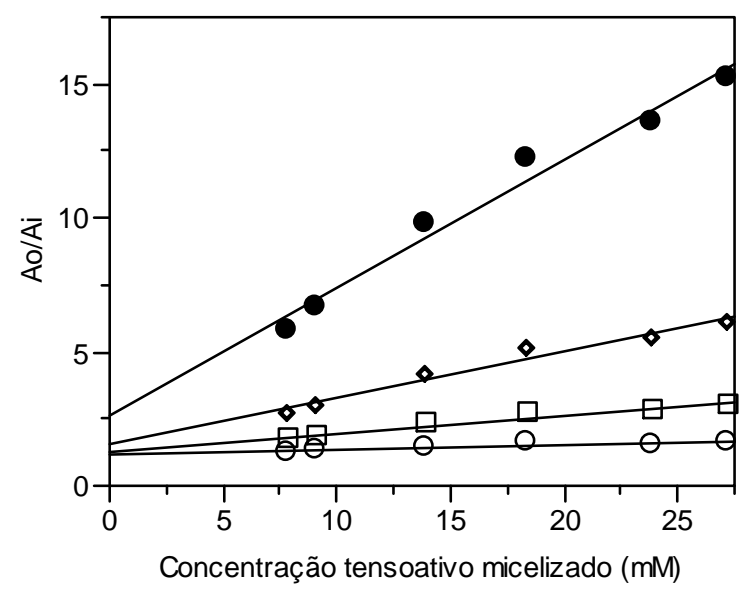

Figura 19: Gráfico de $\mathrm{A}_{\mathrm{o}} / \mathrm{A}_{\mathrm{i}}$ em função da concentração de TERGITOL 15-S-15 micelizado para aromáticos: $(\circ)$ benzeno; $(\square)$ metil benzeno; $(\diamond)$ etil benzeno; $(\bullet)$ propil benzeno. 


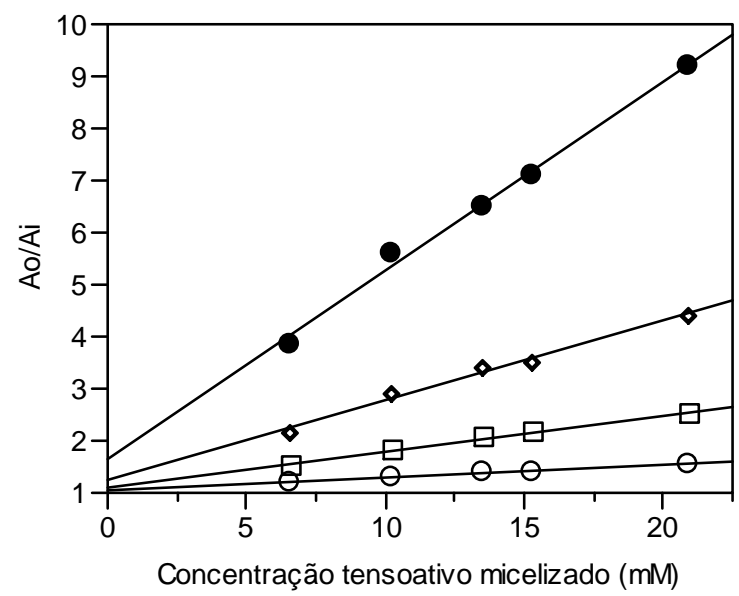

Figura 20: Gráfico de $\mathrm{A}_{\mathrm{o}} / \mathrm{A}_{\mathrm{i}}$ em função da concentração de TERGITOL 15-S-20 micelizado para aromáticos: $(\circ)$ benzeno; $(\square)$ metil benzeno; $(\diamond)$ etil benzeno; $(\bullet)$ propil benzeno.

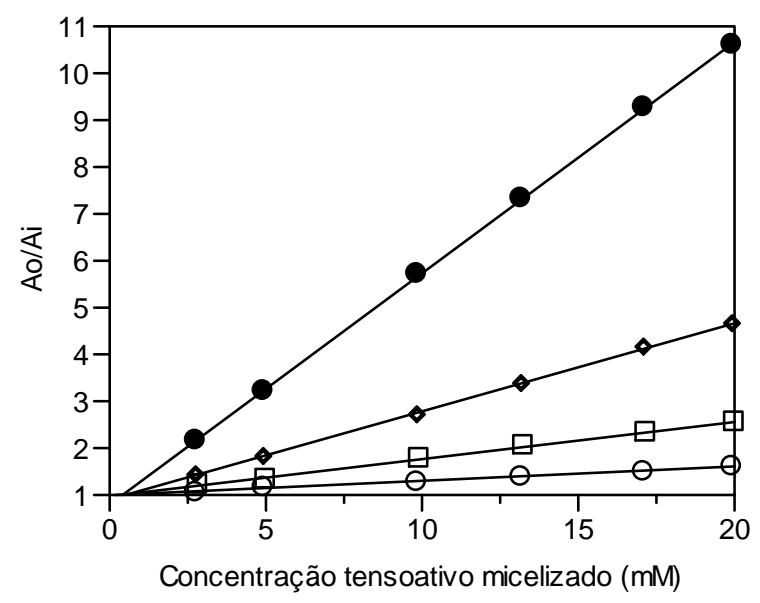

Figura 21: Gráfico de $\mathrm{A}_{\mathrm{o}} / \mathrm{A}_{\mathrm{i}}$ em função da concentração de TERGITOL 15-S-30 micelizado para aromáticos: $(\circ)$ benzeno; $(\square)$ metil benzeno; $(\diamond)$ etil benzeno; $(\bullet)$ propil benzeno. 
As figuras 22 a 28 mostram os gráficos de $A_{0} / A_{i}$ em função da concentração de tensoativo micelizado utilizados na determinação da constante de incorporação micelar para octilamina e hexilamina.

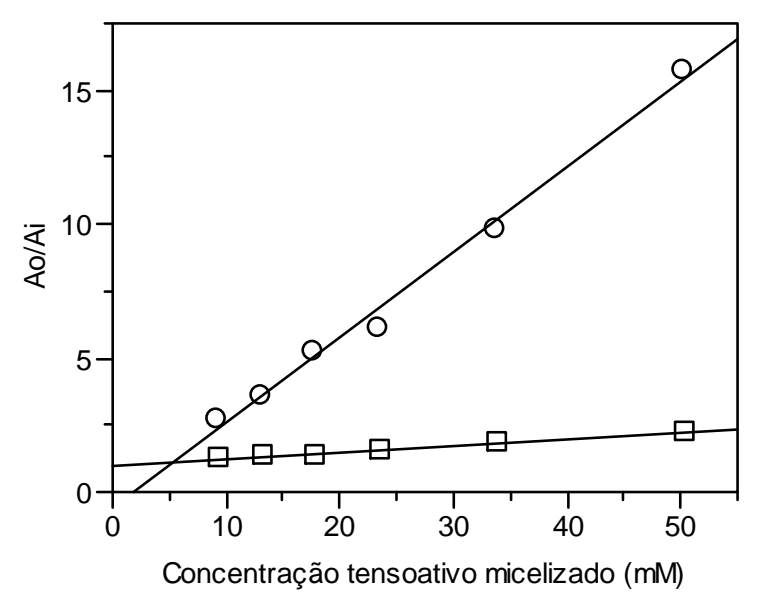

Figura 22: Gráfico de $\mathrm{A}_{\mathrm{o}} / \mathrm{A}_{\mathrm{i}}$ em função da concentração de TERGITOL 15-S-7 micelizado para alquilaminas: ( $($ ) octilamina; ( $\square$ ) hexilamina.

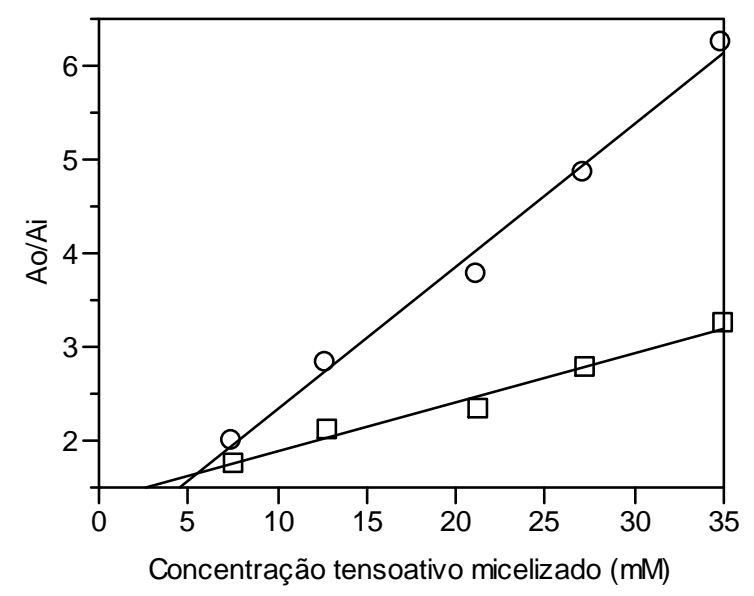

Figura 23: Gráfico de $A_{o} / A_{i}$ em função da concentração de TERGITOL 15-S-9 micelizado para alquilaminas: ( $)$ octilamina; ( $\square$ ) hexilamina. 


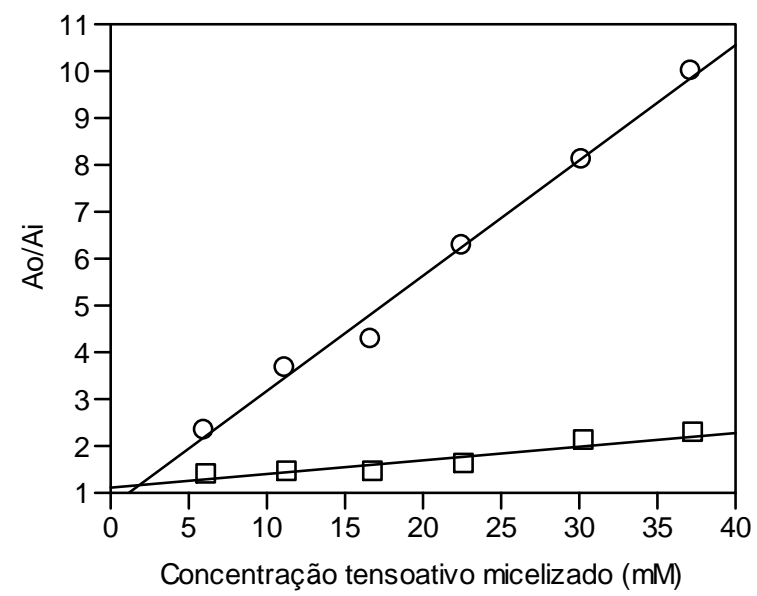

Figura 24: Gráfico de $\mathrm{A}_{\mathrm{o}} / \mathrm{A}_{\mathrm{i}}$ em função da concentração de TERGITOL 15-S-12 micelizado para alquilaminas: ( $)$ octilamina; $(\square)$ hexilamina.

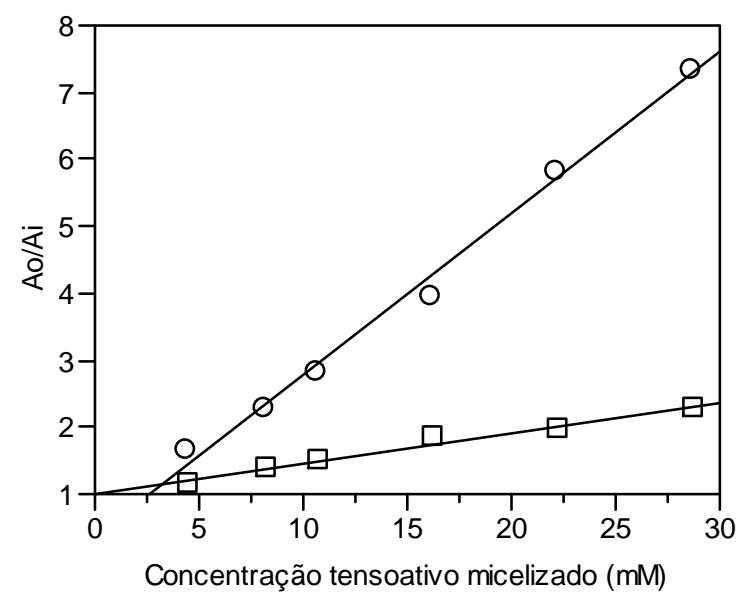

Figura 25: Gráfico de $\mathrm{A}_{\mathrm{o}} / \mathrm{A}_{\mathrm{i}}$ em função da concentração de TERGITOL 15-S-15 micelizado para alquilaminas: (०) octilamina; ( $\square$ ) hexilamina. 


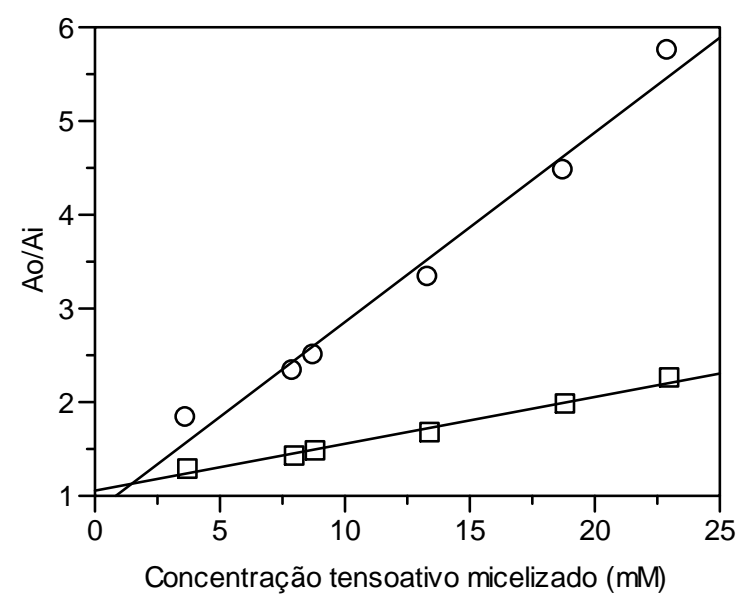

Figura 26: Gráfico de $\mathrm{A}_{\mathrm{o}} / \mathrm{A}_{\mathrm{i}}$ em função da concentração de TERGITOL 15-S-20 micelizado para alquilaminas: (০) octilamina; ( $\square$ ) hexilamina.

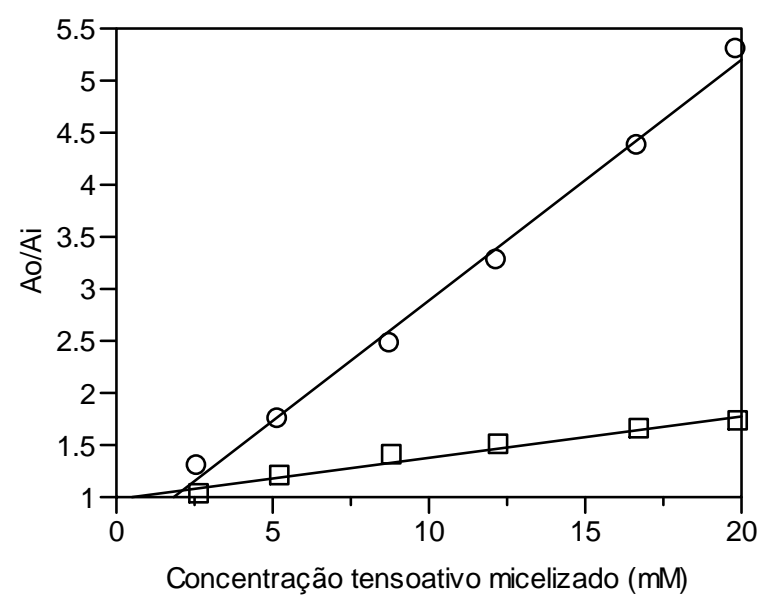

Figura 27: Gráfico de $\mathrm{A}_{\mathrm{o}} / \mathrm{A}_{\mathrm{i}}$ em função da concentração de TERGITOL 15-S-30 micelizado para alquilaminas: (०) octilamina; ( $\square$ ) hexilamina. 


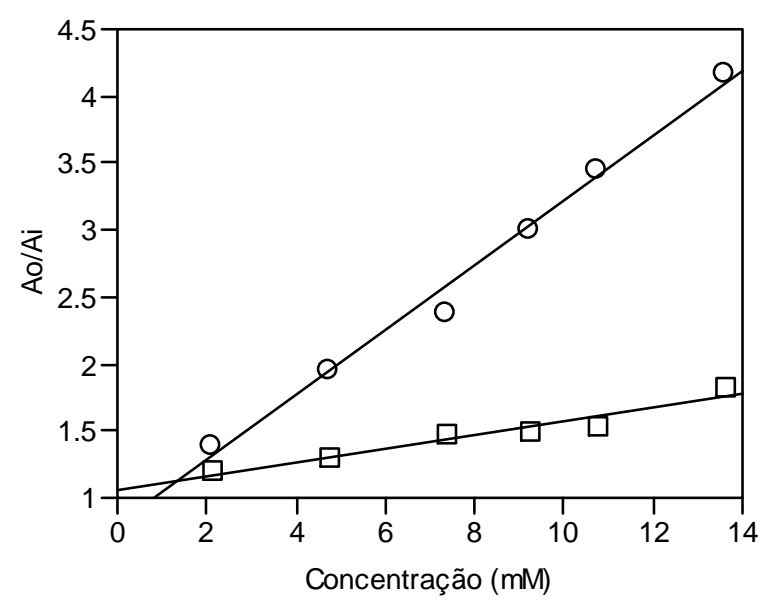

Figura 28: Gráfico de $\mathrm{A}_{\mathrm{o}} / \mathrm{A}_{\mathrm{i}}$ em função da concentração de TERGITOL 15-S-40 micelizado para alquilaminas: ( $($ ) octilamina; ( $\square$ ) hexilamina.

As figuras 29 a 33 mostram os gráficos de $A_{0} / A_{i}$ em função da concentração de tensoativo micelizado utilizados na determinação da constante de incorporação micelar para 1-octino e 1-hexino.

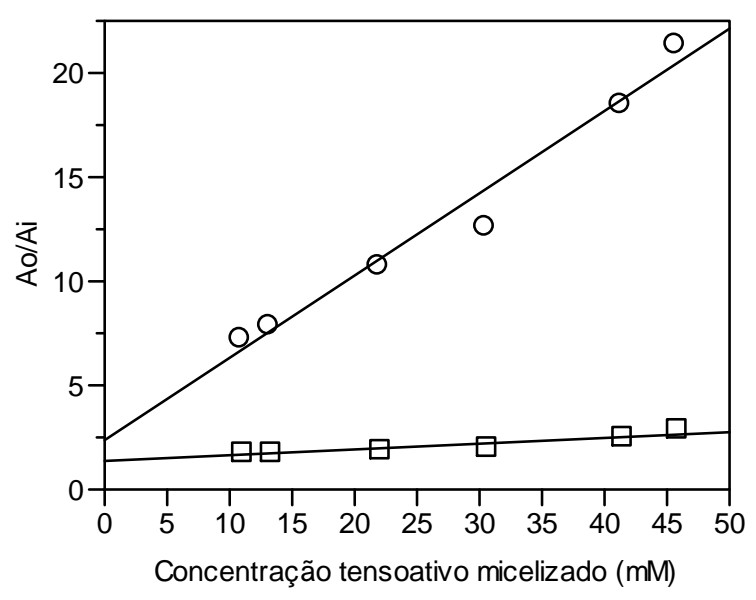

Figura 29: Gráfico de $A_{o} / A_{i}$ em função da concentração de TERGITOL 15-S-7 micelizado para alquilaminas: (०) 1-octino; ( $\square$ ) 1-hexino. 


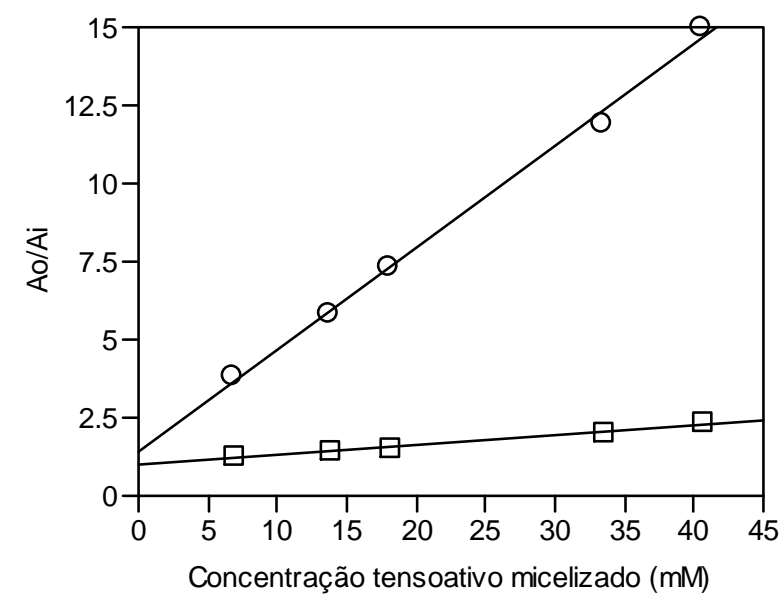

Figura 30: Gráfico de $A_{0} / A_{i}$ em função da concentração de TERGITOL 15-S-9 micelizado para alquilaminas: ( $)$ ) 1-octino; ( $\square$ ) 1-hexino.

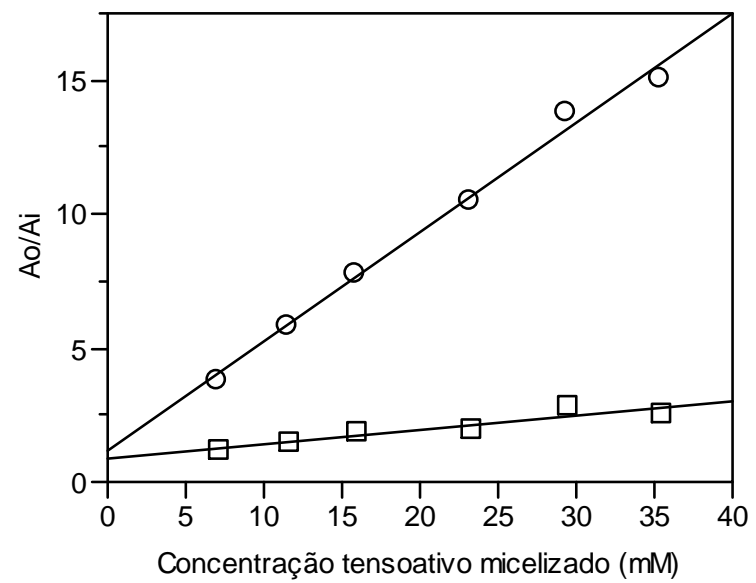

Figura 31: Gráfico de $\mathrm{A}_{\mathrm{o}} / \mathrm{A}_{\mathrm{i}}$ em função da concentração de TERGITOL 15-S-12 micelizado para alquilaminas: ( $\circ$ ) 1-octino; ( $\square$ ) 1-hexino. 


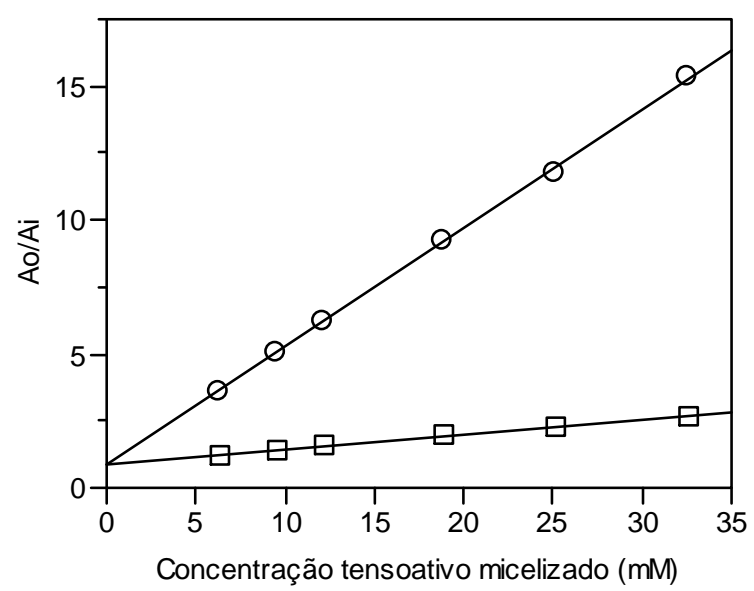

Figura 32: Gráfico de $\mathrm{A}_{\mathrm{o}} / \mathrm{A}_{\mathrm{i}}$ em função da concentração de TERGITOL 15-S-15 micelizado para alquilaminas: (o) 1-octino; ( $\square$ ) 1-hexino.

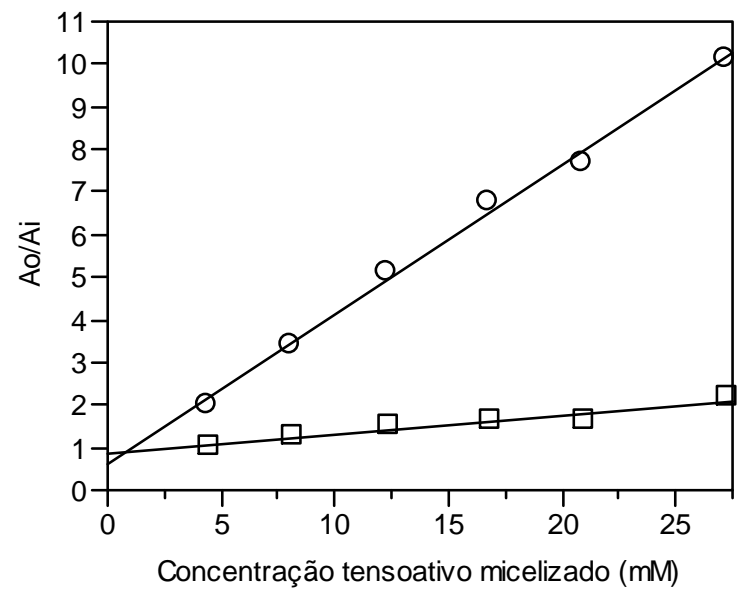

Figura 33: Gráfico de $\mathrm{A}_{\mathrm{o}} / \mathrm{A}_{\mathrm{i}}$ em função da concentração de TERGITOL 15-S-20 micelizado para alquilaminas: (o) 1-octino; ( $\square$ ) 1-hexino. 
As figuras 34 a 40 mostram os gráficos de $A_{0} / A_{i}$ em função da concentração de tensoativo micelizado utilizados na determinação da constante de incorporação micelar para 1-heptanol, 1-hexanol e 1-pentanol.

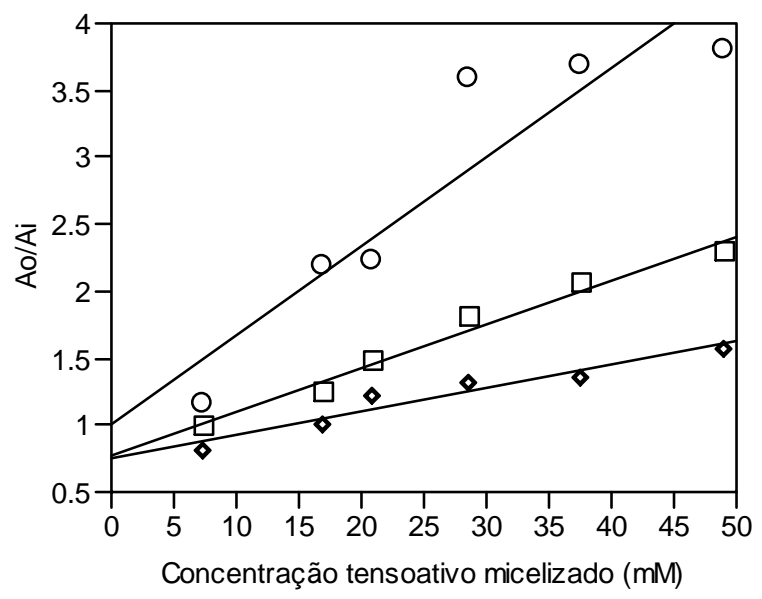

Figura 34: Gráfico de $\mathrm{A}_{\mathrm{o}} / \mathrm{A}_{\mathrm{i}}$ em função da concentração de TERGITOL 15-S-7 micelizado para álcoois: ( ○) 1-heptanol; ( $\square$ ) 1-hexanol, ( $\diamond)$ 1-pentanol.

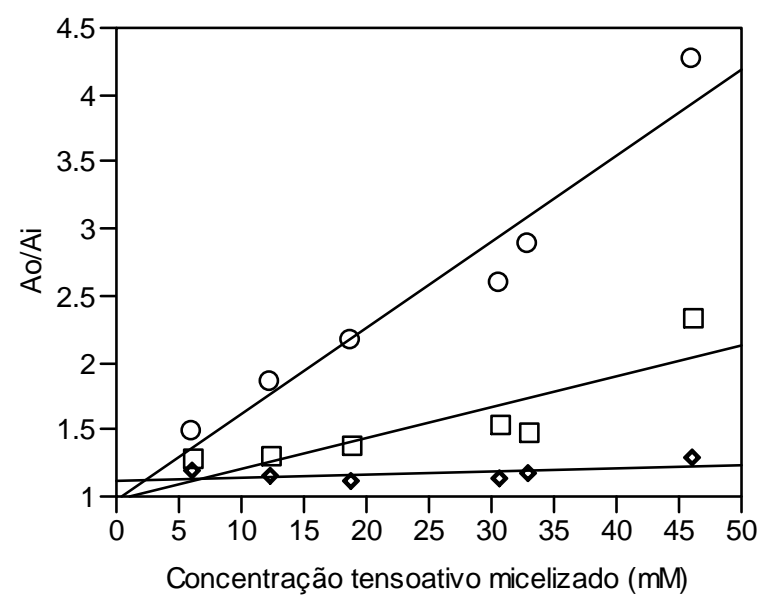

Figura 35: Gráfico de $A_{o} / A_{i}$ em função da concentração de TERGITOL 15-S-9 micelizado para álcoois: (○) 1-heptanol; ( $\square$ ) 1-hexanol, ( $\diamond)$ 1-pentanol. 


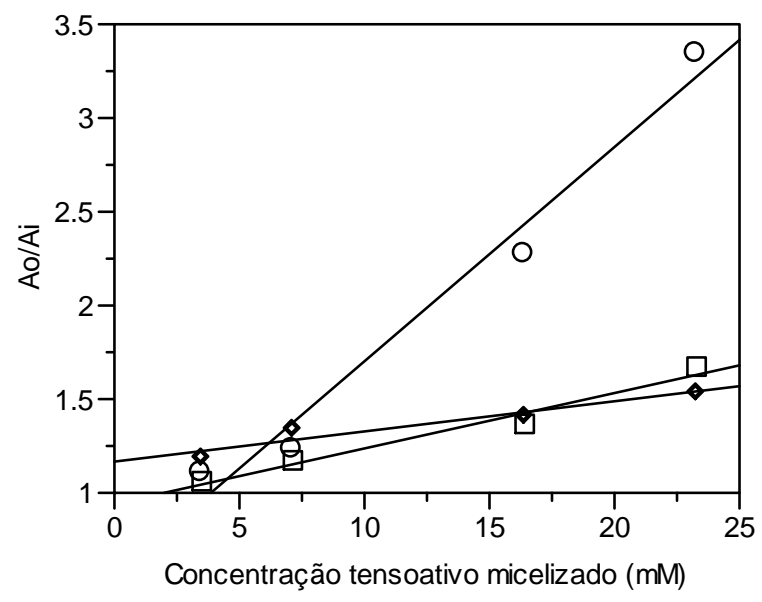

Figura 36: Gráfico de $\mathrm{A}_{\mathrm{o}} / \mathrm{A}_{\mathrm{i}}$ em função da concentração de TERGITOL 15-S-12 micelizado para álcoois: ( ○) 1-heptanol; ( $\square$ ) 1-hexanol, ( $\diamond)$ 1-pentanol.

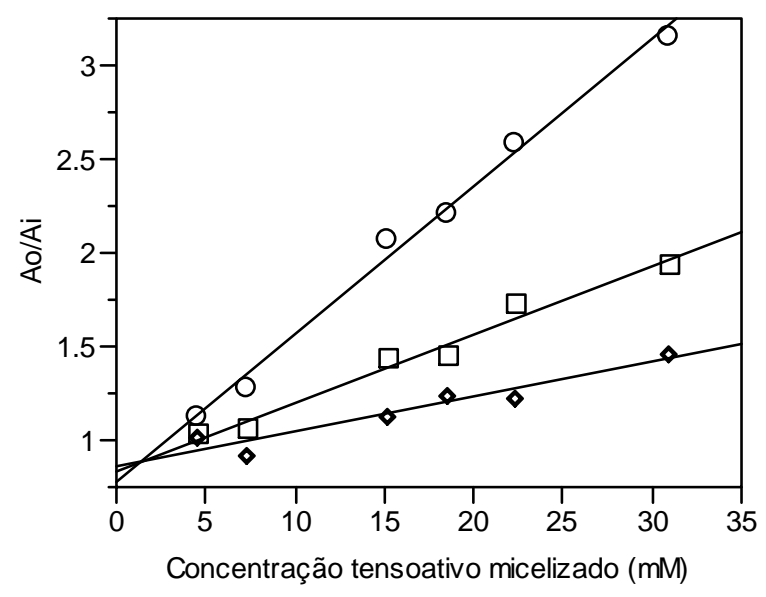

Figura 37: Gráfico de $\mathrm{A}_{\mathrm{o}} / \mathrm{A}_{\mathrm{i}}$ em função da concentração de TERGITOL 15-S-15 micelizado para álcoois: (०) 1-heptanol; ( $\square$ ) 1-hexanol, ( $\diamond)$ 1-pentanol. 


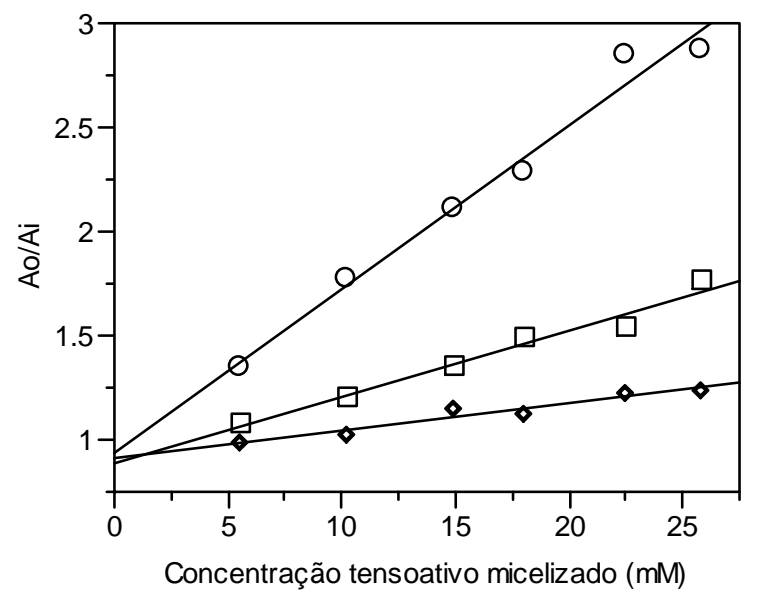

Figura 38: Gráfico de $\mathrm{A}_{\mathrm{o}} / \mathrm{A}_{\mathrm{i}}$ em função da concentração de TERGITOL 15-S-20 micelizado para álcoois: ( ○) 1-heptanol; ( $\square$ ) 1-hexanol, ( $\diamond)$ 1-pentanol.

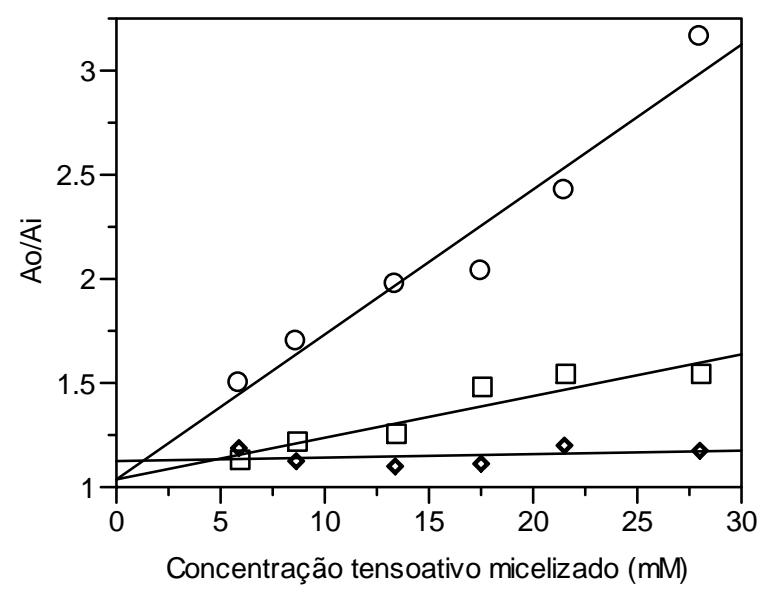

Figura 39: Gráfico de $A_{o} / A_{i}$ em função da concentração de TERGITOL 15-S-30 micelizado para álcoois: (०) 1-heptanol; ( $\square$ ) 1-hexanol, ( $\diamond)$ 1-pentanol. 


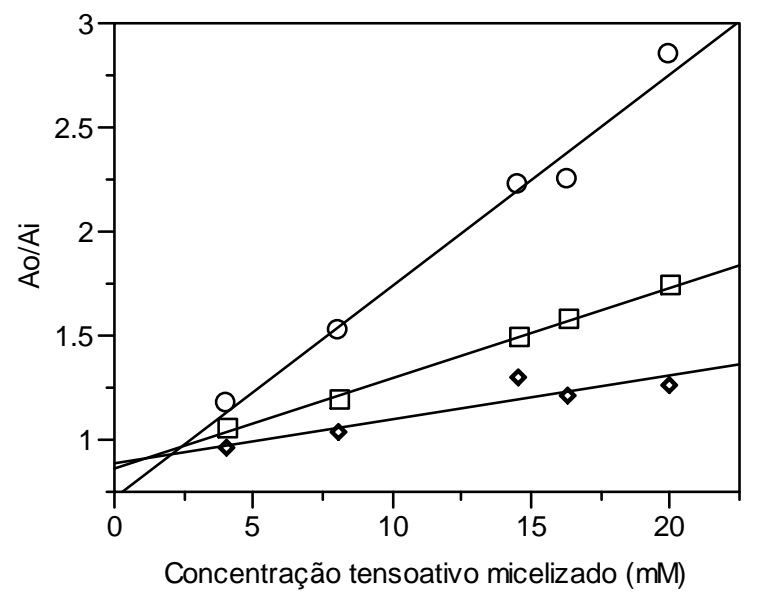

Figura 40: Gráfico de $A_{o} / A_{i}$ em função da concentração de TERGITOL 15-S-40 micelizado para álcoois: ( ○) 1-heptanol; ( $\square$ ) 1-hexanol, ( $\diamond)$ 1-pentanol.

As figuras 41 e 42 mostram os gráficos de $A_{0} / A_{i}$ em função da concentração de tensoativo micelizado utilizados na determinação da constante de incorporação micelar para n-undecano e n-dodecano.

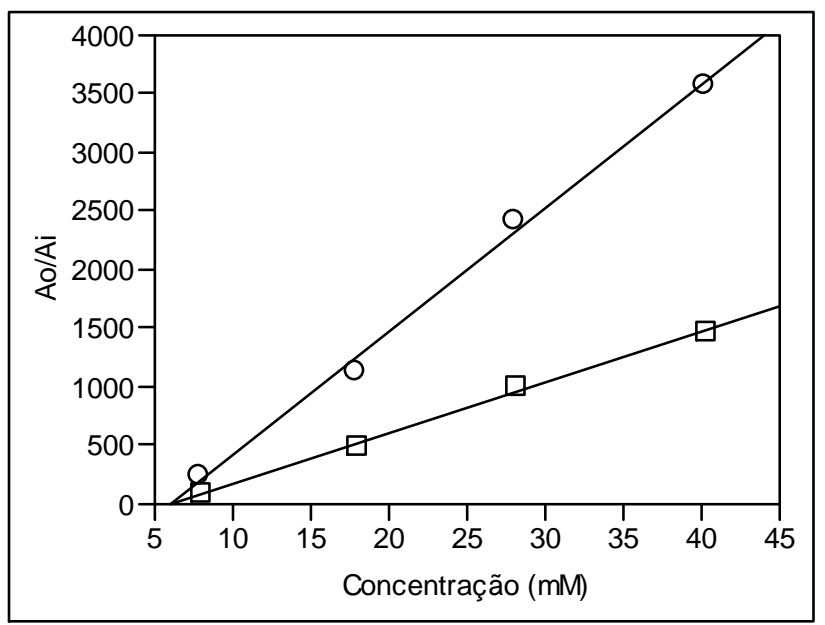

Figura 41: Gráfico de $A_{o} / A_{i}$ em função da concentração de TERGITOL 15-S-7 micelizado para álcoois: (०) n-dodecano; ( $\square$ ) n-undecano. 


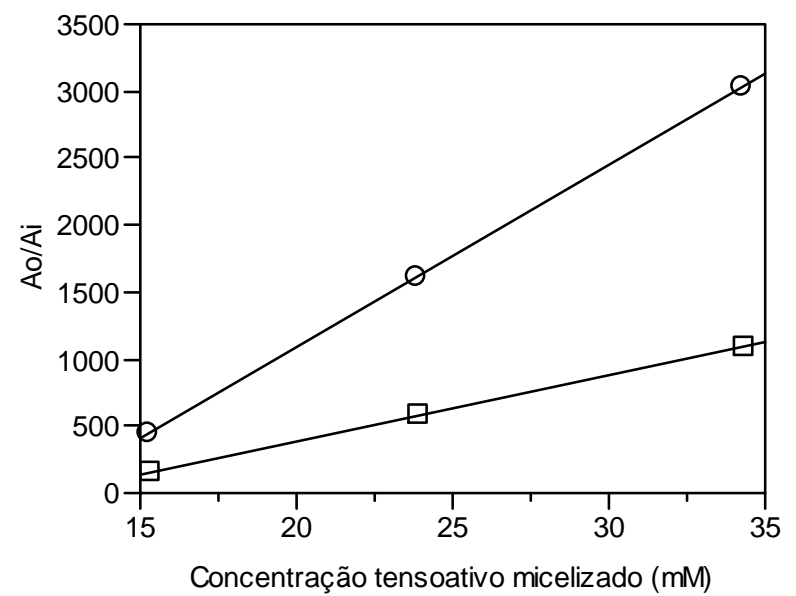

Figura 42: Gráfico de $A_{o} / A_{i}$ em função da concentração de TERGITOL 15-S-20 micelizado para álcoois: (०) n-dodecano; ( $\square$ ) n-undecano. 


\subsection{DETERMINAÇÃO DA CONSTANTE DE INCORPORAÇÃO MICELAR POR SOLUBILIZAÇÃO EM SATURAÇÃO COM ANÁLISE ESPECTROFOTOMÉTRICA}

Através do aumento da solubilidade de solutos pouco solúveis em função da concentração de tensoativo, pode-se determinar a constante de incorporação micelar, $K_{s}$, conforme o método descrito por Sepulveda et al. (1986).

Através da equação:

$$
\frac{S_{T}}{S_{0}}=1+K_{s}\left[C_{D}\right]
$$

e sabendo-se que:

$$
S_{T}=S_{w}+S_{m i c}
$$

na qual $S_{T}$ é a concentração total de soluto, $S_{0}$ é a concentração de soluto na fase aquosa e $S_{m i c}$ é a concentração analítica de soluto na micela, pode-se determinar a constante de incorporação micelar, $\mathrm{K}_{\mathrm{s}}$, a partir da inclinação de um gráfico de $S_{T} / S_{0}$ em função da concentração de tensoativo micelizado, $\left[C_{D}\right]$.

As figuras 43 a 49 mostram os gráficos de $S_{T} / S_{0}$ em função da concentração de tensoativo micelizado utilizados na determinação da constante de incorporação micelar para pireno e antraceno. 


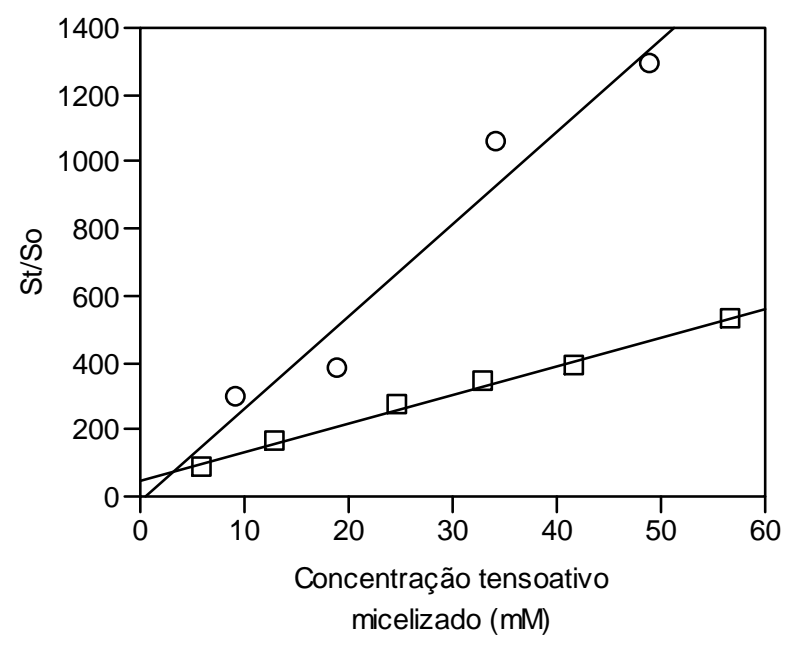

Figura 43: Gráfico de $\mathrm{S}_{\mathrm{t}} / \mathrm{S}_{\mathrm{o}}$ em função da concentração de TERGITOL 15-S-7 micelizado para: (०) pireno; ( $\square$ ) antraceno.

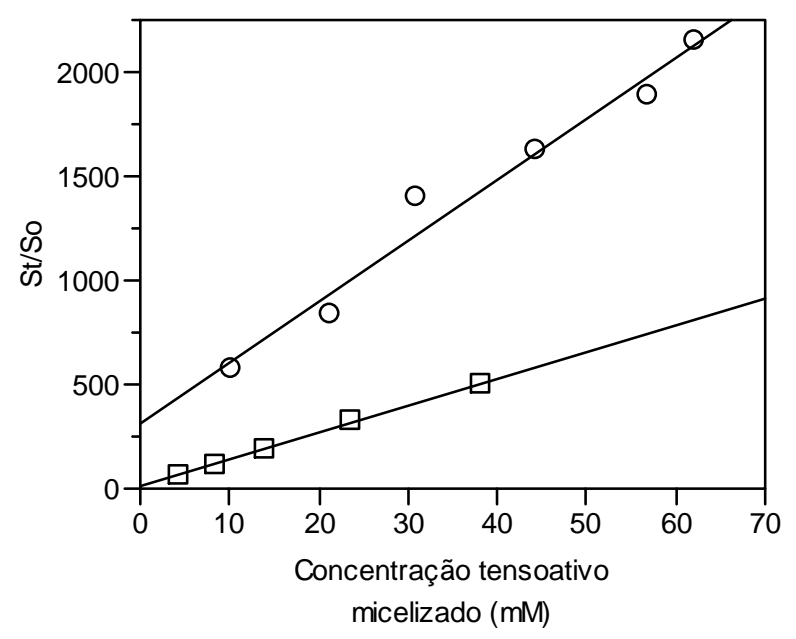

Figura 44: Gráfico de $\mathrm{S}_{\mathrm{t}} / \mathrm{S}_{\mathrm{o}}$ em função da concentração de TERGITOL 15-S-9 micelizado para: (०) pireno; ( $\square$ ) antraceno. 


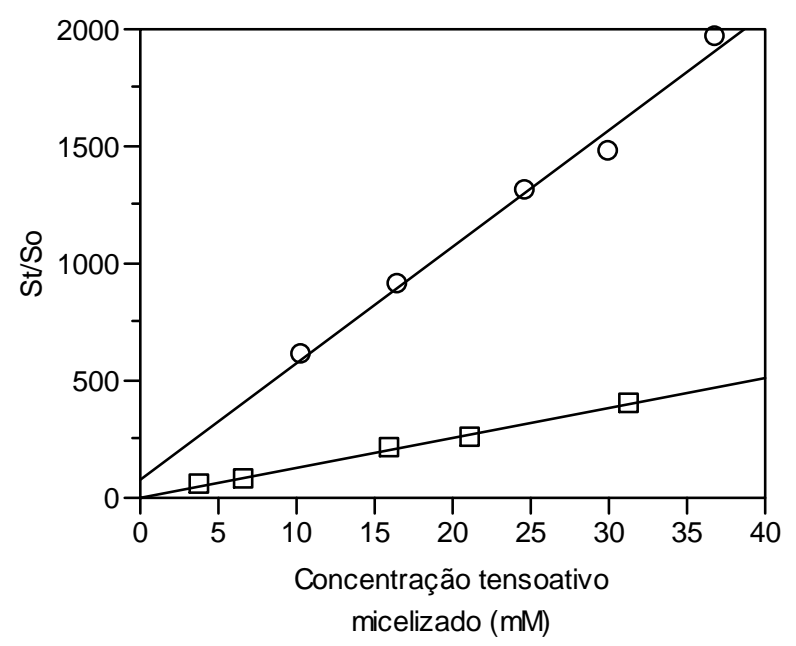

Figura 45: Gráfico de $\mathrm{S}_{\mathrm{t}} / \mathrm{S}_{\mathrm{o}}$ em função da concentração de TERGITOL 15-S-12 micelizado para: (०) pireno; ( $\square$ ) antraceno.

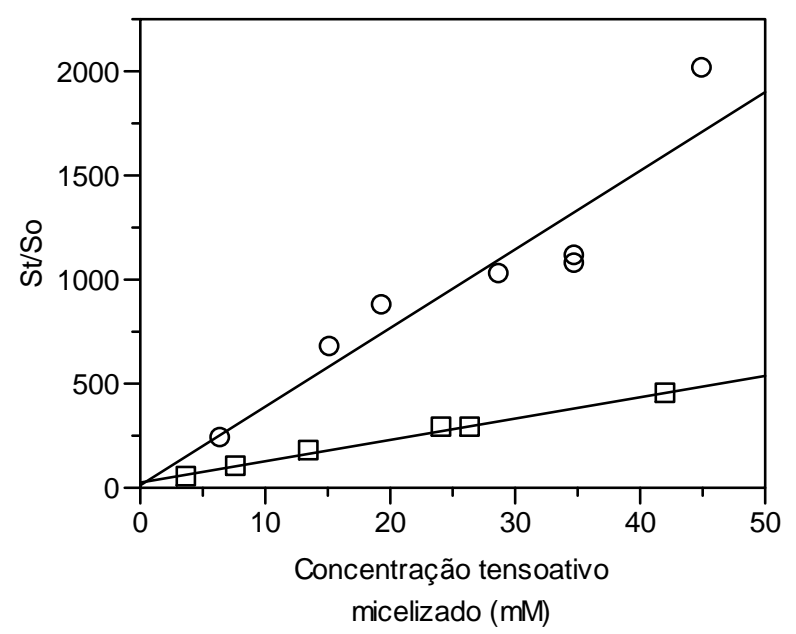

Figura 46: Gráfico de $\mathrm{S}_{\mathrm{t}} / \mathrm{S}_{\mathrm{o}}$ em função da concentração de TERGITOL 15-S-15 micelizado para: (०) pireno; ( $\square)$ antraceno. 


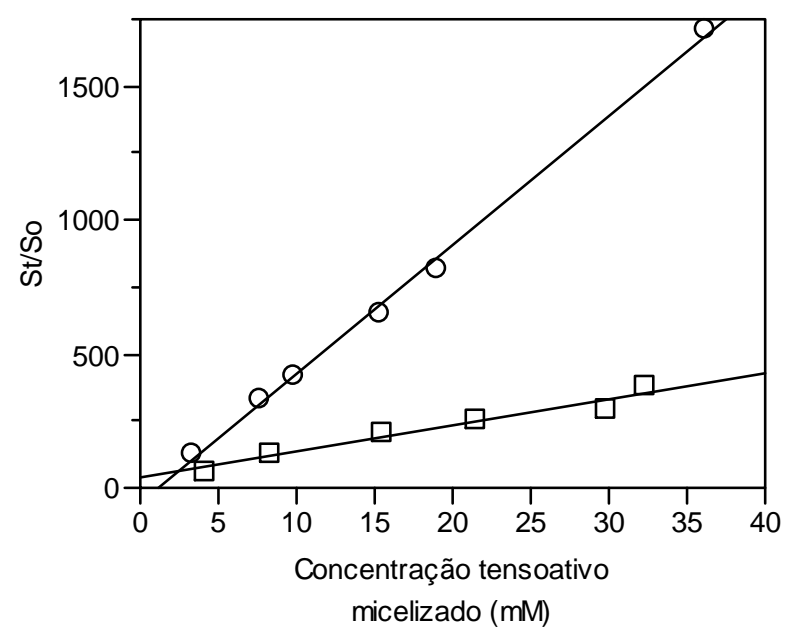

Figura 47: Gráfico de $\mathrm{S}_{\mathrm{t}} / \mathrm{S}_{\mathrm{o}}$ em função da concentração de TERGITOL 15-S-20 micelizado para: (०) pireno; ( $\square$ ) antraceno.

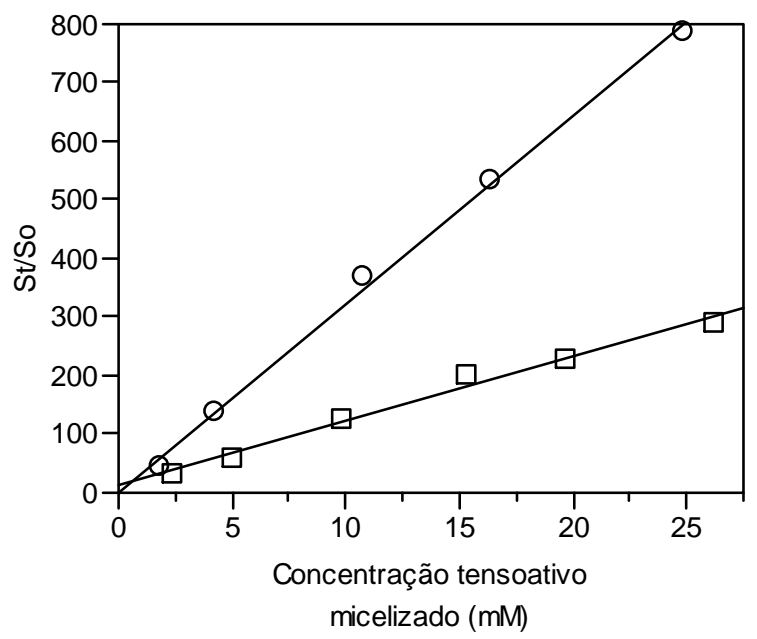

Figura 48: Gráfico de $\mathrm{S}_{\mathrm{t}} / \mathrm{S}_{\mathrm{o}}$ em função da concentração de TERGITOL 15-S-30 micelizado para: (०) pireno; ( $\square$ ) antraceno. 


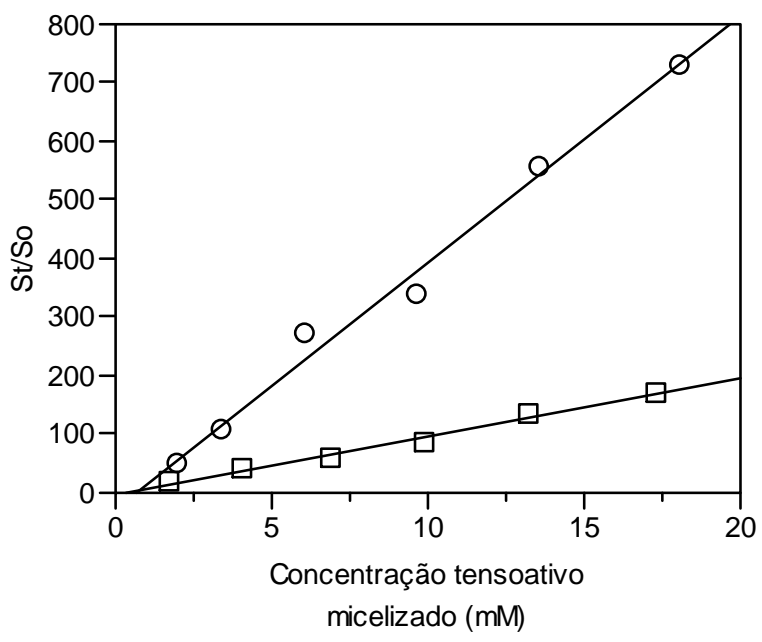

Figura 49: Gráfico de $\mathrm{S}_{\mathrm{t}} / \mathrm{S}_{\mathrm{o}}$ em função da concentração de TERGITOL 15-S-40 micelizado para: (०) pireno; ( $\square$ ) antraceno.

As figuras 50 a 55 mostram os gráficos de $S_{T} / S_{0}$ em função da concentração de tensoativo micelizado utilizados na determinação da constante de incorporação micelar para bifenilo e benzofenona.

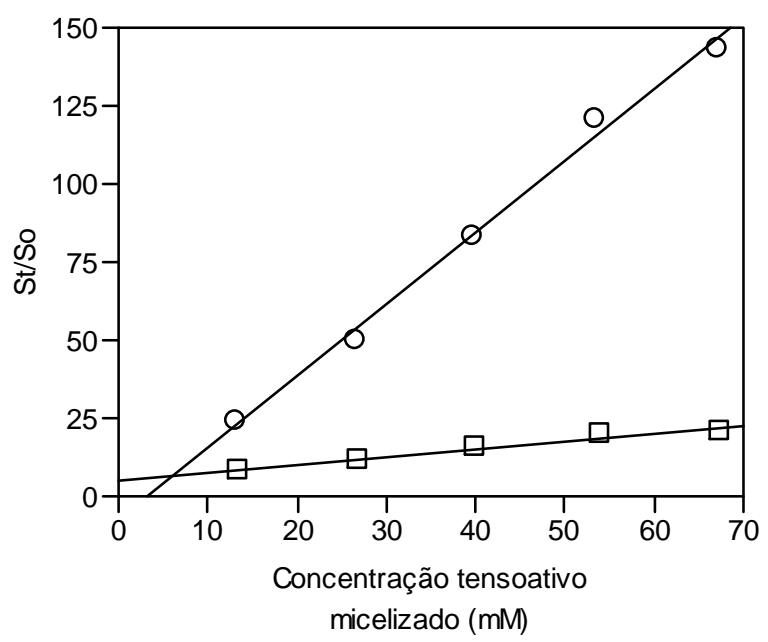

Figura 50: Gráfico de $\mathrm{S}_{\mathrm{t}} / \mathrm{S}_{\mathrm{o}}$ em função da concentração de TERGITOL 15-S-9 micelizado para: (०) bifenila; ( $\square$ ) benzofenona. 


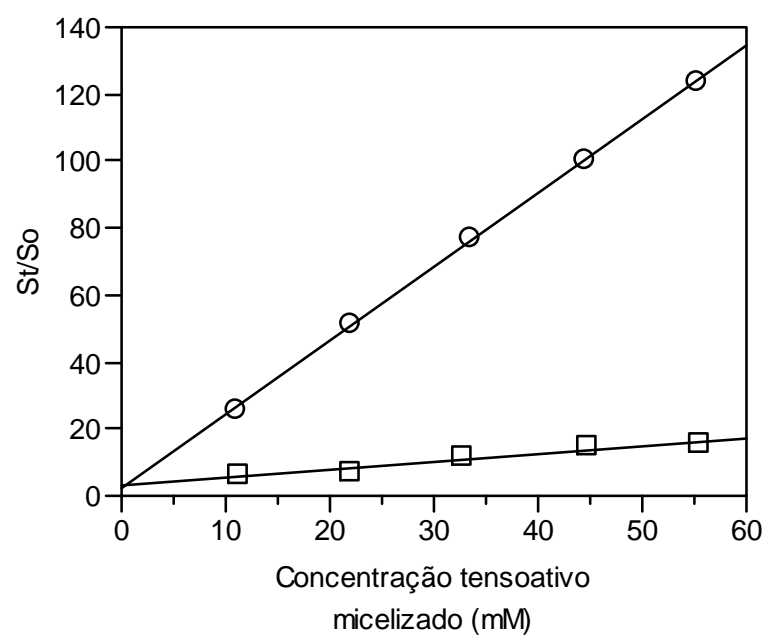

Figura 51: Gráfico de $\mathrm{S}_{\mathrm{t}} / \mathrm{S}_{\mathrm{o}}$ em função da concentração de TERGITOL 15-S-12 micelizado para: (०) bifenila; ( $\square$ ) benzofenona.

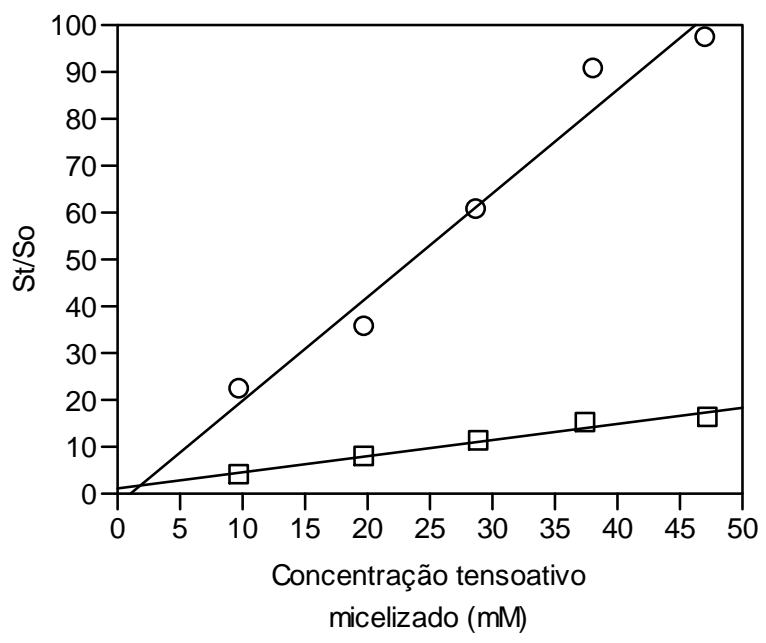

Figura 52: Gráfico de $\mathrm{S}_{\mathrm{t}} / \mathrm{S}_{\mathrm{o}}$ em função da concentração de TERGITOL 15-S-15 micelizado para: (०) bifenila; ( $\square$ ) benzofenona. 


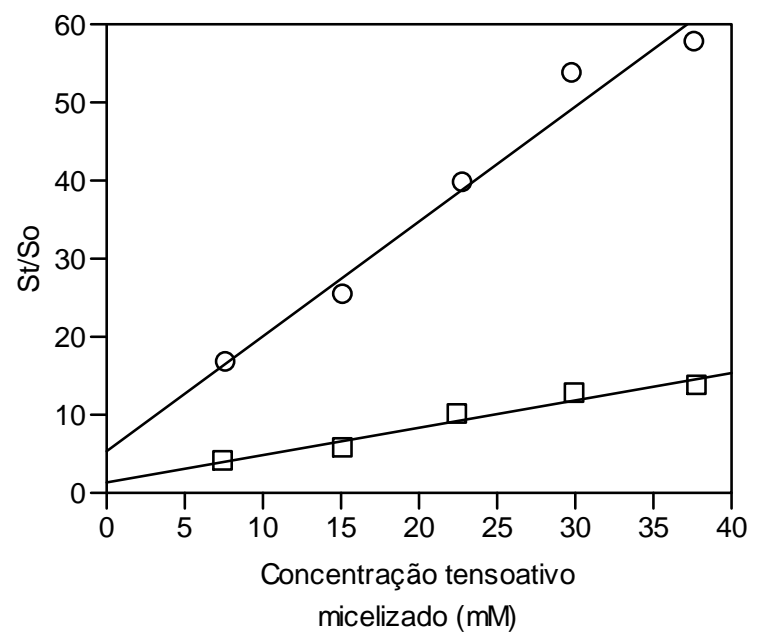

Figura 53: Gráfico de $\mathrm{S}_{\mathrm{t}} / \mathrm{S}_{\mathrm{o}}$ em função da concentração de TERGITOL 15-S-20 micelizado para: (०) bifenila; ( $\square$ ) benzofenona.

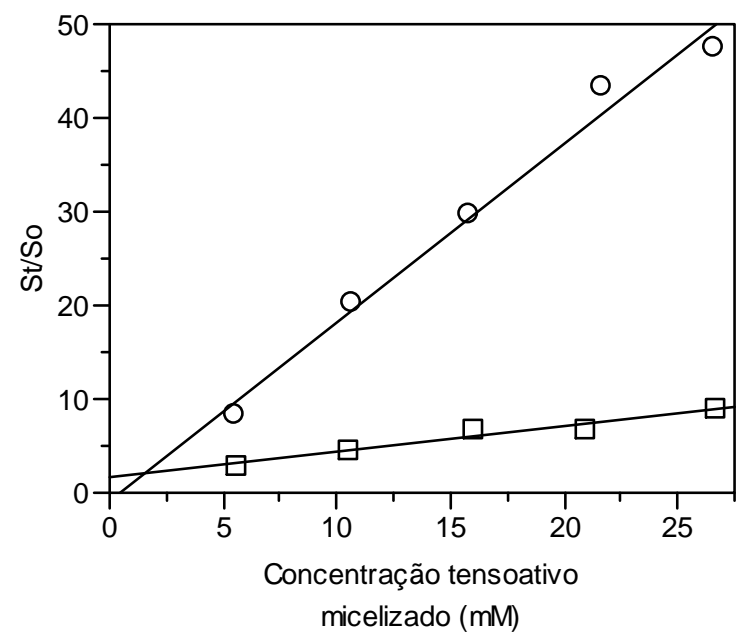

Figura 54: Gráfico de $\mathrm{S}_{\mathrm{t}} / \mathrm{S}_{\mathrm{o}}$ em função da concentração de TERGITOL 15-S-30 micelizado para: (०) bifenila; ( $\square$ ) benzofenona. 


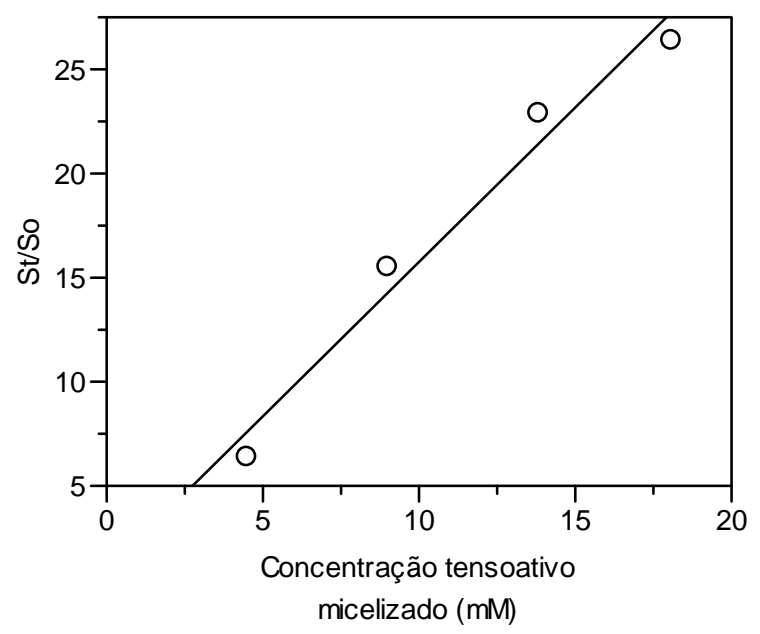

Figura 55: Gráfico de $\mathrm{S}_{\mathrm{t}} / \mathrm{S}_{\mathrm{o}}$ em função da concentração de TERGITOL 15-S-40 micelizado para: (०) bifenila.

As figuras 56 e 57 mostra o gráfico de $S_{T} / S_{0}$ em função da concentração de tensoativo micelizado utilizados na determinação da constante de incorporação micelar para ácido 2-hidroxibenzóico.

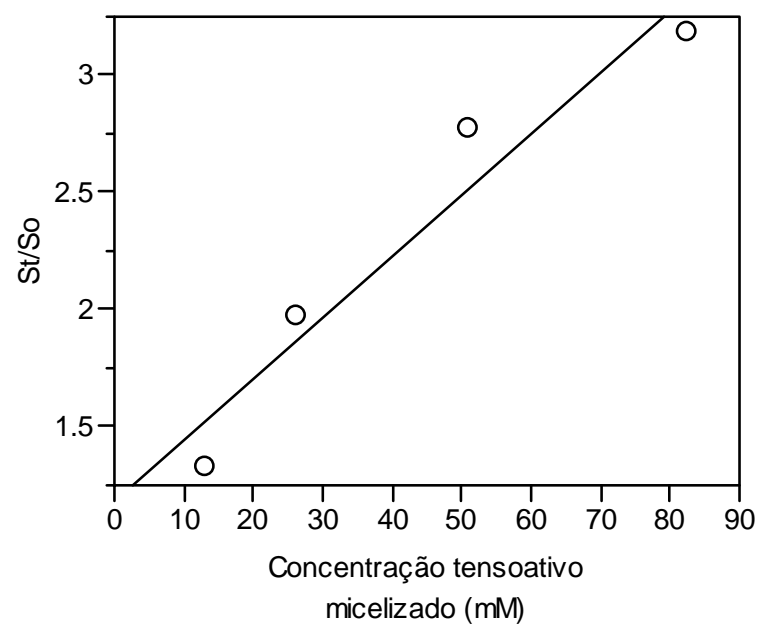

Figura 56: Gráfico de $\mathrm{S}_{\mathrm{t}} / \mathrm{S}_{\mathrm{o}}$ em função da concentração de TERGITOL 15-S-7 micelizado para ácido 2-hidroxibenzóico. 


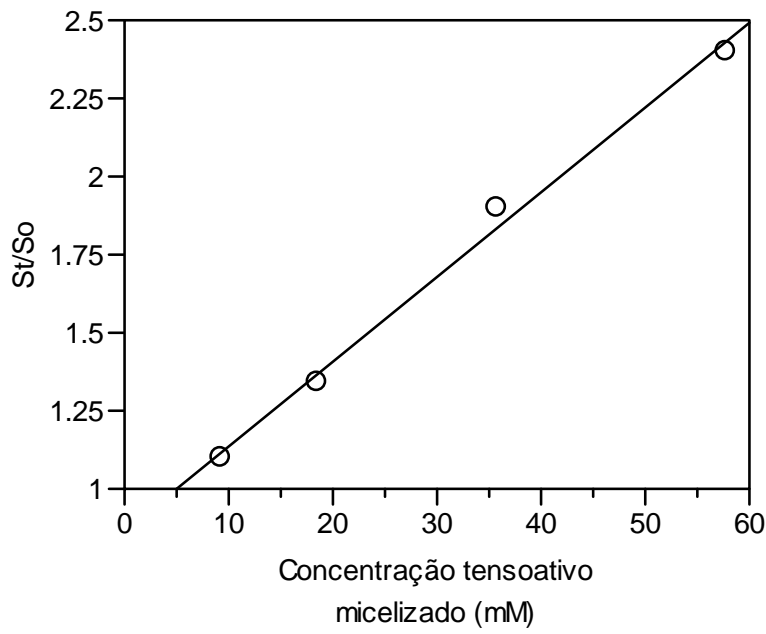

Figura 57: Gráfico de $\mathrm{S}_{\mathrm{t}} / \mathrm{S}_{\mathrm{o}}$ em função da concentração de TERGITOL 15-S-20 micelizado para ácido 2-hidroxibenzóico. 
Os valores da constante de incorporação micelar, em sua forma logarítimica, obtidos experimentalmente para todos tensoativos e solutos availados nesse estudo são descritos na Tabela 13.

Tabela 13: Constante de incorporação micelar, $\log \mathrm{K}_{\mathrm{s}}$ para os solutos e tensoativos estudados.

\begin{tabular}{|c|c|c|c|c|c|c|c|}
\hline Composto & $15-\mathrm{S}-7$ & $15-S-9$ & $15-S-12$ & $15-S-15$ & $15-\mathrm{S}-20$ & $15-S-30$ & $15-S-40$ \\
\hline 2-heptanona & 1,26 & 1,22 & 1,20 & 1,45 & 1,40 & 1,51 & 1,42 \\
\hline 2-octanona & 1,78 & 1,78 & 1,70 & 1,88 & 1,84 & 1,90 & 1,81 \\
\hline 1-pentanol & 1,24 & & 1,20 & 1,27 & 1,12 & & 1,32 \\
\hline 1-hexanol & 1,52 & & 1,48 & 1,56 & 1,51 & 1,31 & 1,64 \\
\hline 1-heptanol & 1,82 & 1,81 & 2,06 & 1,90 & 1,90 & 1,84 & 2,01 \\
\hline Antraceno & 3,93 & 4,11 & 4,10 & 4,01 & 3,99 & 4,04 & 4,00 \\
\hline Pireno & 4,44 & 4,47 & 4,70 & 4,58 & 4,68 & 4,51 & 4,62 \\
\hline 1-hexino & 1,45 & 1,48 & 1,72 & 1,75 & 1,65 & & \\
\hline 1-octino & 2,60 & 2,51 & 2,61 & 2,65 & 2,54 & & \\
\hline n-undecano & 4,64 & & & & 4,69 & & \\
\hline n-dodecano & 5,02 & & & & 5,13 & & \\
\hline Benzene & 1,33 & 1,46 & 1,44 & 1,26 & 1,40 & 1,49 & \\
\hline Metal benzeno & 1,94 & 1,94 & 1,94 & 1,82 & 1,84 & 1,90 & \\
\hline etil benzene & 2,38 & 2,37 & 2,35 & 2,24 & 2,18 & 2,27 & \\
\hline Propel benzeno & 2,85 & 2,86 & 2,80 & 2,68 & 2,56 & 2,69 & \\
\hline 1-hexilamina & 1,38 & 1,72 & 1,48 & 1,66 & 1,70 & 1,60 & 1,71 \\
\hline 1-octilamina & 2,51 & 2,20 & 2,40 & 2,39 & 2,32 & 2,38 & 2,39 \\
\hline benzofenona & & 2,40 & 2,38 & 2,54 & 2,55 & 2,43 & \\
\hline Bifenilo & & 3,36 & 3,34 & 3,34 & 3,17 & 3,28 & 3,17 \\
\hline ácido salicílico & 1,42 & & & & 1,43 & & \\
\hline
\end{tabular}


A Tabela 14 contém os valores dos coeficientes de correlação, $R^{2}$, individuais por cada par soluto-tensoativo das regressões lineares realizadas na determinação dos valores de constante de incorporação micelar, $K_{s}$, descritos na Tabela 13.

Tabela 14: Coeficientes de correlação para as regressões lineares na determinação da constante de incorporação micelar, $\log \mathrm{K}_{\mathrm{s}}$ para os solutos e tensoativos estudados.

\begin{tabular}{|c|c|c|c|c|c|c|c|}
\hline Composto & $15-S-7$ & $15-S-9$ & $15-\mathrm{S}-12$ & $15-S-15$ & $15-\mathrm{S}-20$ & $15-\mathrm{S}-30$ & $15-\mathrm{S}-40$ \\
\hline 2-heptanona & 0,99 & 0,98 & 0,96 & 0,98 & 0,98 & 0,98 & 0,97 \\
\hline 2-octanona & 0,99 & 0,95 & 0,99 & 0,99 & 0,99 & 0,99 & 0,99 \\
\hline 1-pentanol & 0,93 & & 0,91 & 0,92 & 0,95 & & 0,84 \\
\hline 1-hexanol & 0,98 & & 0,97 & 0,98 & 0,97 & 0,88 & 0,99 \\
\hline 1-heptanol & 0,86 & 0,94 & 0,98 & 0,99 & 0,98 & 0,95 & 0,98 \\
\hline Antraceno & 0,99 & 0,99 & 0,99 & 0,99 & 0,96 & 0,99 & 0,99 \\
\hline Pireno & 0,91 & 0,97 & 0,98 & 0,87 & 0,99 & 0,99 & 0,99 \\
\hline 1-hexino & 0,89 & 0,97 & 0,89 & 0,99 & 0,93 & & \\
\hline 1-octino & 0,97 & 0,99 & 0,99 & 0,99 & 0,99 & & \\
\hline n-undecano & 0,99 & & & & 0,99 & & \\
\hline n-dodecano & 0,99 & & & & 0,99 & & \\
\hline Benzene & 0,99 & 0,99 & 0,99 & 0,82 & 0,99 & 0,99 & \\
\hline metil benzeno & 0,99 & 0,99 & 0,99 & 0,97 & 0,98 & 0,99 & \\
\hline etil benzene & 0,99 & 0,99 & 0,99 & 0,96 & 0,99 & 0,99 & \\
\hline propil benzeno & 0,99 & 0,99 & 0,99 & 0,98 & 0,99 & 0,99 & \\
\hline 1-hexilamina & 0,99 & 0,98 & 0,89 & 0,98 & 0,99 & 0,97 & 0,94 \\
\hline 1-octilamina & 0,99 & 0,99 & 0,99 & 0,99 & 0,98 & 0,99 & 0,99 \\
\hline Benzofenona & & 0,97 & 0,95 & 0,96 & 0,97 & 0,96 & \\
\hline Bifenilo & & 0,99 & 0,99 & 0,97 & 0,97 & 0,98 & 0,97 \\
\hline ácido salicílico & 0,93 & & & & 0,99 & & \\
\hline
\end{tabular}




\subsection{EFICIÊNCIA DE LIMPEZA}

\subsubsection{Eficiência de limpeza no processo de lavagem de tecidos}

Curvas de calibração para análise de trioleina foram construídas utilizando-se hexadecanoato de etila como padrão interno. Soluções de tetrahidrofurano contendo $0,38 \%$ do padrão interno foram preparadas anteriormente a cada estudo realizado e uma curva de calibração foi construída para cada solução preparada. Para faixa de concentração em estudo, $0,02 \%$ a $0,31 \%$ de trioleina em tetrahidrofurano, a curva de calibração mostrou linearidade, o que permite a quantificação de trioleina residual no tecido após processo de lavagem. Uma curva de calibração terça é mostrada na Figura 58.

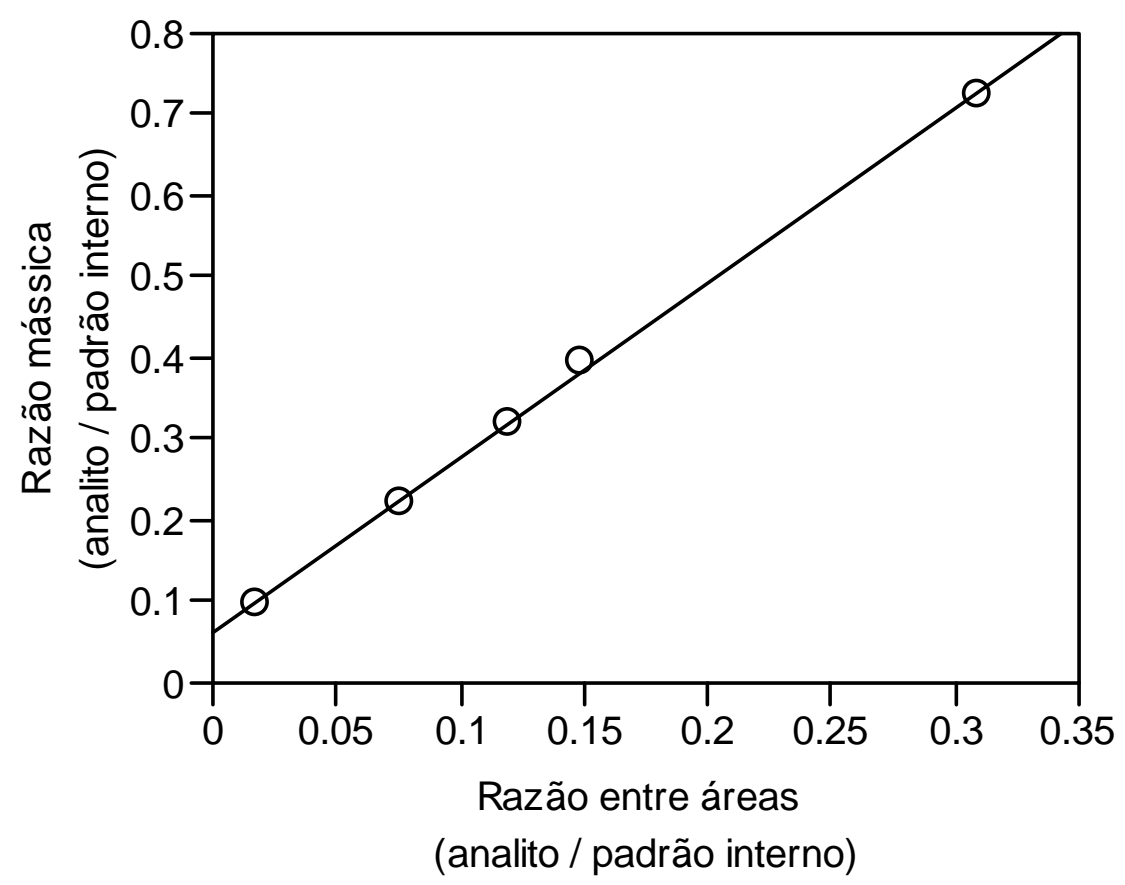

Figura 58: Curva de calibração típica de trioleina em tetrahidrofurano utilizando-se hexadecanoato de etila como padrão interno $\left(\mathrm{R}^{2}=0,998\right)$. 
A análise de eficiência de limpeza para concentração mássica constante de tensoativo de 2250 ppm (desvio padrão de 20ppm), Figura 59, foi realizada em triplicata para cada tensoativo.

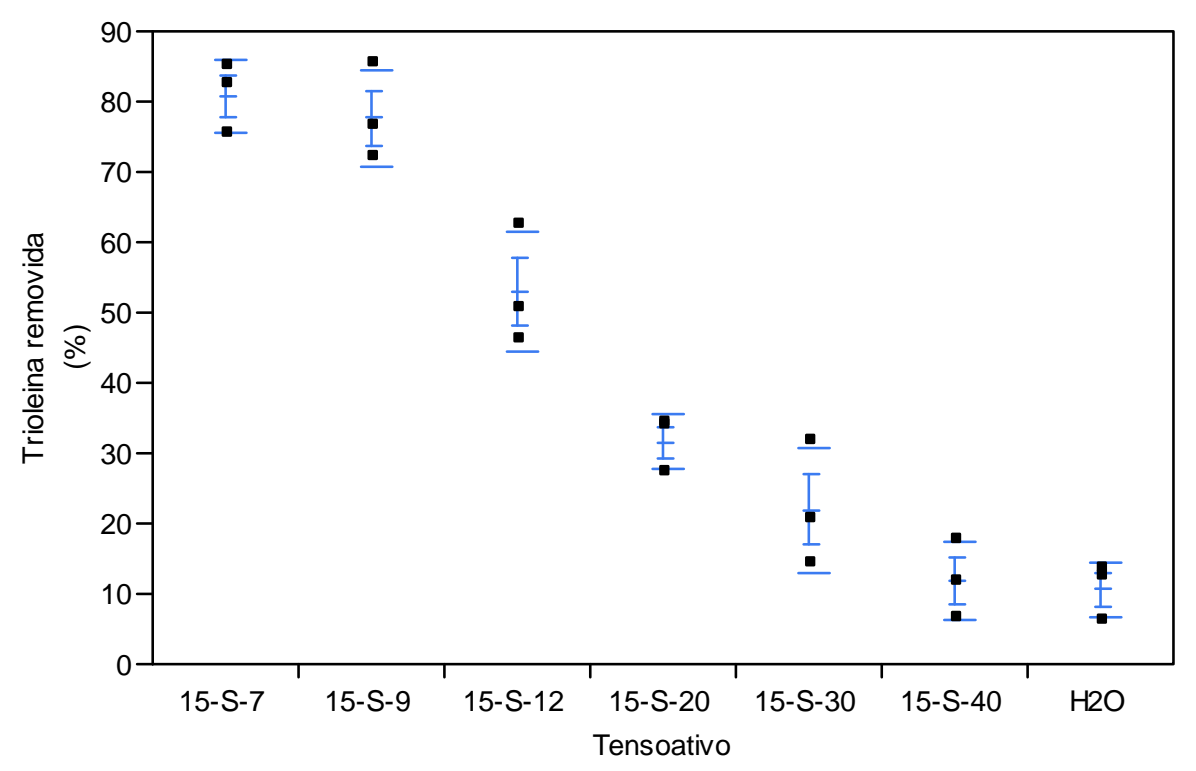

Figura 59: Gráfico comparando a fração de trioleina removida do tecido para os tensoativos com grau de etoxilação entre 7 e 40 e água.

A análise de eficiência de limpeza em função da concentração de tensoativo foi realizada para TERGITOL 15-S-7 e TERGITOL 15-S-40. Neste estudo, os tensoativos foram estudados nas seguintes concentrações: $1,25 \mathrm{mM}, 3,00 \mathrm{mM}$ e 4,52mM para TERGITOL 15-S7 e 1,22mM, 2,90mM e 4,60mM para TERGITOL 15-S-40. A Figura 60 mostra os resultados obtidos nesse estudo. 


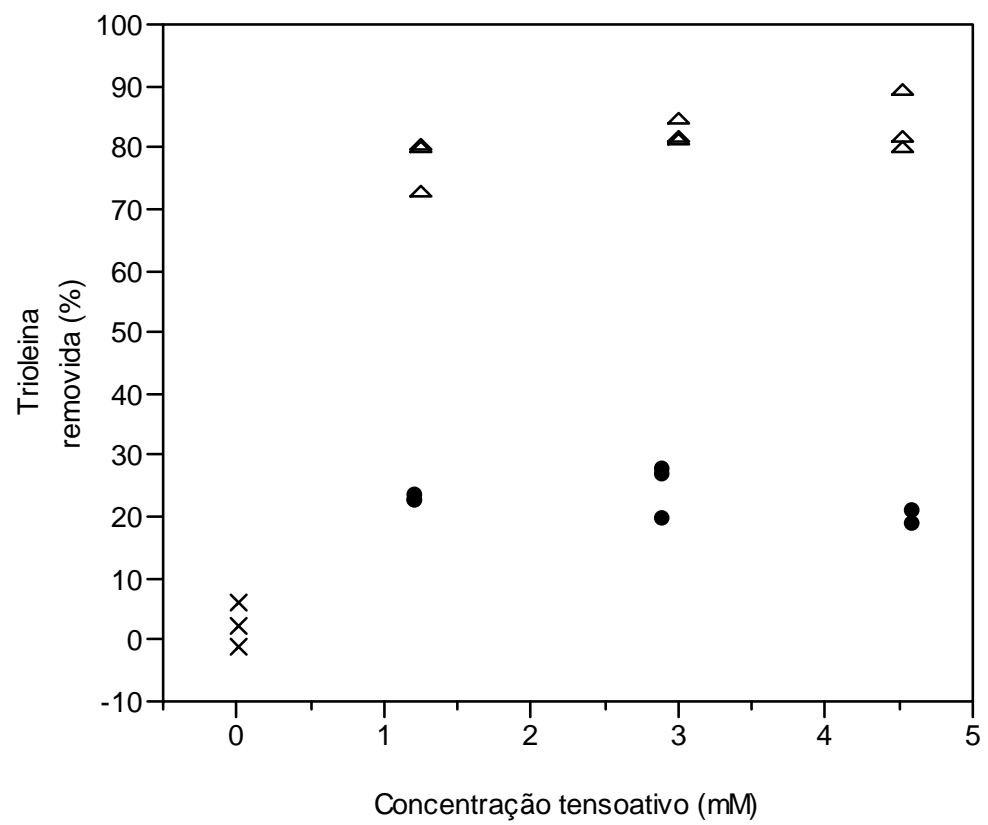

Figura 60: Gráfico comparando a fração de trioleina removida do tecido para os tensoativos com grau etoxilação 7 e 40 em função da concentração de tensoativo: $(\Delta)$ TERGITOL 15-S-7, (•) TERGITOL 15-S-40 e (×) água.

\subsubsection{Eficiência de limpeza para superfícies sólidas}

A eficiência de limpeza para remoção de uma sujeira padrão de superfície sólida foi determinada para concentração mássica de tensoativos de $1 \%$, representando uma concentração típica utilizada em produtos de limpeza. A Figura 61 mostra o resultado desse estudo para os tensoativos TERGITOL 15-S com grau de etoxilação variando entre 7 e 40 . 


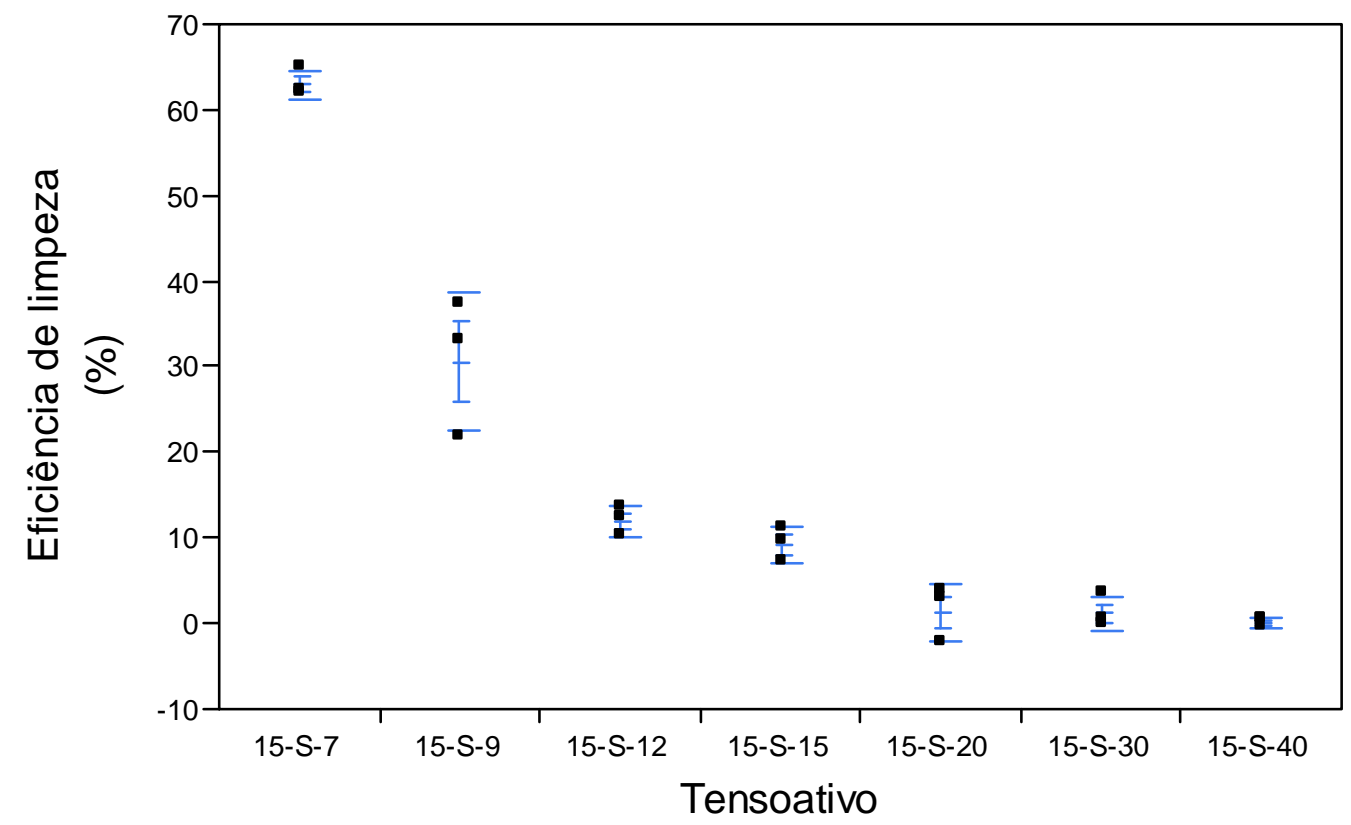

Figura 61: Gráfico comparando a eficiência de limpeza para sujeira padrão para os tensoativos com grau de etoxilação entre 7 e 40.

A análise de eficiência de limpeza em função da concentração de tensoativo foi realizada para TERGITOL 15-S-7 e TERGITOL 15-S-40. Neste estudo, os tensoativos foram estudados nas seguintes concentrações: $5 \mathrm{mM}$ e $19 \mathrm{mM}$ para os tensoativos TERGITOL 15-S7 e TERGITOL 15-S-40. A Figura 62 mostra os resultados obtidos nesse estudo. 


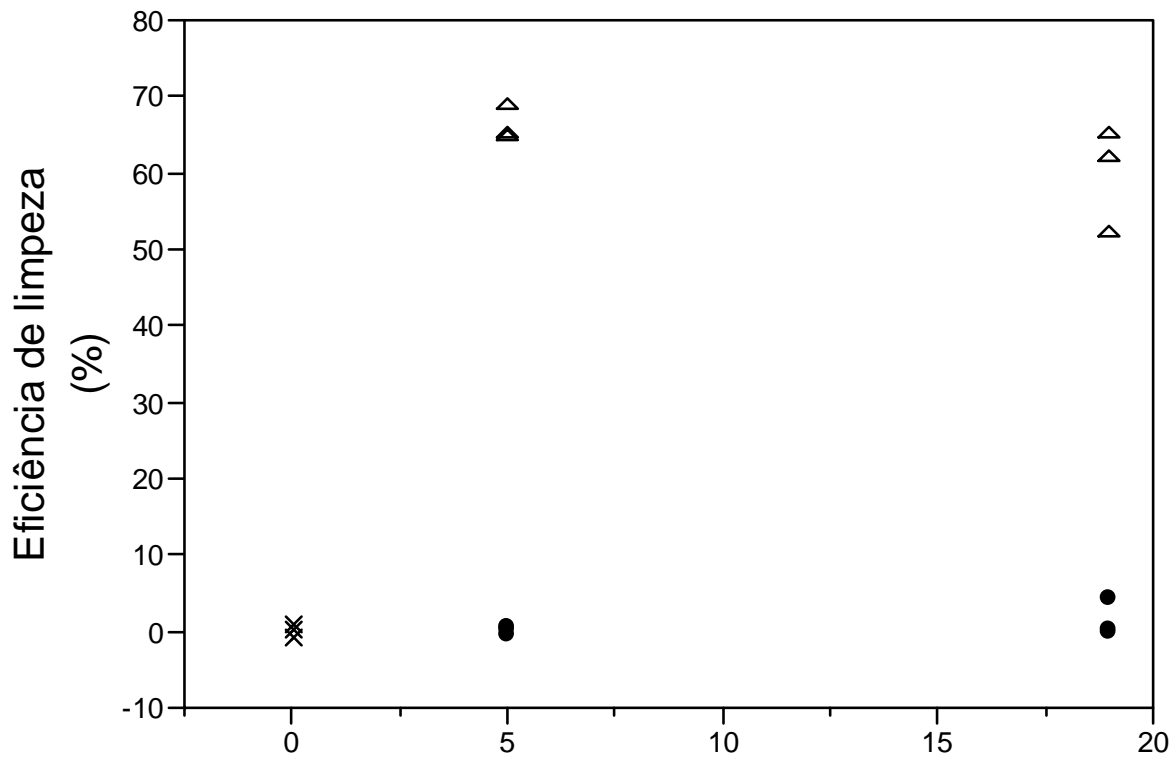

Concentração (mM)

Figura 62: Gráfico comparando a eficiência de limpeza para sujeira padrão para os tensoativos com grau etoxilação 7 e 40 em função da concentração de tensoativo: $(\Delta)$ TERGITOL 15-S-7, (•) TERGITOL 15-S-40 e (×) água. 


\section{DISCUSSÃO}

O efeito do aumento do grau de etoxilação na concentração micelar crítica, Tabela 12, deve ser analisado em função da contribuição sobre a variação da energia livre de micelização em função do aumento da fração hidrofílica do tensoativo como ilustrado na Figura 63.

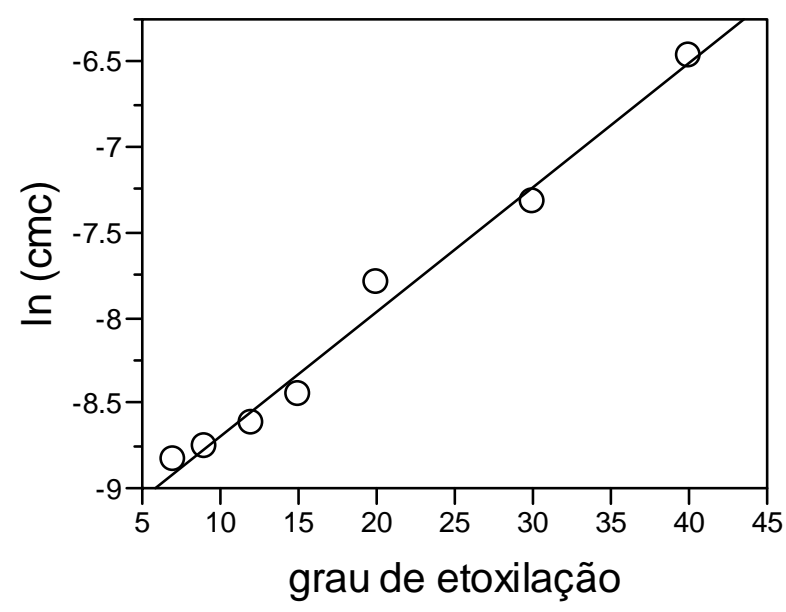

Figura 63: Gráfico de $\ln (\mathrm{cmc})$ em função do grau de etoxilação

A regressão linear, com um coeficiente de correlação de 0,986 e um valor de $\mathrm{F}$ de 343 , fornece a Equação 33 .

$$
\ln (c m c)=0,073 E O-9,42
$$

O valor positivo do coeficiente angular desta regressão e a comparação das Equações 6 e 25 indica que o aumento do grau de etoxilação resulta em uma variação positiva da 
energia livre de micelização. Esse comportamento é esperado e observado de maneira geral para os tensoativos não iônicos independentemente da estrutura do hidrófobo dos tensoativos uma vez que o aumento do grau de etoxilação torna o tensoativo mais hidrofílico como demonstrado por Hsia et al. (1956).

Os coeficientes angulares das curvas de regressão pré-micelização, Figura 8, foram utilizados no cálculo da concentração em excesso superficial, $\Gamma$, e no cálculo da área por molécula, A, na interface água - ar de acordo com as Equações 34 e 35 conforme descrito por Rosen et al. (1982).

$$
\begin{gathered}
\Gamma=\frac{1}{2,303 R T}\left(\frac{-\partial \gamma}{\partial \log C}\right)_{T} \\
A=\frac{10^{23}}{N \Gamma}
\end{gathered}
$$

onde $R=8,314 \mathrm{~J} \mathrm{~mol}^{-1} \mathrm{~K}^{-1}, T$ é a temperatura absoluta, $(-\partial \gamma / \log C)_{T}$ é o coeficiente angular obtido na Figura 8 e $N$ é o número de Avogadro.

Os resultados obtidos para concentração micelar crítica, concentração em excesso superficial e área por molécula estão descritos na Tabela 15 
Tabela 15: Valores de concentração micelar crítica, concentração em excesso superficial e área por molécula

\begin{tabular}{cccc}
\hline Tensoativo & $\mathrm{cmc}(\mathrm{mM})$ & $\Gamma\left(\mathrm{mol} / \mathrm{cm}^{2} \times 10^{10}\right)$ & $A\left(\mathrm{~nm}^{2} \times 100\right)$ \\
\hline TERGITOL 15-S-7 & 0,15 & 4,13 & 40,2 \\
TERGITOL 15-S-9 & 0,16 & 3,56 & 46,7 \\
TERGITOL 15-S-12 & 0,18 & 3,05 & 54,6 \\
TERGITOL 15-S-15 & 0,21 & 2,47 & 67,3 \\
TERGITOL 15-S-20 & 0,41 & 1,94 & 85,4 \\
TERGITOL 15-S-30 & 0,66 & 1,74 & 95,2 \\
TERGITOL 15-S-40 & 1,5 & 1,56 & 106,3 \\
\hline
\end{tabular}

A evidência do aumento da cmc e do aumento da área na interface ar-líquido em função do aumento do grau de etoxilação é o comportamento esperado para tensoativos não iônicos etoxilados. A questão a ser respondida é se a mudança na hidrofilicidade dos tensoativos afeta sua capacidade de solubilizar solutos em um processo de partição entre água e pseudo-fase micelar.

A partição de um soluto entre água e um meio condensado é evidentemente dependente da constituição e propriedades físico-químicas do meio de solubilização. Como discutido na introdução deste estudo, a partição de um soluto entre água e a pseudo-fase micelar é definida pela constante de incorporação micelar, $K_{s}$. A análise da variação de $K_{s}$ em função do grau de etoxilação é elucidativa sobre a natureza do meio de solubilização dos tensoativos em estudo. A dependência de $K_{s}$ com o grau de etoxilação seria indicativo de que a partição é afetada pela natureza do hidrófilo dos tensoativos em questão e que a solubilização ocorre em uma região onde o hidrófilo esteja presente. Uma outra hipótese para explicar a possível dependência de $K_{s}$ com o grau de etoxilação seria de que o aumento da área do hidrófilo do tensoativo interfere na estrutura micelar alterando as propriedades do sítio de solubilização de maneira que a partição de solutos entre água e este meio micelar seja impactada. Entretanto, a independência de $K_{s}$ com o grau de etoxilação seria indicativo de 
que a partição do soluto ocorre entre água e o centro da micela constituído essencialmente de hidrófobo. Neste caso, ainda que variações no grau de etoxilação possam alterar estrutura e geometria micelar, o centro da micela permaneceria inalterado do ponto de vista de sua capacidade de interagir com solutos no processo de partição (interações estas que podem ser específicas ou não específicas como descrito na introdução deste trabalho).

Para o sistema em estudo, os valores obtidos para $\log K_{s}$ variam entre 1,12, valor obtido para 1-pentanol e TERGITOL 15-S-20, e 5,1, valor obtido para n-dodecano e TERGITOL 15-S-20. Assim, as Figuras 64 a 66 mostram, para essa faixa de variação, o comportamento da partição em função do grau de etoxilação dos tensoativos.

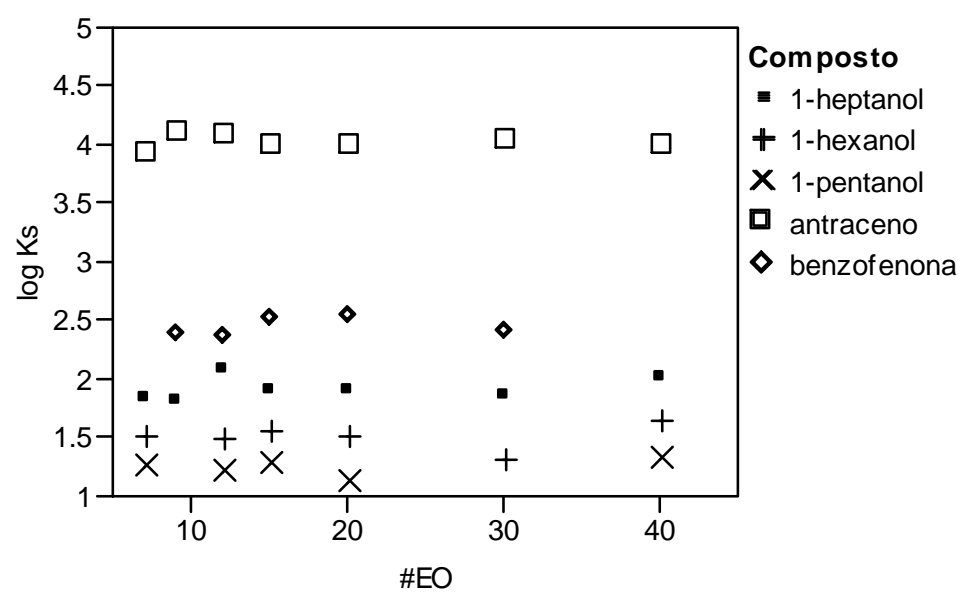

Figura 64: Gráfico de $\log K_{s}$ em função do grau de etoxilação dos tensoativos para álcoois, antraceno e benzofenona 


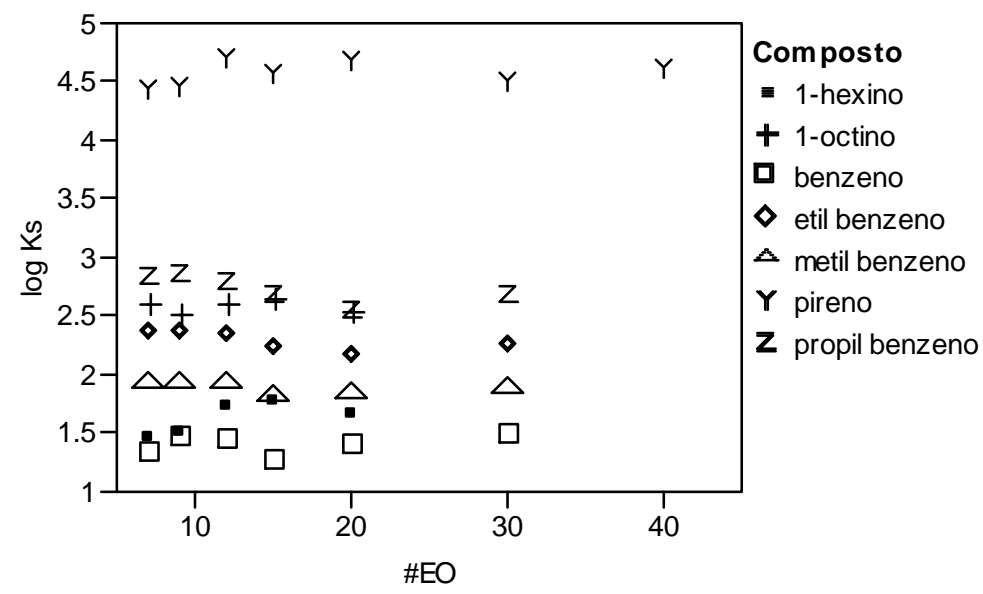

Figura 65: Gráfico de $\log K_{s}$ em função do grau de etoxilação dos tensoativos para alcinos, aromáticos e pireno.

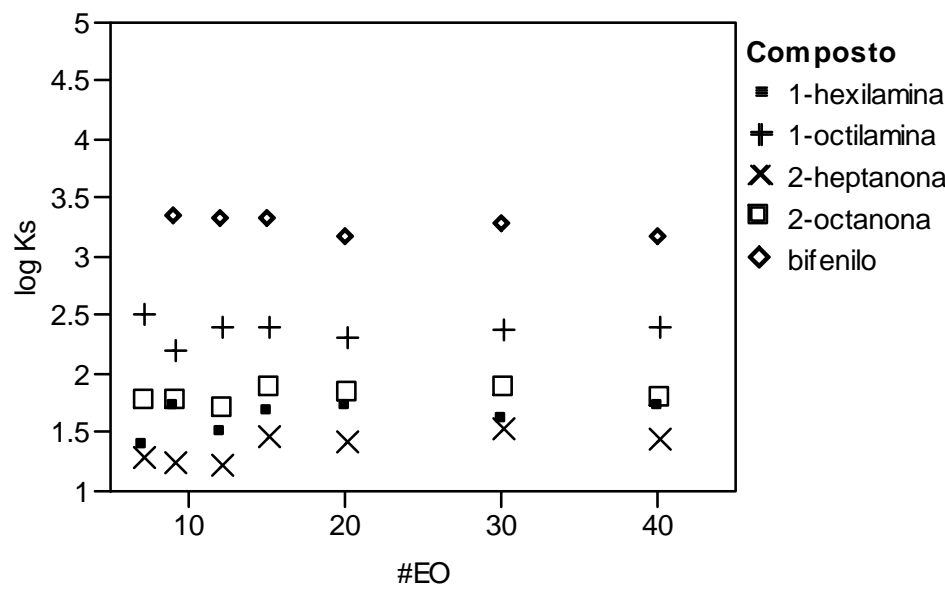

Figura 66: Gráfico de $\log K_{s}$ em função do grau de etoxilação dos tensoativos para alquil aminas, cetonas e bifenilo. 
Tabela 16: Coeficientes de correlação para regressão linear de log $K_{s}$ em função do grau de etoxilação dos tensoativos TERGTOL 15-S (compostos com dados para apenas dois tensoativos foram excluídos dessa análise).

\begin{tabular}{cc}
\hline Composto & Coeficiente de Correlação \\
\hline 2-heptanona & 0,505 \\
2-octanona & 0,195 \\
1-pentanol & 0,197 \\
1-hexanol & 0,005 \\
1-heptanol & 0,118 \\
Antraceno & 0,015 \\
Pireno & 0,082 \\
1-hexino & 0,467 \\
1-octino & 0,001 \\
Benzene & 0,154 \\
metil benzene & 0,179 \\
etil benzene & 0,435 \\
propil benzene & 0,479 \\
1-hexilamina & 0,221 \\
1-octilamina & 0,001 \\
Benzofenona & 0,052 \\
Bifenilo & 0,555 \\
\hline
\end{tabular}

A ausência de correlação entre $\log K_{s}$ e grau de etoxilação para os tensoativos em estudo, evidenciada pelos valores baixos do coeficiente de correlação em uma tentativa de regressão linear entre esses parâmetros, ver Tabela 16, mostra claramente que o coeficiente de incorporação micelar é independente do grau de etoxilação desses tensoativos. Esse resultado confirma a premissa de que, em sistemas diluídos, a solubilização de compostos não solúveis em água por tensoativos se comporta como um processo de partição entre dois meios condensados: água e centro da micela. Consequentemente, fica evidenciado que para 
tensoativos não iônicos, o aumento do grau de etoxilação não altera o meio de solubilização onde compostos não iônicos são incorporados.

Esses resultados estão de acordo com os resultados obtidos por Prak (2007) que determinou os coeficientes de partição micelar de 4-nitrotolueno, 2,3-dinitrotolueno, 2,4dinitrotolueno, 2,6-dinitrotolueno e 2,4,6-trinitrotolueno em micelas dos tensoativos nonilfenol etoxilados com grau de etoxilação variando entre 8 e 40 e não detectou correlação entre o grau de etoxilação e o coeficiente de partição.

Com o objetivo de descrever a partição dos solutos entre água e pseudo-fase micelar em função da natureza do soluto, os parâmetros de solubilidade de Abraham foram utilizados na construção de uma equação baseada em relações lineares de energia livre. Os valores de constante de incorporação micelar obtidos experimentalmente e descritos na Tabela 13, foram utilizados como a variável de resposta em uma regressão linear múltipla onde as variáveis de entrada utilizadas são os parâmetros de solubilidade de Abraham dos solutos descritos na Tabela 17. 
Tabela 17: Parâmetros de solubilidade de Abraham para solutos estudados.

\begin{tabular}{cccccc}
\hline Composto & $\mathrm{E}$ & $\mathrm{S}$ & $\mathrm{A}$ & $\mathrm{B}$ & $\mathrm{V}$ \\
\hline 2-heptanona & 0,12 & 0,68 & 0,00 & 0,51 & 1,11 \\
2-octanona & 0,11 & 0,68 & 0,00 & 0,51 & 1,25 \\
1-pentanol & 0,22 & 0,42 & 0,37 & 0,48 & 0,87 \\
1-hexanol & 0,21 & 0,42 & 0,37 & 0,48 & 1,01 \\
1-heptanol & 0,21 & 0,42 & 0,37 & 0,48 & 1,15 \\
Antraceno & 2,29 & 1,34 & 0,00 & 0,26 & 1,45 \\
Pireno & 2,81 & 1,71 & 0,00 & 0,29 & 1,59 \\
1-hexino & 0,17 & 0,23 & 0,12 & 0,10 & 0,87 \\
1-octino & 0,16 & 0,23 & 0,12 & 0,10 & 1,15 \\
n-undecano & 0 & 0 & 0 & 0 & 1,66 \\
n-dodecano & 0 & 0 & 0 & 0 & 1,80 \\
Benzeno & 0,61 & 0,52 & 0,00 & 0,14 & 0,72 \\
metil benzene & 0,60 & 0,52 & 0,00 & 0,14 & 0,86 \\
etil benzene & 0,61 & 0,51 & 0,00 & 0,15 & 1,00 \\
propil benzene & 0,53 & 0,48 & 0,03 & 0,23 & 1,17 \\
1-hexilamina & 0,20 & 0,35 & 0,16 & 0,61 & 1,05 \\
1-octilamina & 0,19 & 0,35 & 0,16 & 0,61 & 1,34 \\
Benzofenona & 1,45 & 1,50 & 0,00 & 0,50 & 1,48 \\
Bifenilo & 1,36 & 0,99 & 0,00 & 0,22 & 1,32 \\
ácido salicílico & 0,89 & 0,84 & 0,71 & 0,39 & 0,99 \\
\hline
\end{tabular}

A Equação 36 descreve, para TERGITOL 15-S, a relação entre $\log K_{s}$ e os parâmetros de solubilidade de Abraham:

$$
\log K_{s}=-0,42+1,21 E-1,73 S-0,40 A-1,13 B+3,01 V
$$

Para essa regressão, o coeficiente de correlação obtido é 0.985 , e o valor de teste F é 1390. A Tabela 18 mostra os valores de F parciais dos termos da equação 36. 
Tabela 18: Valores de F parciais e erros para os coeficientes da equação de correlação determinada para TERGITOL 15-S

\begin{tabular}{cccc}
\hline & Coeficiente & Erro & F parcial \\
\hline E & 1,21 & 0,05 & 491 \\
S & $-1,73$ & 0,09 & 309 \\
A & -0.40 & 0,10 & 15,0 \\
B & $-1,13$ & 0,10 & 117 \\
V & 3,01 & 0,06 & 2286 \\
Constante & $-0,42$ & 0,09 & \\
\hline
\end{tabular}

A Figura 67 mostra os valores experimentais de $\log K_{s}$ e valores preditos pela Equação 36.

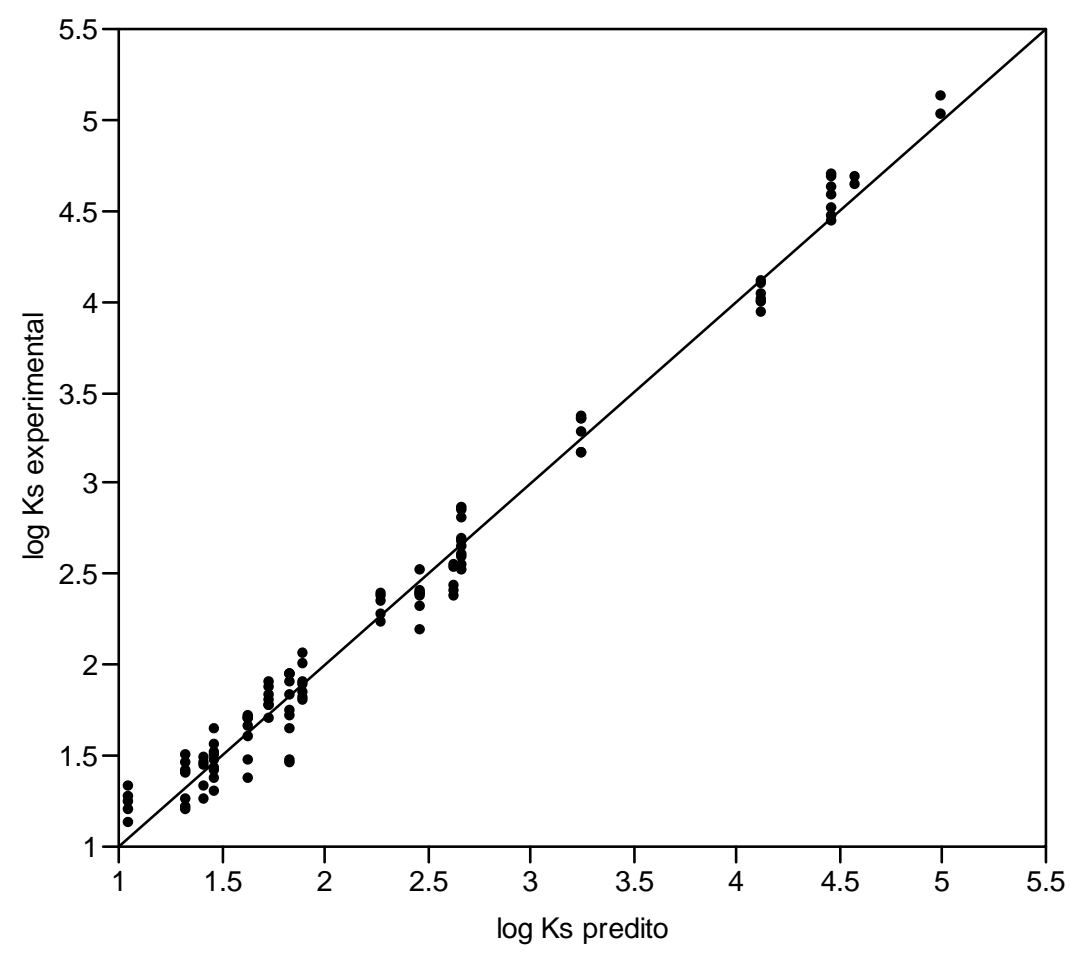

Figura 67: Gráfico de $\log K_{s}$ experimental versus $\log K_{s}$ predito para TERGITOL 15-S. 
É importante observar que os parâmetros escolhidos para determinação da LSER para TERGITOL 15-S apresentam distribuição abrangente dos parâmetros de solubilidade de Abraham conforme demonstrado na Figura 68.
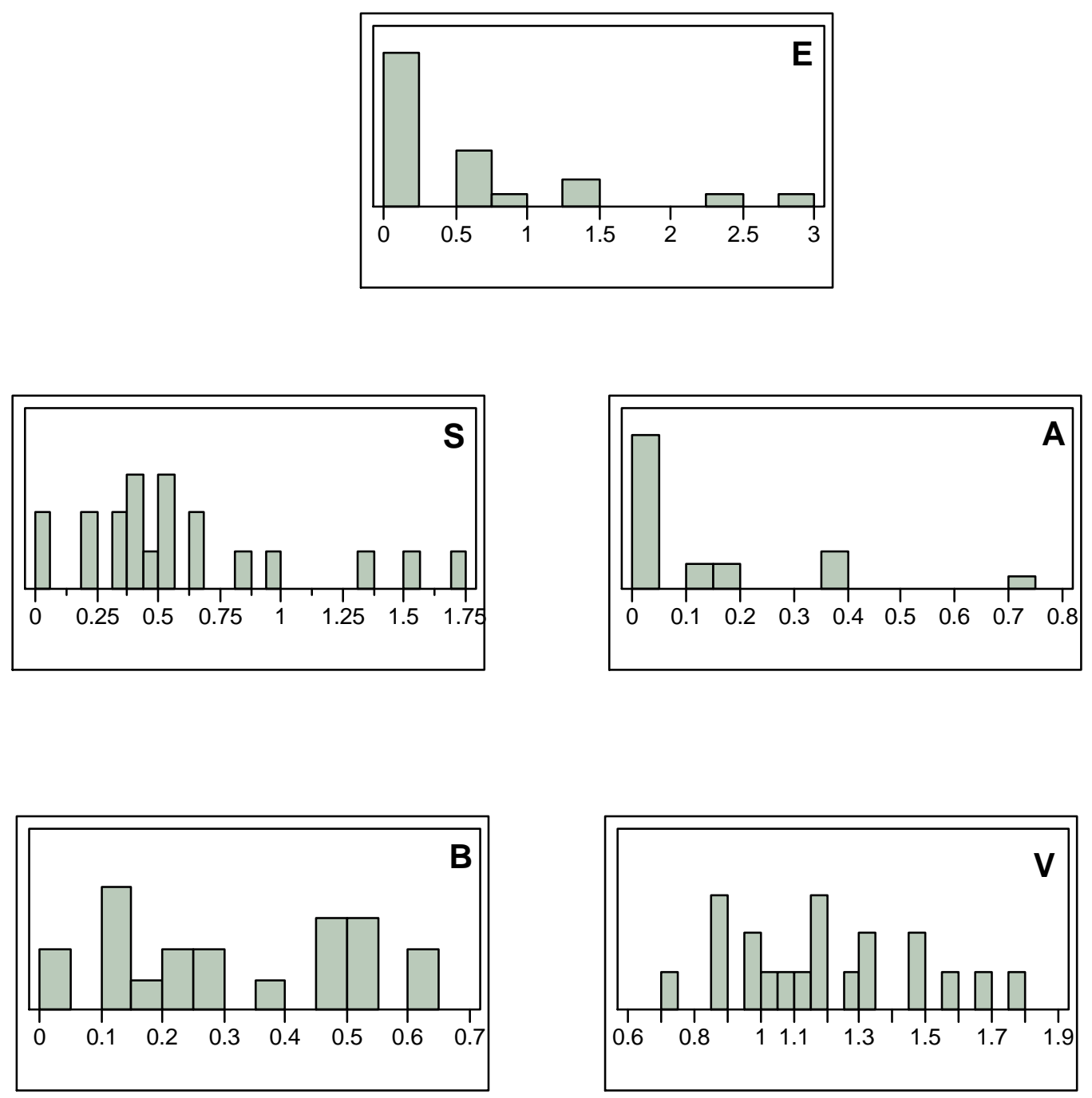

Figura 68: Distribuição dos parâmetros de solubilidade de Abraham utilizados neste estudo. 
A Tabela 19 compara a faixa de variação para os parâmetros descritivos do soluto sugeridos por Vitha e Carr (1997) com a faixa de variação deste trabalho

Tabela 19: Limite inferior e limite superior dos parâmetros descritivos dos solutos utilizados. (os valores do limite inferior de E, S, A e B desse estudo mostrados na tabela excluem os alcanos que apresentam valor zero para esses parâmetros).

\begin{tabular}{ccccc}
\hline \multirow{2}{*}{ Parâmetro } & \multicolumn{2}{c}{ Vitha e Carr 1997 } & \multicolumn{2}{c}{ Este estudo } \\
& Limite inferior & Limite superior & Limite inferior & Limite superior \\
\hline E & 0,12 & 0,97 & 0,11 & 2,81 \\
S & 0,42 & 0,96 & 0,23 & 1,71 \\
A & 0,00 & 0,43 & 0,00 & 0,71 \\
B & 0,14 & 0,51 & 0,10 & 0,61 \\
V & 0,31 & 1,42 & 0,72 & 1,80 \\
\hline
\end{tabular}

Para validação da LSER obtida é também importante verificar a correlação entre os parâmetros utilizados como descritores dos solutos. A Figura 69 e a Tabela 20 mostram que para o sistema em estudo há uma forte correlação ente E e S. 


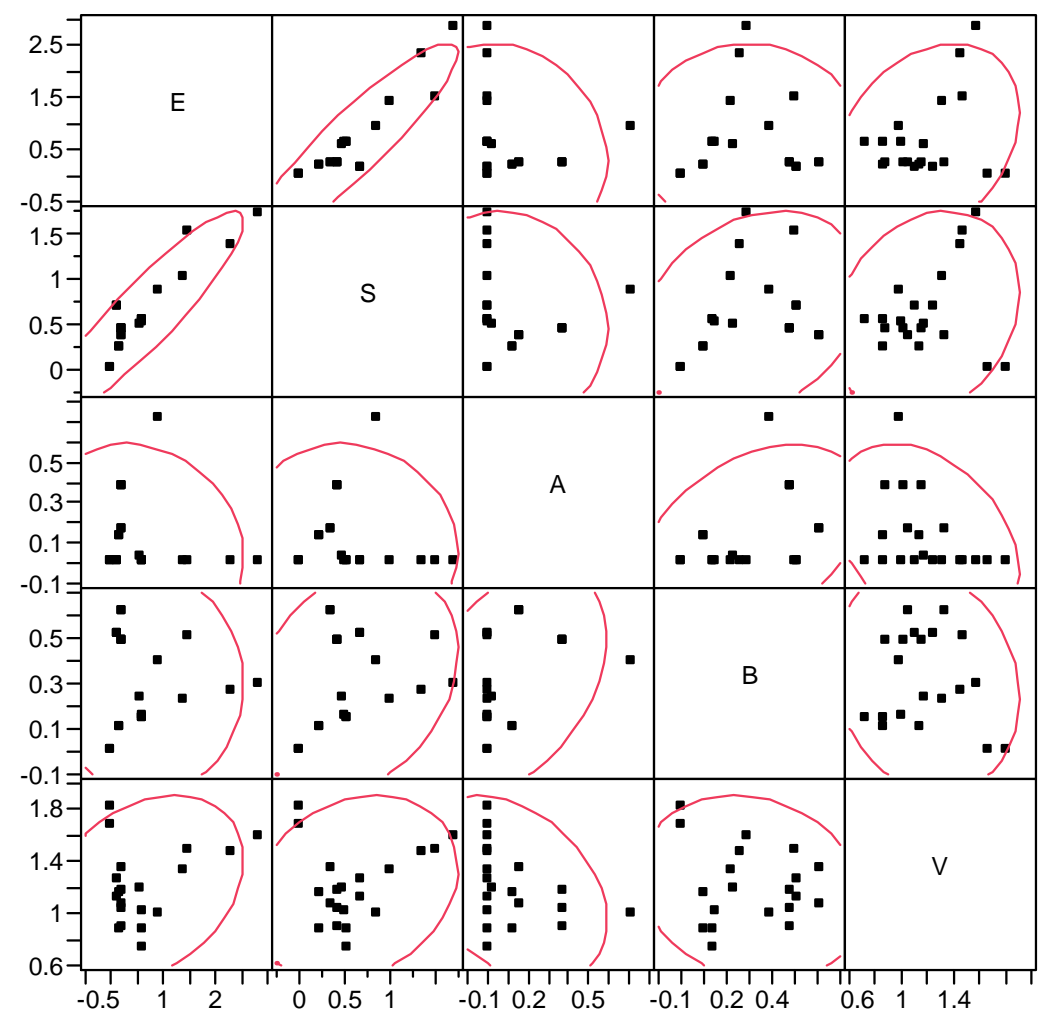

Figura 69: Gráfico da matriz de correlação dos parâmetros E, S, A, B e V dos solutos estudados.

Tabela 20: Matriz de correlação dos parâmetros E, S, A, B e V dos solutos estudados.

\begin{tabular}{c|ccccc}
\hline \multicolumn{1}{c|}{} & $\mathbf{E}$ & $\mathbf{S}$ & $\mathbf{A}$ & $\mathbf{B}$ & $\mathbf{V}$ \\
\cline { 2 - 6 } $\mathrm{E}$ & 1.0000 & & & & \\
$\mathrm{~S}$ & 0.9106 & 1.0000 & & & \\
$\mathrm{~A}$ & -0.1931 & -0.1321 & 1.0000 & & \\
$\mathrm{~B}$ & -0.0305 & 0.2630 & 0.3921 & 1.0000 & \\
$\mathrm{~V}$ & 0.3060 & 0.2193 & -0.3611 & -0.1553 & 1.0000 \\
\hline
\end{tabular}

Uma estratégia para verificar a robustez da LSER na existência de correlações entre os parâmetros descritivos do soluto é aplicar a regressão linear múltipla para um subconjunto do conjunto total de solutos utilizados e comparar os coeficientes obtidos na regressão do conjunto total com os coeficientes obtidos na regressão do subconjunto. 
A análise dos solutos em estudo, Tabela 17, mostra que os compostos aromáticos, benzofenona, pireno, antraceno e bifenilo, são contribuidores para os problemas de correlação entre E e S. A exclusão desses compostos do conjunto de dados utilizados para regressão linear múltipla resulta na Equação 37 como LSER para o subconjunto de dados.

$$
\log K_{s}=-0,66+1.26 E-1,50 S-0,39 A-1.16 B+3,15 V
$$

Para essa regressão, o coeficiente de correlação obtido é 0.977 , e o valore de teste F é 661. A Tabela 21 mostra os valores de F parciais dos termos da Equação 37. A Figura 70 mostra o gráfico dos valores de $\log K_{s}$ obtidos experimentalmente em função dos valores de $\log K_{s}$ calculados através da LSER descrita na Equação 37.

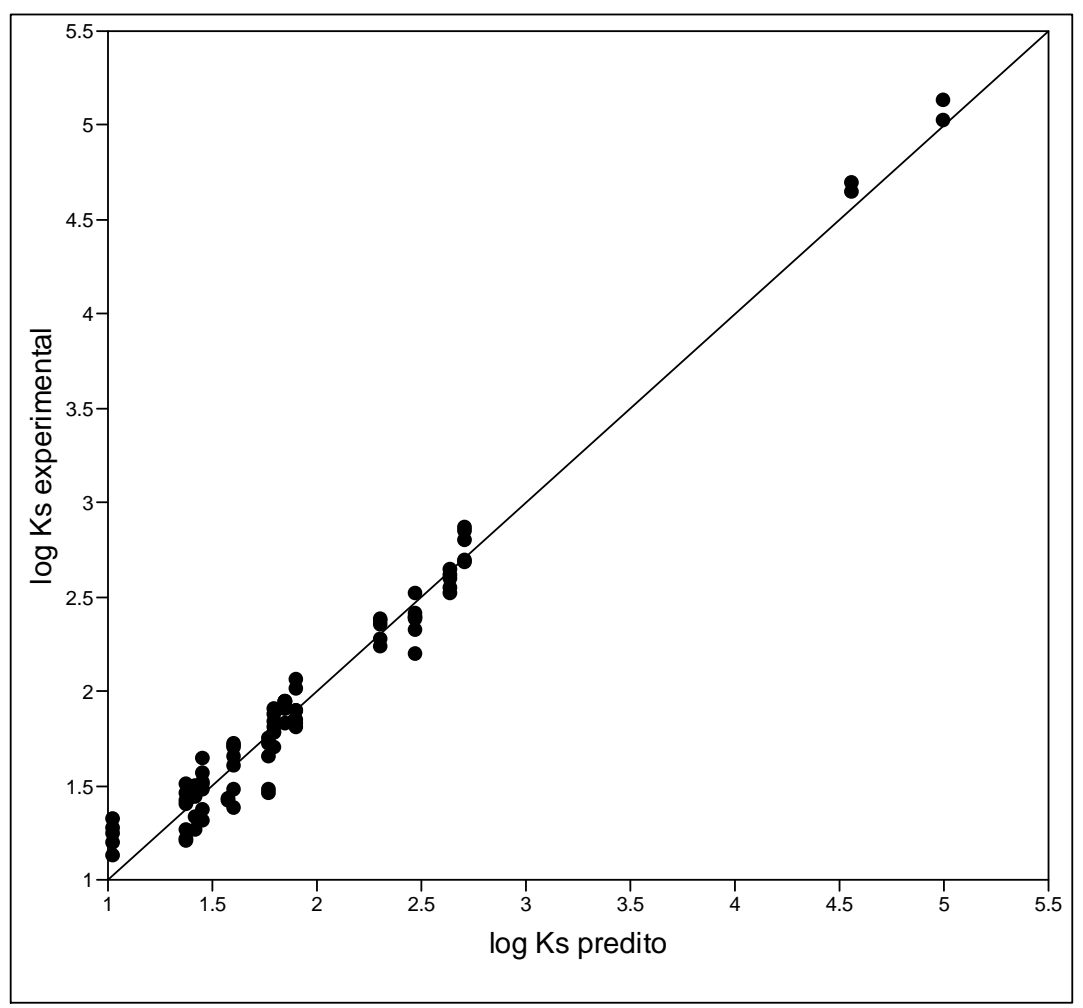

Figura 70: Gráfico de $\log K_{s}$ experimental versus $\log K_{s}$ predito para TERGITOL $15-\mathrm{S}$ com exclusão de aromáticos específicos. do conjunto de solutos. 
Tabela 21: Valores de F parciais e erros para os coeficientes da equação de correlação determinada para TERGITOL 15-S com exclusão de policíclicos aromáticos. do conjunto de solutos.

\begin{tabular}{cccc}
\hline & Coeficiente & Erro & F parcial \\
\hline E & 1,26 & 0,10 & 161 \\
S & $-1,50$ & 0,12 & 169 \\
A & -0.39 & 0,10 & 16 \\
B & $-1,16$ & 0,11 & 119 \\
V & 3,15 & 0,07 & 1647 \\
Constante & $-0,66$ & 0,08 & \\
\hline
\end{tabular}

A matriz de correlação para o subconjunto de solutos selecionados, Tabela 22, mostra que a remoção dos compostos aromáticos específicos do conjunto total de solutos resolveu o problema de correlação existente entre E e S.

Tabela 22: Matriz de correlação dos parâmetros E, S, A, B e V com exclusão de policíclicos aromáticos. do conjunto de solutos estudados.

\begin{tabular}{c|ccccc}
\hline \multicolumn{1}{c}{} & $\mathbf{E}$ & $\mathbf{S}$ & $\mathbf{A}$ & $\mathbf{B}$ & $\mathbf{V}$ \\
\cline { 2 - 6 } $\mathrm{E}$ & 1.0000 & & & & \\
$\mathrm{~S}$ & 0.6447 & 1.0000 & & & \\
$\mathrm{~A}$ & 0.3199 & 0.3462 & 1.0000 & & \\
$\mathrm{~B}$ & -0.0750 & 0.5102 & 0.4340 & 1.0000 & \\
$\mathrm{~V}$ & -0.5883 & -0.5913 & -0.2549 & -0.2102 & 1.0000 \\
\hline
\end{tabular}

Finalmente, uma análise dos coeficientes das Equações 36 e 37, Tabela 23, mostra que a retirada dos compostos aromáticos do conjunto de dados não altera de maneira significativa os coeficientes da LSER obtida para TERGITOL 15-S. Como o subconjunto de dados não apresenta o problema de correlação entre E e S, é possível concluir que a Equação 
36 é válida e pode ser utilizada para predizer a partição de solutos entre água e a pseudo-fase micelar dos tensoativos TERGITOL 15-S.

Tabela 23: Comparação entre os coeficientes das LSERs obtidas para o conjunto total de solutos e o subconjunto de solutos (com exclusão de policíclicos aromáticos).

\begin{tabular}{ccc}
\hline & $\begin{array}{c}\text { Conjunto total de } \\
\text { solutos }\end{array}$ & $\begin{array}{c}\text { Subconjunto }{ }^{*} \text { de } \\
\text { solutos }\end{array}$ \\
\hline E & 1,23 & 1,26 \\
S & $-1,68$ & $-1,50$ \\
A & -0.40 & -0.39 \\
B & $-1,01$ & $-1,16$ \\
V & 2,83 & 3,15 \\
Constante & $-0,31$ & $-0,66$ \\
\hline
\end{tabular}

*Subconjunto com exclusão de antraceno, pireno, bifenilo e benzofenona.

Visando correlacionar o processo de solubilização descrito neste trabalho com processos que utilizam tensoativos industrialmente, a eficiência de tensoativos na remoção de materiais de natureza hidrofóbica de tecido foi estudada. Trioleina foi selecionada pois representa um triglicerídeo típico. Este estudo visou elucidar se o mecanismo de limpeza dáse através de um processo de solubilização. Os resultados da Figura 59 mostram claramente que em mesma concentração mássica, e em uma concentração típica utilizada nessa aplicação, existe uma forte relação entre o grau de etoxilação e a eficiência de remoção de trioleina. Como esses tensoativos apresentam peso molecular distintos, uma possível hipótese para explicar os resultados observados na Figura 59 é que a diferença observada dá-se não por uma diferença de eficácia intrínseca, mas sim devido ao fato de que, para uma dada concentração mássica, a concentração molar do tensoativo diminui com o aumento de grau de etoxilação e consequentemente a concentração de hidrófobo diminui. 
Um segundo estudo foi realizado visando testar essa hipótese e a eficiência de limpeza foi estudada para TERGITOL 15-S-7 e TERGITOL 15-S-40 em função de sua concentração molar, de maneira que a comparação entre dois tensoativos seja realizada à uma mesma concentração de hidrófobo. Os limites superior e inferior escolhidos foram aqueles obtidos no estudo descrito na Figura 59 onde TERGITOL 15-S-7 está presente a uma concentração de 4,5mM e TERGITOL 15-S-40 está presente a uma concentração de 1,1mM. Os resultados obtidos neste segundo estudo, Figura 60, mostram claramente que a eficiência de limpeza não é dependente da concentração molar de tensoativos e sim da natureza do tensoativo. Esse resultado nega a hipótese de que o processo de detergência é regido por um processo de solubilização (no caso específico da remoção de sujidades de natureza oleosa de tecidos).

Um estudo similar foi realizado na remoção de uma sujidade padrão de uma superfície sólida de acordo com metodologia padronizada utilizada na indústria. Os resultados obtidos quando os tensoativos foram avaliados em mesma concentração mássica, Figura 61, também mostram forte dependência com o grau de etoxilação dos tensoativos. De maneira similar ao estudo de limpeza de trioleina de tecidos, um segundo estudo foi realizado comparando TERGITOL 15-S-7 e TERGITOL 15-S-40 nas mesmas concentrações molares, $5 \mathrm{mM}$ e $19 \mathrm{mM}$, definidas pelos limites superior e inferior do estudo realizado com tensoativos na concentração mássica de $1 \%$. Os resultados obtidos, Figura 62, também confirmam que a eficiência de limpeza não é função, na faixa estudada, da concentração molar dos tensoativos o que também confirma que esse processo não é governado pelo processo de solubilização.

O aumento do grau de etoxilação aumenta a área por molécula na interface, aumenta a tensão superficial de equilíbrio e aumenta da tensão interfacial entre a solução aquosa de tensoativo e os compostos não solúveis em água como dodecano, trioleina e a mistura de óleos na sujidade padrão. Isso sugere que os mecanismos de limpeza são correlacionados 
com essas propriedades e não com um processo de solubilização. As Figura 71 e 69 corroboram essa hipótese pois mostram uma correlação direta, mas aparentemente não linear, entre redução da tensão interfacial e as eficiências de limpeza de tecidos e de superfícies sólidas.

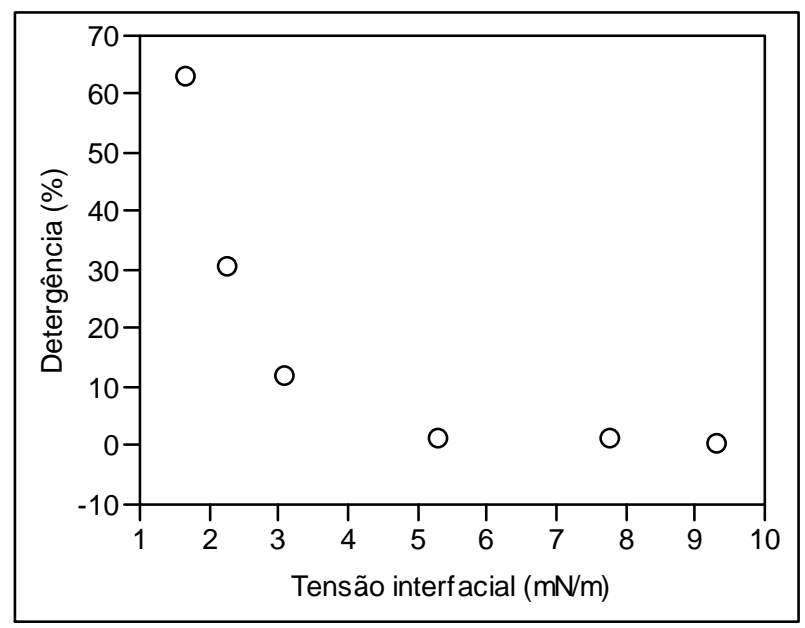

Figura 71: Detergência de superfície sólida em função da tensão interfacial entre as soluções de TERGITOL 15-S e a sujidade padrão.

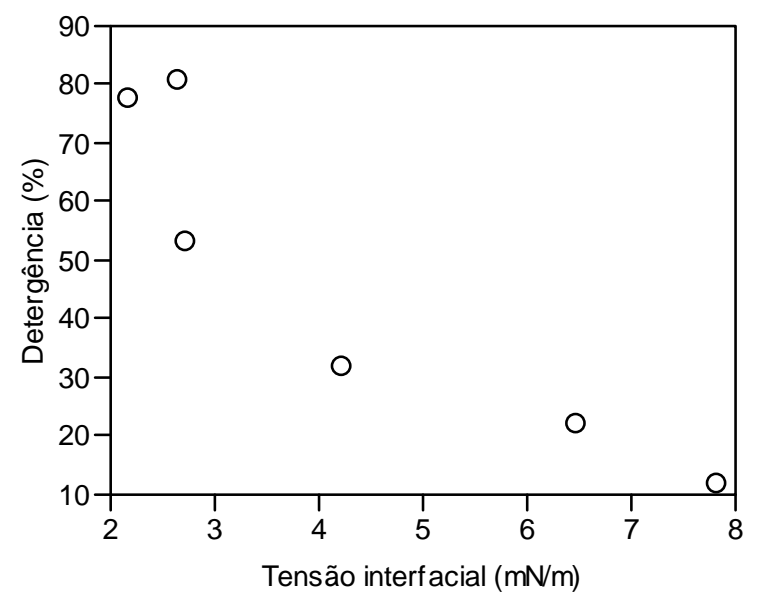

Figura 72: Detergência de tecido em função da tensão interfacial entre as soluções de TERGITOL $15-\mathrm{S}$ e a trioleina. 


\section{CONCLUSÕES}

Para os tensoativos não iônicos estudados, álcoois secundários etoxilados, concluiu-se que a solubilização através de um processo de partição entre água e pseudo-fase micelar é independente da natureza da porção hidrofílica desses tensoativos uma vez que o aumento do grau de etoxilação não altera os valores da constante de incorporação micelar, $K_{s}$. Esse resultado indica que a solubilização ocorre em um ambiente constituído pelo hidrófobo do tensoativo onde a cabeça hidrofílica não contribui com a solubilização.

Consequentemente, para processos reconhecidamente controlados por um mecanismo de partição entre água e pseudo-fase micelar, os tensoativos com baixo grau de etoxilação são mais eficientes sob uma análise de concentração mássica pois a fração de hidrófobo no tensoativo diminui com o aumento do grau de etoxilação.

Foi também objetivo deste trabalho estabelecer a capacidade preditiva de solubilização para álcoois secundários etoxilados através de relações lineares de energia livre. Levando-se em conta que os valores de $K_{s}$ independem do número de unidades de óxido de eteno presentes na cabeça polar do tensoativo, foi suficiente estabelecer uma relação linear de energia livre para TERGITOL 15-S. Na LSER resultante, volume molar do soluto é o parâmetro de maior impacto no processo de solubilização seguido pelo parâmetro de dipolaridade / polarizabilidade.

Mostrou-se que processos de limpeza aplicados a remoção de sujidades de tecidos e superfícies sólidas não estão correlacionados ao mecanismo de solubilização descrito por um processo de partição. A dependência da redução de tensão interfacial com o grau de etoxilação sugere que a eficiência de limpeza, para superfícies sólidas e para tecidos, está correlacionada de maneira direta, mas não linear, com a capacidade do tensoativo de 
concentrar-se na interface "sujidade-solução aquosa de tensoativo" reduzindo assim a tensão interfacial entre os dois meios. 


\section{REFERÊNCIAS BIBLIOGRÁFICAS}

AATCC-17 Evaluation of wetting agents, Research Triangle Park, Carolina do Norte: American Association of Textile Chemists and Colorists, 2005.

ASTM Standard D93 Standard Test Methods for Flash Point by Pensky-Martens Closed Cup Tester. West Conshohocken, Pensilvania: ASTM International, 2008.

ASTM Standard D1173 Standard Test Method for Foaming Properties of Surface-Active Agents, West. Conshohocken, Pensilvania: ASTM International, 2007

ASTM Standard D5343-06 Standard Guide for Evaluating Cleaning Performance of Ceramic Tile Cleaners, West. Conshohocken, Pensilvania: ASTM International, 2006.

ABRAHAM, M. H. Scales of Solute Hydrogen-bonding: Their Construction and Application to Physicochemical and Biochemical Processes, Chemical Society Review, v. 22, p. 73-83, $1993 \mathrm{a}$

ABRAHAM, M. H. Hydrogen bonding XXVII. Solvation parameters for functionally substituted aromatic compounds and heterocyclic compounds, from gas-liquid chromatographic data, J. of Chromatography, v. 644, p. 95-139, 1993 b.

ABRAHAM, M. H. Hydrogen bonding. 31. Construction of a scale of solute effective or summation hydrogen-bond basicity, J. of Physical Organic Chemistry, v. 6, p. 660-684, $1993 \mathrm{c}$.

ABRAHAM, M. H.; CHADHA, H. S.; DIXON, J. P.; RAFOLS, C.; TREINER, C. Hydrogen bonding. Part 41. Factors that influence the distribution of solutes between water and hexadecylpyridinium chloride micelles, J. of Chemical Society, Perkin Transaction 2, p. 19-24, 1997. 
ABRAHAM, M. H.; GRELLIER, P. L.; ABBOUD, J. L. M.; DOHERTY, R. M.; TAFT, R. W. Solvent effects in organic chemistry - recent developments, Canadian Journal of Chemistry, v. 66, p. 2673-2686, 1988.

ABRAHAM, M. H.; GRELLIER, P.L.; PRIOR, D.V.; DUCE, P.P.; MORRIS, J.J.; TAYLOR, P.J. Hydrogen Bonding. Part 7. A Scale of Solute Hydrogen-bond Acidity based on log K Values for Complexation in Tetrachloromethane, J. of Chemical Society, Perkin Transaction 2, p. 699-711, 1989.

ABRAHAM, M. H.; GRELliER, P.L.; PRIOR, D.V.; MORRIS, J.J.; TAYLOR, P.J. Hydrogen Bonding. Part 10. A Scale of Solute Hydrogen-bond Basicity using log K Values for Complexation in Tetrachloromethane, J. of Chemical Society, Perkin Transaction 2, p. 521-529, 1990b.

ABRAHAM, M. H.; HAFTVAN, J. A.; WHITING, G. S.; LEO, A. Hydrogen Bonding. Part 34. The Factors that Influence the Solubility of Gases and Vapours in Water at $298 \mathrm{~K}$, and a New Method for its Determination, J. of Chemical Society, Perkin Transaction 2., p. 17771791,1994

ABRAHAM, M. H.; IBRAHIM, A.; ZISSIMOS, A. M. Determination of sets of solute descriptors from chromatographic measurements, J. of Chromatography A, v. 1037, p. 2947, 2004.

ABRAHAM, M. H.; MCGOWAN, J. C. The Use of Characteristic Volumes to Measure Cavity Terms in Reversed Phase Liquid Chromatography, Chromatographia, v. 23, p. 243246, 1987.

ABRAHAM, M. H.; WHITING, G. S. Hydrogen bonding XXI. Solvation parameters for alkylaromatic hydrocarbons from gas-liquid chromatographic data, J. of Chromatography, v. 594, p. 229-241, 1992.

ABRAHAM, M. H.; WHITING, G. S.; DOHERTY, R. M.; SHUELEY, W. J. Hydrogen Bonding. Part 13. A New Method for the Characterisation of GLC Stationary Phases-The Laffort Data Set, J. of Chemical Society, Perkin Transaction 2, p. 1451-1460, 1990a. 
ABRAHAM, M. H.; Whiting, G. S.; DOHERTY, R. M.; SHUELEY, W. J. Hydrogen bonding XVI. A new solute solvation parameter, $\pi$, from gas chromatographic data, J. of Chromatography, v. 587, p. 213-228, 1991.

ALMGREN, M.; GRIESER, F.; THOMAS, J. K. Dynamic and static aspects of solubilization of neutral arenes in ionic micellar solutions, J. of the American Chemical Society, v. 101, p. 279-291, 1979.

BAILEY, D. J.; DORSEY, J. G. Linear solvation energy relationships of mixed micelles of sodium dodecyl sulfate and decanol: towards a better model of octanol /water partitioning, $\mathbf{J}$. of Chromatogry A, v. 919, p. 181-194, 2001.

BARRY, B. W.; RUSSEL, G. F. J. Prediction Of Micellar Molecular Weights And Thermodynamics Of Micellization Of Mixtures Of Alkyltrimethylammonium Salts , J. of Colloid and Interface Science, v. 40, p. 174-194, 1972.

BECHER, P. Nonionic surface-active compounds. VII. Interfacial tensions of solutions of nonionic surface-active agents, J. of Colloid and Interface Science, v. 18, p. 665-673, 1963.

BOURREL, M.; SCHECHTER, R. S. Microemulsions and Related Systems - Formulation, Solvency and Physical Properties Schick, In: M. J.; Fowkes, F. M. Surfactant Series, New York: Marcel Dekker, 1988. p. 42.

BUJAKE, J. E.; GODDARD, E. D. Surface Composition Of Sodium Lauryl Sulphonate And Sulphate Solutions By Foaming And Surface Tension, Transactions of the Faraday Society, v. 61, p. 190-195, 1965.

CLINT, J. H. Surfactant Agregation, New York: Chapman and Hall, 1992.p. 82-129.

CLINT, J. H.; WALKER, T. Thermodynamics of Micellization of Homologous Series of nAlkyl Methyl Sulphoxides and n-Alkyl(dimethy1)phosphine Oxides, J. of Chemical Society, Faraday Transaction 1, v. 71, p. 946-954, 1975. 
CORKILL, J. M.; GOODMAN, J. F.; HARROLD, S. P. Thermodynamics of Micellization of Non-Ionic Detergents, Transactions of the Faraday Society, v. 60, p. 202-207, 1964.

CORRIN, M. L.; HARKINS, W. D. The Effect of Salts on the Critical Concentration for the Formation of Micelles in Colloidal Electrolytes, J. of the American Chemical Society, v. 69, p. 683-688, 1947.

CROOK, E. H.; FORDYCE, D. B.; TREBBI, G. F. Molecular weight distribution of nonionic surfactants. Surface and interfacial tension of normal distribution and homogeneous p,toctylphenoxyethoxyethanols (OPE's), J. of Physical Chemistry, v. 67, p. 1987-1994, 1963.

CROOK, E. H.; TREBBI, G. F.; FORDYCE, D. B. Thermodynamic Properties of Solutions of Homogeneous p,t-Octylphenoxyethoxyethanols (OPE1-10), J. of Physical Chemistry, v. 68, p. 3592-3599, 1964.

ELWORTHY, P. H.; MYSELS, K. H. The Surface Tension Of Sodium Dodecylsulfate Solutions And The Phase Separation Model Of Micelle Formation, J. of Colloid Science., v. 21, p. 331-347, 1966.

EVANS, H. C. Alkyl sulphates. Part I. Critical micelle concentrations of the sodium salts, J. of Chemical Society, p. 579-586, 1956.

EVANS, D. F. Self-organization of amphiphiles, Langmuir, v. 4, p. 3-12, 1988.

EVERETT, D. H. Manual of Symbols and Terminology for Physicochemical Quantities and Units, Pure and Applied Chemistry, 1972, v. 31, p. 577-638, 1972.

FRANK, H. S.; EVANS, M. W. Free Volume and Entropy in Condensed Systems III, J. Chemical Physics, v. 13, p. 507-532, 1945.

FREITAS, A. A. Estudos de Incorporação de Solutos Não-Iônicos em Micelas de Detergentes Zwitteriônicos. 88f. Dissertação (Mestrado em Físico Química) - Instituto de Química, Universidade de São Paulo, São Paulo, 2001. 
GEE, G.; HIGGINSON, W. C.; LEVESLEY, P.; TAYLOR, K. J. Polymerisation of Epoxides. Part I. Some Kinetic Aspects of the Addition of Alcohols to Epoxides catalysed by Sodium Alkoxides, J. of Chemical Society, p. 1338-1344, 1959a.

GEE, G.; HIGGINSON, W. C.; MERRAL, G.T. Polymerisation of Epoxides. Part II. Some Kinetic Aspects of the Addition of Alcohols to Epoxides catalysed by Sodium Alkoxides, J. of Chemical Society, p. 1345-1352, $1959 \mathrm{~b}$.

GEIGER, A. In: STANLEY, H.E.; OSTROWSKY, N., Correlations and Connectivity, Dordrescht, Holanda: Kluwer Academic Publishers, (1990)

GOEBEL, A.; LUNKENHEIMER, K. Interfacial Tension of the Water/n-Alkane Interface, Langmuir, v. 13, p. 369-372, 1997.

HANSEN, F. K.; FAGERHEIM, H. The influence of oil phase on the adsorption of non-ionic surfactants investigated by the automatic sessile drop method, Colloids and Surfaces, v. 137, p. 217-230, 1998.

HARTLEY, G. S. Aqueous Solutions of parafin chain salts. Paris: Hermann \& Cie, 1936.

HOORFAR, M.; NEUMANN, A. W. Recent progress in Axisymmetric Drop Shape Analysis (ADSA), Advances in Colloid and Interface Science, v. 121, p. 25-49, 2006.

HSIAO, L.; DUNNING, H. D.; LORENZ, P. B. Critical Micelle Concentrations of Polyoxyethylated Non-ionic Detergents, J. of Physical Chemistry, v. 60, p. 657-660, 1956.

ISRAELACHVILI, J. N. Intermolecular \& Surface Forces. Ed. 2., San Diego, California: Academic Press, 1991. p. 370-382.

KATO, T.; SEIMIYA, T. Study on intermicellar interactions and micelle size distribution in aqueous solutions of nonionic surfactants by measurements of mutual diffusion and selfdiffusion coefficients, J. of Physical Chemistry, v. 90, p. 3159-3167, 1986. 
KLEVENS, H. B. Critical Micelle Concentrations as Determined by Refraction, J. of Physical Chemistry, v. 52, p. 130-148, 1948.

MEGURO, K.; TAKASAWA, Y.; KAWAHASHI, N.; TABATA, Y.; UENO, M. Micellar Properties of a Series of Octaethyleneglycol-n-alkyl Ethers with Homogeneous Ethylene Oxide Chain and Their Temperature Dependence, J. of Colloid and Interface Science, v. 83 , p. 50-56, 1981.

MOTA, F. L.; QUIMADA, A. J.; PINHO, S. P.;MACEDO, E. A. Aqueous Solubility of Some Natural Phenolic Compounds, Industrial Engineering Chemistry Research, v. 47, p. 5182-5189, 2008.

MUTELET, F.; GUERMOUCHE, M. H.; ROGALSKI, M. New Method to Determine LSER Parameters, Chromatographia, v. 57, p. 729-733, 2003.

MYSELS, E. K.; MYSELS, K. J. Conductimetric Determination of the Critical Micelle Concentration of Surfactants in Salt Solutions, J. of Colloid Science, v. 20, p. 315-321, 1965.

NACE, V. H. Nonionic Surfactants - Polyoxyalkylene Block Copolymers, In: Schick, M. J.; Fowkes, F. M. Surfactant Series, New York: Marcel Dekker, 1996. p. 8.

NELSON, H. D.; DELIGNY, C. L. Determination of the Solubilities of Some n-Alkanes in Water at Different Temperatures by Means of Gas Chromatography, Recueil des Travaux Chimiques - Des Pays-Bas, v. 87, p. 528-544, 1968.

NEMETHY, G.; SCHERAGA, H. A. Structure of Water and Hydrophobic Bonding in Proteins II, J. of Chemical Physics, v. 36, p. 3401-3417, 1962.

NILSSON, P. G.; LINDMAN, B. Water self-diffusion in nonionic surfactant solutions. Hydration and obstruction effects, J. Physical Chemistry, v. 87, p. 4756-4761, 1983.

PADDAY, F.; PITT, A. R.; PASHLEY, R. M. Menisci at a Free Liquid Surface: Surface Tension from the Maximum Pull on a Rod, J. of the Chemical Society, Faraday Transactions 1, v. 71, p. 1919-1931, 1975. 
PAlatinus, J. A.; CARROLl, F. A., ARGENTON, A. B.; QUINA, F. H. An improved characteristic molecular volume parameter for linear solvation energy relationships of acyclic alkanes, J. of Physical Organic Chemistry, v. 19, p. 725-730, 2006.

PHILliPS, J. N. The Energetics of Micelle Formation, Transactions of the Faraday Society, v. 51, p. 561-569, 1955.

PORTER, M. R. Handbook of Surfactants, Nova York: Blackie \& Son, 1991.p. 116-178.

PRAK, D. J. L. Solubilization of nitrotoluenes in micellar nonionic surfactant solutions, Chemosphere, v. 68, p. 1961-1967, 2007.

PUVVADA, S.; BLANKSCHTEIN, D. Molecular Thermodynamic Approach to Predict Micellization, Phase Behaviour, and Phase Separation of Micellar Solutions. I. Application to Nonionic Surfactants, J. of Chemical Physics, v. 92, p. 3710-.3724, 1990.

QUINA, F. H.; ALONSO, E. O.; FARAH, J. P. S. Incorporation of Nonionic Solutes into Aqueous Micelles: A Linear Solvation Free Energy Relationship Analysis, J. of Physical Chemistry, v. 99, p. 11708-11714, 1995.

RAKUTANI, K.; ONDA, Y.; INAOKA, T. Surfactants Derived from Secondary Alcohols, In: KARSA, D. R. (1999) Industrial Applications of Surfactants IV. Cambridge: Royal Society of Chemistry, 1999. p.193-212.

RODRIGUES, M. A.; ALONSO, E. O.; CHANG, Y. W.; FARAH, J. P. S.; QUINA, F. H. A Linear Solvation Free Energy Relationship Analysis of Solubilization in Mixed Cationic-Nonionic Micelles, Langmuir, v. 15, p. 6770-6774, 1999.

ROSEN, M. J. Surfactants and Interfacial Phenomena, Ed. 2. Nova York: Wiley, 1978. p. 88.

ROSEN, M. J.; COHEN, A. W.; DAHANAYAKE, M.; HUA, X. Y. Relationship of structure to properties in surfactants. 10. Surface and thermodynamic properties of 2- 
odecyloxypoly(ethenoxyethanol)s, $\mathrm{C} 12 \mathrm{H} 25(\mathrm{OC} 2 \mathrm{H} 4) \mathrm{xOH}$, in aqueous solution, J. of Physical Chemistry, v. 86, p. 541-545, 1982.

RUSANOV, A. I.; PROKHOROV, Interfacial Tensiometry. Amesterdam: Elsecier Science, 1996.p.48-73.

SANTACESARIA, E.; DI SERIO, M.; LISI, L. Kinetics of nonylphenol polyethoxylation catalyzed by potassium hydroxide, Industrial and Engineering Chemistry, v. 29, p. 719$725,1990$.

SEPULVEDA, L.; LISSI, E.; QUINA, F. H. Interactions Of Neutral Molecules With Ionic Micelles, Advances in Colloid and Interface Science, v. 25, p. 1-57, 1986.

SCHICK, M. J.; GILBERT, A. H. Effect of urea, guanidinium chloride, and dioxane on the c.m.c. Of branched-chain nonionic detergents, J. of Colloid Science, v. 20, p. 464-472, 1965.

SCHOTT, H.; ROYCE, A. E.; HAN, S. K. Effect of Inorganic Additives on Solutions of Nonionic Surfactants VII, J. of Collloid and Interface Science, v. 98, p. 196-201, 1984.

STONE, M. C. A Field Guide to Digital Color, Natick, Massachusetts: A K Peters, 2003.p. 43-86.

TANFORD, C. Theory of micelle formation in aqueous solutions, J. of Physical Chemistry, v. 78, p. 2469-2479, 1974.

The Dow Chemical Company, Tergitol 15-S Surfactants High Detergency, Biodegradable SAEs, Midland, Michigan, 2006.

VITHA, M.; CARR, P. W. The Chemical Interpretation and Practice of Linear Salvation Energy Relationships in Chromatography, J. of Chromatography A, v. 1126, p. 143-194, 2006. 
VITHA, M. F.; CARR, P. W. Study of the Polarity and Hydrogen-Bond Ability of Dodecyltrimethylammonium Bromide Micelles by the KamLet-Taft Solvatochromic Comparison Method, J. of Physical Chemistry B, v. 102, p. 1888-,1895 1998.

VITHA, M. F.; DALLAS, A. J.; CARR, P. W. A Comparison of Water-Sodium Dodecyl Sulfate Phase Transfer Linear Solvation Energy Relationships and Databases, J. of Colloid and Interface Science, v. 187, p. 179-183, 1997. 


\section{SÚMULA CURRICULAR}

\section{DADOS PESSOAIS}

Nome: André Bozzo Argenton

Local e Data de Nascimento: 29 de março de 1974, São Paulo - SP

\section{EDUCAÇÃo}

Ensino Médio:

Colégio Augusto Laranja, São Paulo, SP, 1992

Curso Superior:

Instituto de Química - USP - São Paulo, SP

1993 - 1996: Bacharelado em Química com atribuições tecnológicas.

2000 - 2003: Mestrado em Físico-Química

2004 - 2009: Doutorando em Físico-Química

\section{OCUPAÇÃO}

The Dow Chemical Company (EUA) 2007 - atual

Gerente de desenvolvimento de aplicações na área de suporte à formulações de produtos de consumo.

DOW Brasil

Químico de Pesquisa e Desenvolvimento 1999 - 2007

COLGATE PALMOLIVE

Químico de Pesquisa e Desenvolvimento 1997 - 1999

\section{PUBLICAÇÕES}

PALATINUS, J.A.; CARROLL, F.A.; ARGENTON, A.B., QUINA, F.H. An improved characteristic molecular volume parameter for linear solvation energy relationships of acyclic alkanes, Journal Of Physical Organic Chemistry, v. 19, p. 725-730, 2006

PALATINUS, J. A.; SAMS, C.M.; BEESTON, C.M.; CARROLL, F.A., ARGENTON A.B. , QUINA, F.H. Kinney revisited: An improved group contribution 
method for the prediction of boiling points of acyclic alkanes, Industrial \& Engineering Chemistry Research, V. 45, p. 6860 - 6863, 2006

MORGON, N. H.; ARgEnTON, A. B.; SILVA, M. L. P.; RIVEROS, J. M. Experimental And Theoretical Characterization Of Fsi(Och3)(2)(Och2)(-): A Gas Phase Fluoride-Siloxirane Adduct, Journal of the American Chemical Society., v. 119, p. 1708-1716, 1997 